\title{
The Geoscience Laser Altimeter System (GLAS) Laser Transmitter
}

\author{
Robert S. Afzal ${ }^{1}$, Anthony W. Yu ${ }^{2}$, Joseph L. Dallas ${ }^{3}$, Anthony Melak ${ }^{4}$, Alan Lukemire ${ }^{5}$, \\ L. Ramos-Izqueirdo ${ }^{6}$, and William Mamakos ${ }^{7}$ \\ NASA Space Lidar Technology Center, 5000 College Ave, College Park, MD 20740
}

\begin{abstract}
Current Affiliations
${ }^{1}$ Aculight Corp., 11805 North Creek Parkway S., Ste 113, Bothell, WA 98011

${ }^{2}$ NASA-GSFC, Laser \& Electro-Optics Branch, MC554, Greenbelt, MD 20771

${ }^{3}$ Avo Photonics, 700 Business Center Drive, Suite \#125, Horsham, PA 19044

${ }^{4} 7308$ Willow Ave, Takoma Park, MD 20912

${ }^{5}$ Space Power Electronics Inc., 108 Audrey Way, Kathleen, GA 31047

${ }^{6}$ NASA-GSFC, Optics Branch, MC551, Greenbelt, MD 20771

${ }^{7}$ Design Interface Inc., 3451 Gamber Road, Finksburg, MD 21048
\end{abstract}




\begin{abstract}
The Geoscience Laser Altimeter System (GLAS), launched in January 2003, is a laser altimeter and lidar for the Earth Observing System's (EOS) ICESat mission. GLAS accommodates three, sequentially operated, diode-pumped, solid-state, Nd:YAG laser transmitters. The laser transmitter requirements, design and qualification test results for this space-based remote sensing instrument is summarized and presented
\end{abstract}

Copyright

OCIS codes:

140.3580 Lasers, solid-state,

140.4480 Optical amplifiers

140.4780 Optical resonator,

140.3540 Lasers, $Q$-switched

120.2830 Height measurements

280.3640 Lidar 


\section{Introduction}

The Geoscience Laser Altimeter System (GLAS), ${ }^{1,2}$ launched January 12, 2003 at 4:45 PST on board a Boeing Delta II expendable launch vehicle from Vandenberg Air Force Base, California, is the sole instrument for the ICESat ${ }^{3,4}$ (Ice, Cloud and Land Elevation Satellite) mission. GLAS is a satellite laser altimeter and atmospheric lidar whose primary mission is the global monitoring of the Earth's ice sheet mass balance. GLAS also provides high precision land topography and global monitoring of aerosols and cirrus cloud heights. Combining a 1-m beryllium telescope, 1 GHz digitizer, analog and photon counting silicon APD's, an on-board laser beam pointing measurement system, ${ }^{5}$ variable conductance heat pipes for thermal management, and a 2-color diode-pumped, solid-state laser, the GLAS instrument is providing an unprecedented high precision and accuracy data set $(5 \mathrm{~cm}$ vertical accuracy, $2.4 \mathrm{~cm}$ precision) on the vertical structure of the Earth surface and atmosphere. GLAS is designed to accommodate 3 transmitters intended to be operated sequentially on a common optical bench opposite the laser beam pointing measurement system known as the stellar reference system. Figure 1 shows the location of the lasers on the GLAS instrument. The previous state-of-the-art in space based solid-state lasers is the Mars Orbiting Laser Altimeter (MOLA), ${ }^{8,9}$ on the Mars Global Surveyor spacecraft collecting topography data of the planet Mars. ${ }^{10}$ The GLAS lasers ${ }^{6,7}$ represent the next generation of space-based remote sensing laser transmitters. The GLAS lasers generally have an order-of-magnitude higher performance than MOLA in power, beam quality, improved efficiency, and other technological advances. Figure 2 shows a photograph of a completed flight laser ready for delivery to the instrument. The GLAS lasers were designed and built by NASAGoddard Space Flight Center at the Space Lidar Technology Center (SLTC). This paper will discuss the laser requirements and the design developed to meet them. Additionally, the 
development process is reviewed with particular attention paid to the testing and qualification of the transmitters.

\section{Development History}

The GLAS project remained in the concept and risk reduction phase through the mid 1990's. By April 1997 a full functional breadboard of the laser was completed which met the electro-optical requirements for the laser. Along with the formal approval to proceed toward flight, a small, dedicated, multidisciplinary team was formed to work full time on the development of the GLAS lasers. The core development team was about 16 scientists, technicians and staff. In the winter of 1997, a cooperative agreement was established between NASA-GSFC and the University of Maryland to modify an existing facility to form the SLTC. The facility was a self contained development facility with $2000 \mathrm{ft}^{2}$ of class 1000 cleanrooms, 5 laser labs, an electronics lab, a machine shop, office space, shipping, receiving and bonded storage. By spring of 1998 the SLTC was in full operation and by December 1998 the $1^{\text {st }}$ Engineering Model (EM) was completed and fully tested. Results from the EM testing indicated the opto-mechanical configuration of the engineering model needed to be modified as well as finalization of all flight processes and assembly instructions. The laser was reassembled as the Engineering Test Unit (ETU) and fully qualified to flight levels by flight assembly documentation and met all flight requirements by November 1999. Concomitantly, the flight parts were being delivered and accepted into the SLTC and the $1^{\text {st }}$ flight laser was delivered in September 2000. The third and final flight laser was delivered in February 2001. Figure 3 shows the collection of laser hardware developed for the GLAS program. During integration to the GLAS instrument, one of the flight lasers had a diode failure and was reworked and re-qualified and reintegrated onto GLAS in February 2002. 


\section{Laser Design}

The laser requirements were derived from a flow down process from the science requirements with feedback from the laser design team on specifications the team felt it could design and build to. The final top level performance requirements for the lasers are summarized in Table 1 .

Additionally the laser needs to operate from $10^{\circ} \mathrm{C}$ to $35^{\circ} \mathrm{C}$ and survive non-operating from $0^{\circ} \mathrm{C}$ to $50^{\circ} \mathrm{C}$. The expected launch loads were up to $8 \mathrm{grms}$ for 1 minute. The mission life is for 3 years with a 5-year goal. Under continuous operation at $40 \mathrm{~Hz}$, the lasers will accumulate 1.26 billion shots per year.

Particularly challenging in simultaneously meeting these requirements, is the combination of short pulse width, high pulse energy and excellent beam quality. Short pulses are typically generated by short cavities with high gain. Shorter cavities tend to allow for higher order transverse modes in high gain lasers unless the pulse energies are low. To keep the transmitters optics small and to avoid the use of large beam expanders to meet the divergence requirements, the final beam quality needed to be in the range of $M^{2} \approx 2$. An early design trade study evaluated design options in laser architecture, laser materials and component maturity. Although ruggedized lasers tend to be crossed-Porro power oscillators, a master-oscillator, power-amplifier (MOPA) design was the most promising architecture for meeting the transmitter performance objectives. ${ }^{11}$ In addition to breadboarding the laser architecture, three additional risk areas were to be investigated during the early design phase. Those areas were Q-switches, diode pump reliability and risk of optical damage.

For the GLAS laser, the MOPA design consisted of a short pulse TEM $_{00}$ oscillator is followed by 2 amplification stages to meet the final energy level requirement. Optical aberrations were minimized with zig-zag slabs, and beam image inversions using prisms between 
the first and the second amplifier passes. A schematic of the optical layout within the laser housing is shown in Figure 4. A photograph of the optical bench of laser serial number 1, which was used as flight laser 3 during on-orbit operations, is shown in Figure 5.

\section{Oscillator}

Initially the oscillator design was based on a side-pumped, Cr:Nd:YAG, Brewster cut, 7 bounce zig-zag slab, electro-optically Q-switched laser that emitted $2.5 \mathrm{~mJ}$ in a TEM $\mathrm{T}_{00}$ mode. ${ }^{12}$ Given past experience with difficulties using E-O Q-switch materials like Lithium Niobate in vacuum, and its typically low damage threshold, a secondary path to develop a passively Q-switched oscillator as a replacement was undertaken. ${ }^{13}$ The oscillator was demonstrated, pumped by two $100 \mathrm{~W}$ Q-cw diode-bars, passively Q-switched, and generating $2 \mathrm{~mJ}, 5 \mathrm{~ns}$ near diffraction limited $\left(\mathrm{M}^{2}<1.1\right)$ pulses at $40 \mathrm{~Hz}$. The passive Q-switch was $\mathrm{Cr}^{4+}: \mathrm{YAG}$ with a single pass optical density of $0.46 @ 1064 \mathrm{~nm}$. Important in this design was the use of 2 pump bars which can be significantly derated (typically to $65 \mathrm{~W} /$ bar) while still meeting the output pulse energy and transverse mode quality. The laser design philosophy to minimize complexity, was to run all the diodes in series with maximum peak current of $100 \mathrm{~A}$ for $200 \mu \mathrm{sec}$. Since the oscillator is the heart of the oscillator design, and could be considered a single point failure, the design needed as much derating margin as possible. Two long term exposure experiments were constructed to evaluate the aging mechanisms and long term performance of these oscillator designs. ${ }^{14,15}$ Additionally diode array tests were conducted to gain confidence in long term operation as well as characterizing anticipated lifetime improvements from diode derating. ${ }^{16,17}$

The oscillator cavity had an optical path length of $15 \mathrm{~cm}$ with a longitudinal mode spacing of $1.09 \mathrm{GHz}$. The laser had no active longitudinal mode control and could operate in a single longitudinal mode or up to 3 modes depending on the oscillator temperature and the 
overlap of the modes with the gain curve. The cavity reflectors were a Porro prism as the high reflector and a flat glass optics with $50 \%$ reflecting thin film coating as the output coupler. The Porro prism minimizes tilt misalignment in one axis but the laser is still tilt sensitive in the orthogonal axis. Figure 6 shows a photograph of the laser oscillator. One can see from the image the optical layout and the orientation of the Porro knife-edge. In this orientation the oscillator is insensitive to optical bench distortion due to in-plane thermal gradients. Vertical tilt however had to be well controlled. The tilt sensitivities are shown in Figure 7.

The oscillator slab was $1.2 \mathrm{~mm}$ thick and owing to the short absorption path length for the diode pump light the oscillator pump diode had to be actively temperature controlled to keep the diodes on band with the Nd:YAG absorption. Figure 8 shows the oscillator threshold current as a function of diode temperature for flight laser \#2. One can see there is an optimum temperature for lowest current. Due to the steep dependence of current on temperature on the hot side, one must be careful however not to set the temperature at the minimum.

As the diode ages, more current needs to be supplied to the diode to keep the laser operating at threshold for a fixed pump time of $200 \mu \mathrm{s}$. As more current is applied the pump laser wavelength thermal chirp shifts the diode wavelength to longer wavelengths. This red-shift changes the pump wavelength and crystal absorption overlap and can increase the threshold pump current if operating at the minimum current and leading to a run away effect where the laser stops reaching threshold even at $100 \mathrm{~A}$. For this reason the oscillator pump diode temperature set point was set at $2^{\circ} \mathrm{C}$ colder than the minimum current temperature. By setting the temperature lower than the minimum there is the added benefit as the diode ages and more current is required for the laser, the diode shifts more into the absorption band thereby minimizing the need for more pump current. The diode temperature was controlled by a thermo- 
electric cooler (TEC). The slab was heat sunk directly to the laser housing. Therefore the slab temperature follows the laser housing temperature and is not temperature controlled along with the diode. There is a slight dependence on laser wavelength and gain as a function of slab temperature. Since absolute wavelength control was not necessary to meet specifications, additional complexity to control slab temperature was not deemed necessary. Figure 9 shows the thermal predictions of the oscillator gain module.

\section{Laser Modeling}

Laser energetics modeling for the oscillator was accomplished by writing a coupled rate equation model similar to Xiao and Bass. ${ }^{18}$

The four coupled equations are:

$$
\begin{aligned}
& \frac{d n}{d t}=-\gamma \sigma c n \phi \\
& \frac{d \phi}{d t}=\left[2 \sigma l_{s l a b} n-2 \sigma_{g s} n_{g s} l_{p q s}-\left(\text { Loss }_{c a v}+\ln \left(\frac{1}{R}\right)\right)\right] \frac{\phi}{t_{r}} \\
& \frac{d n_{g s}}{d t}=-\sigma_{g s} c \phi n_{g s} \\
& \frac{d n_{e s}}{d t}=\sigma_{e s} c \phi n_{e s}
\end{aligned}
$$

where $n=$ initial excited state inversion density, $\phi=$ circulating photon flux, $\sigma=$ gain cross section for $\mathrm{Nd}^{3+}: \mathrm{YAG}=2.8 \times 10^{-19} \mathrm{~cm}^{2}, \sigma_{\mathrm{gs}}=$ ground state absorption cross section for $\mathrm{Cr}^{4+}: \mathrm{YAG}=2.2 \times 10^{-19} \mathrm{~cm}^{2}, \sigma_{\mathrm{es}}=$ excited state absorption cross section for $\mathrm{Cr}^{4+}: \mathrm{YAG}=8.7 \mathrm{x}$ $10^{-19} \mathrm{~cm}^{2}, \gamma=$ inversion reduction factor $=1.2, l_{p q s}=$ length of the passive Q-switch material, $n_{g s}$ $=\mathrm{Cr}^{4+}:$ YAG ground state density $=4.7 \times 10^{-18} \mathrm{~cm}^{3}, n_{e s}=\mathrm{Cr}^{4+}: \mathrm{YAG}$ excited state density, Loss ${ }_{c a v}$ $=$ dissipative cavity losses, $\mathrm{R}=$ output coupler reflectivity, $\mathrm{t}_{\mathrm{r}}=$ cavity round trip time and $\mathrm{c}=$ 
speed of light. The initial excited state population in the gain medium was calculated by integrating the following gain equation in time. This is a fairly standard integration but with the added constraint of including an ad hoc loss for amplified spontaneous emission.

$$
n=\sum_{0}^{T} \frac{P A b s \chi \xi}{h v A l} \delta t-\frac{n \delta t}{t_{s p o n}}\left[G_{e o} e^{\frac{1.20 n l}{\gamma}}+\left(1-G_{e o}\right) e^{\frac{1.20 n \sqrt{A}}{\gamma}}\right]
$$

where $T=$ pump time, $\delta t=$ integrating time interval, $P=$ pump power, $A b s=$ fraction of pump power absorbed by the slab, $\chi=$ pump coupled into the slab, Abs = fraction of pump power

absorbed by slab (temperature dependent), $l=$ gain length, $A=$ gain area, $\xi=$ fraction of absorbed photon that end up in the upper laser level $=0.96, t_{\text {spon }}=$ spontaneous lifetime $=230$ $\mu$ sec. $G_{e o}$ is a geometry field-of-view factor based on the solid angle subtended by the slab.

Temperature dependence of the inversion density is calculated by knowing the absorption of the $\mathrm{Nd}^{3+}: \mathrm{YAG}$ as a function of wavelength, then applying the wavelength shift of the diodes with temperature and calculating the fraction of absorbed pump power. The initial conditions are $n_{0}=\mathrm{n}$ at the end of the pump time $\mathrm{T}, n_{\mathrm{gs}}=$ the saturable absorber density, $n_{\mathrm{gs}}=0$, and the photon flux $\phi$ is arbitrarily picked at a low number like 1000. After inputting the other measurable quantities like cavity length, the equations are solved and pulse energy and width calculated. The model is fairly accurate in predicting energy to about $10 \%$ but tends to underestimate the pulse width by about $30 \%$. Improvements in the model would be to have spatial dependence in the gain and photon flux as well as ground state bleaching of the absorber by ASE.

\section{Preamplifier}

The amplifier chain was isolated from the oscillator by a Faraday rotator made of Terbium Gallium Garnet (TGG) between polarizers that were also used to polarization couple the laser 
beam into and out of the preamplifier. The output pulses from the oscillator were expanded by a $2 \mathrm{x}$ telescope, and amplified by a double-pass preamplifier stage pumped by $8,100 \mathrm{~W}$ bars (operating at $100 \mathrm{~A}$ or $85 \mathrm{~W} /$ bar) resulting in $15 \mathrm{~mJ}$ pulses with an $\mathrm{M}^{2} \approx 1.4$. This stage utilizes a polarization coupled double pass, $2.3 \times 2.3 \mathrm{~mm}^{2}, 8$ bounce zig-zag slab with a Porro-prism for beam symmetrization. Zig-zag slabs are known to minimize uniaxial thermal gradients in the zig-zag plane. However the non-zig-zag plane remains uncompensated. The incoming beam from the oscillator enters the preamplifier slab "S" polarized. After passing through the slab the beam double passes a 0.57 waveplate by reflecting off a Porro prism with the knife edge oriented at $45^{\circ}$ in azimuth. This rotates the polarization from "S" to "P" and inverts the laser beam across a diagonal mapping " $x$ " coordinate of the beam profile into the " $y$ " coordinate. Upon the second pass through the amplifier the slab aberrations are applied symmetrically across the beam profile. The dominant aberration is then focus which can be compensated by the following beam expanders. The slab end faces must be coated to minimize reflection losses for both "P" and "S" polarizations. Figure 10 shows a photograph of the preamplifier section of the laser. Figure 11 shows the single and double pass gains of the preamplifier.

Figure 12 shows the thermal model for the preamplifier gain module. The model shows the diodes will be about $4^{\circ} \mathrm{C}$ hotter than the mount temperature with a $1^{\circ} \mathrm{C}$ gradient from the module interface to the diode interface. The housing side wall temperature was kept fixed at $22^{\circ} \mathrm{C}$. The slab is at about $28^{\circ} \mathrm{C}$ which is similar in temperature to the oscillator slab.

Since the oscillator diodes are temperature controlled and the power amplifier slab has a larger absorption length, it turns out the performance of the preamplifier over temperature dominates the performance of the entire laser's performance over temperature. Each assembled preamplifier was tested for gain as function of temperature. Figure 13 shows the temperature 
dependence of a preamplifier gain module over temperature. This data was collected during the acceptance testing of the pump head which determined gain and peak operating temperature.

The preamplifier gain and stored energy was modeled by following the formalism presented by Lowdermilk and Murray. ${ }^{19}$ The initial gain and stored energy was calculated the same way as seen before in the oscillator. The pulse amplification was calculated by:

$$
E_{\text {out }}=R_{2} A E_{\text {sat }} \ln \left[1+\left(e^{\frac{R_{1} E / A}{E s_{a t}}}-1\right) e^{o u l}\right]
$$

Where $\mathrm{E}_{\mathrm{sat}}=\mathrm{h} v / \sigma \gamma, \mathrm{E}=$ input pulse energy, $\mathrm{A}=$ mode area, $\mathrm{R}_{\mathbf{1}}=$ reflection loss entering the slab, $\mathrm{R}_{2}=$ reflection loss exiting the slab, $\sigma=2.8 \times 10^{-19} \mathrm{~cm}^{2}, \gamma=1.2, \mathrm{n}=$ defined as before, $l=$ slab length. The slab can be broken up into smaller lengths and have this equation applied to the smaller segments having the pulse propagation approximated. After the first pass the gains and stored energies are recalculated and the pulse is propagated back though the amplifier. Figure 14 shows the predicted pulse energy after the preamplifier stage with an input of $1.9 \mathrm{~mJ}$.

\section{Power Amplifier}

After another $2.2 \mathrm{x}$ beam expansion, the beam enters a power amplifier pumped by $44,100 \mathrm{~W}$ bars. The pulses are amplified to $120 \mathrm{~mJ}$ after a double pass with an $\mathrm{M}^{2} \approx 1.8$. The peak laser fluence in the final amplifier is $4 \mathrm{~J} / \mathrm{cm}^{2}$. The first amplifier pass is much like the preamplifier but the initial polarization is "P" polarized and enters a $5.0 \times 5.0 \mathrm{~mm}^{2}, 7$ bounce zig-zag slab. Unlike the preamplifier, however, polarization coupling into and out of the power amplifier was not possible due to thermally induced birefringent depolarization of the beam leading to parasitic lasing in the amplifier chain. Instead, a Brewster cut dove prism used at $45^{\circ}$ azimuth angle surrounded by two $\lambda / 2$ plates are used to minimize reflection loss at the input then to rotate the 
polarization from "P" to "S" polarization for the second path through the amplifier. The beam is then reflected back into the slab at a lower angle of incidence to the input face and traces out a 9 bounce path before emerging from the slab. The slab end faces must be anti-reflection coated for both "P" and "S" polarizations and the 2 different angles of incidence. The beam then clears the input telescope mount and is redirected to enter the doubler and final beam expander. Figure 15 shows a photograph of the power amplifier section of the laser. Figure 16 shows the single and double pass gain of the amplifier stage with fixed input pulse energy of $15 \mathrm{~mJ}$.

The power amplifier, however, had a significantly greater amount of heat that needed to be properly managed. Figure 17 shows the thermal model of the power amplifier. The model shows the diodes will be about $9^{\circ} \mathrm{C}$ hotter than the mount temperature with a $5^{\circ} \mathrm{C}$ gradient from the module interface to the diode interface. The housing side wall temperature was kept fixed at $22^{\circ} \mathrm{C}$. The slab is at about $48^{\circ} \mathrm{C}$ which is hotter than the oscillator slab temperature. This means the spectral gain peak of the amplifier is shifted to a longer wavelength than the oscillator output wavelength. We considered adding a heater circuit to better match the gain peaks of the oscillator to the amplifiers but since it was not needed to meet requirements, the complexity was not added.

For the amplifier, since the slab is thick, the temperature performance of the amplifier is dominated by the absolute temperature of the diodes. The diodes are more efficient at lower temperatures and there by the gain is higher. Figure 18 shows the temperature dependence of the amplifier gain. This data was collected during the acceptance testing of the pump head which determined gain and peak operating temperature. 
Modeling of the power amplifier stage was conducted in the same way as the preamplifier but with the components measured for the power amplifier. Figure 19 shows the predicted energy out of the amplifier over temperature with a constant input of $16 \mathrm{~mJ}$.

Finally, a complete coupled amplifier model was constructed to reflect the combined performance of the amplifier chain. For this model the oscillator output was kept constant at 1.9 mJ. The temperature used was the predicted temperature of the location of the laser thermistor. The preamplifier temperature was biased by $+1^{\circ} \mathrm{C}$ and the power amplifier temperature by $+8^{\circ} \mathrm{C}$ from this telemetry point. The combined gain, stored energy and extraction were calculated and used to predict the laser pulse energy as function of temperature. Also included is an $8 \%$ loss from the amplifier output through the rest of the aft optics train which includes turning mirrors, doubler, final beam expander, housing window and final pointing Risley prisms pair. The model results are shown in Figure 20.

\section{Second Harmonic Generation}

To meet the two-color requirement, the full power beam is then directed to a Lithium Triborate (LBO) doubler designed to convert $30 \%$ of the power into the green, followed by an achromatic, 6x final beam expander. LBO doubler was chosen as the nonlinear material because it was radiation tolerant and was an acceptable type-I doubler which basically maintained the polarization of the 1064 and $532 \mathrm{~nm}$ beams. The $7 \times 7 \times 11 \mathrm{~mm}^{3}$ crystal needed to be temperature controlled to maintain critical phase matching and an operating temperature of $40^{\circ} \mathrm{C}$ was chosen to set the crystal $5^{\circ} \mathrm{C}$ higher than the laser high operating temperature. By setting the LBO temperature higher than the rest of the temperature sensitive elements on the laser bench, a simpler system using heat-only temperature control system can be used rather than a more complex heat and cool control such as that required by the oscillator diode. Figure 21 shows the 
temperature acceptance of the crystal. Based on this data the crystal temperature was required to be controlled to better than $0.5^{\circ} \mathrm{C}$. To minimize the risk of crystal fracture and coating delamination the doubler heater control circuit was designed to ramp the temperature of the LBO from ambient to the operating temperature in 30 minutes. The maximum transient temperature rate of change was $<1^{\circ} \mathrm{C} / \mathrm{min}$. The mount temperature transient was greatest for cooling with power removed from the doubler while in air.

\section{Beam Expander}

After emerging from the doubler the laser beam was expanded to reduce the beam divergence. The final beam expander was a $189 \mathrm{~mm}$ long, 6x magnification Galilean telescope. Its requirements were to maintain the beam divergence for both the $1064 \mathrm{~nm}$ and $532 \mathrm{~nm}$ beams over $\pm 20^{\circ} \mathrm{C}$. The telescope had a negative group doublet made of fused silica and a positive group doublet made with BK7-G18 and SF8-G07. Also the expander was correctable for vacuum operation by only changing the focus of the beam expander by $190 \mu \mathrm{m}$. That is, once the beam expander was aligned for operation in air, the negative group was moved $190 \mu \mathrm{m}$ to defocus the laser beam so it would have the correct divergence when operated in vacuum. The sensitivity of the beam divergence to the defocus of the negative group is shown in Figure 22 . The far-field beam divergence is "Gaussian-like" with a $100 \mu \mathrm{rad}$ full angle divergence and an $M^{2} \approx 2$.

The laser far field beam profiles are shown in Figure 23. The figure shows the laser beam as aligned in air then the vacuum beam profile. The divergence of the laser beam is defined as $86.5 \%$ of the energy contained in a circular aperture of $71 \mu \mathrm{rad}$. Figure 24 shows a measurement of the laser pointing jitter. Following the final beam expander, there is the housing window and two alignment Risley wedges used to set the final pointing of the laser beam when 
integrated onto the instrument. Figure 25 shows the final output energy of the 2 colors as a function of diode drive current. This graph shows the laser meets pulse energy requirements at the 100 A diode drive current.

\section{Optical Components}

The ICESAT/GLAS instrument will be orbiting at an altitude of $600 \mathrm{~km}$. The total accumulative radiation dosage seen by the satellite is estimated to be $40 \mathrm{krad}$ (absorbed in Silicon) over the life of the mission $(5 \mathrm{yrs}) .{ }^{20}$ As part of the optics selection process we need to determine the effects of gamma and high energy electron radiation on several essential optical components used in the laser transmitter subsystem. Optical components within the GLAS laser transmitter included many different flavors. Most of the optics substrates are based on fused silica and are radiation hardened. Other components due to their unique design parameters are based on non-radiation hardened glass such as BK-7 for MIL-spec air-spaced polarizers. In such a case we worked with vendor to re-design their products using similar but radiation hardened glass such as BK7-G18. Optical components tested for gamma and high energy electron radiation are:

1. Terbium Gallium Garnet (TGG, $\mathrm{Tb}_{3} \mathrm{Ga}_{5} \mathrm{O}_{12}$ ) crystal (Optical Isolator),

2. Air spaced polarizing beam splitter cubes with BK7 and BK7-G18 glass materials,

3. Lithium Triborate (LBO) crystal,

4. $\mathrm{Cr}^{4+:} \mathrm{YAG}$ crystal,

5. Electro-optic Q-switch with KD*P Crystal,

6. AlGaAs semiconductor laser diode array bar,

7. Fused Silica substrate lens,

8. AD590 thermal couple,

9. Thermoelectric cooler. 
Two radiation tests were performed at the Goddard Space Flight Center Integrated Radiation Testing and Space Simulation Facility and facility at the Materials and Nuclear Engineering Department, University of Maryland at College Park. The tests were: (1) Gamma radiation - exposure to $\mathrm{Co}^{60}$ gamma radiation to a total dose of $50 \mathrm{krad}$ at a dose rate of 50 $\mathrm{krad} / \mathrm{hr}$ for a duration of 1 hour at GSFC and the; and (2) High energy electron radiation exposure to high energy electron radiation to a total dose of $50 \mathrm{krad}$ using a linear accelerator (LINAC). The LINAC provides energy varies from $2 \mathrm{MeV}$ to $9.5 \mathrm{MeV}$ at a rate of $10 \mathrm{~Hz}$ to 500 Hz. Sample was placed on a stand at a distance from the window of the LINAC. The electron beam pulse energy was adjusted to $7 \mathrm{MeV} /$ pulse and the square pulse width was $3 \mu \mathrm{s}$. A total of $14.3 \mathrm{k}$ pulses was needed to have the effect of $50 \mathrm{krad}$. Spatial profile of the e-beam is Gaussian with FWHM equals $300 \mathrm{keV}$.

TCP of the test samples were done before and after each of the two radiation tests for comparisons. All the samples performed as expected throughout the radiation tests. BK7 material is expected to fail radiation test and Figure 26 shows the effect of radiation on this material, whereas BK7-G18 did not showed any effect from radiation exposure.

Of the entire GLAS laser cavity the highest fluence is found inside the oscillator cavity and is approximately $4 \mathrm{~J} / \mathrm{cm}^{2}$. Thus high quality optical coating and stringent contamination control must be in place to avoid damages to any of the optical components. The optical damage threshold specifications on optical coatings was set to four times the expected fluence level, or $16 \mathrm{~J} / \mathrm{cm}^{2}$. The optical coating on a particular coating run was qualified by damage testing randomly selected "sister" optics from the same run. As part of the initial screening process in accepting incoming optics, all vendors must submit certificate of conformance along with laser optical damage test results. All received optics underwent inspection for cosmetic appearance 
and test and check-out procedures (TCP). Pass/fail criteria on performance were set for each type of components and the results were used to sort and separate the optics into different grades for flight, flight spare, or engineering model lasers build. The qualified optics then moved on to next level of integration.

\section{Laser Driver Power Electronics}

The Laser Driver Power Electronics (LDPE) serves as the electrical interface between the laser and the instrument power and data systems. The primary function of the LDPE is that of delivering clean, tightly regulated, $200 \mu \mathrm{sec}$ wide, $100 \mathrm{~A}$ current pulses to the laser diodes. In addition, the unit also performs a number of other critical functions associated with laser operation.

The LDPE is composed of four major subassemblies, each with a dedicated printed circuit card. These include the Internal Converter, the Boost Converter, the Control Electronics, and the Thermal Control Board. These four cards, the energy storage capacitor bank, the FET heatsink structure, and associated internal harnessing are tightly packaged within the electronics cavity of the Laser Assembly chassis. Figure 27 shows a photograph of the flight integrated LDPE. A block diagram is shown in Figure 28.

The Internal Converter interfaces directly with the spacecraft $+30 \mathrm{~V}$ prime power. This custom discrete forward converter generates all of the isolated low voltages used within the LDPE including $+5 \mathrm{~V},+7 \mathrm{~V}$, and $\pm 10 \mathrm{~V}$. These voltages are required by the internal digital and analog networks distributed on the other LDPE boards. The Internal Converter also provides the externally synchronizable master oscillator for the $122 \mathrm{KHz}$ switching frequency of all converter circuits, and additional common-mode and differential-mode filtering networks. Inclusion of a dedicated internal converter as part of the LDPE removed many of the potential EMI issues and 
concerns with other elements of the GLAS instrument and, in addition, greatly simplified the LDPE interface by eliminating the need for additional external instrument power supplies. Only a single "one voltage / one plug" power interface is required.

The Boost Converter also interfaces directly with the spacecraft $+30 \mathrm{~V}$ prime power. The primary function of this converter is that of transforming the bus voltage from $+30 \mathrm{~V}$ up to the higher voltage (approximately $+114 \mathrm{~V})$ required to drive the series stack of 54 laser diodes (2oscillator, 8-preamplifer and 44-amplifier). Although the diode stack compliance voltage is only $\sim 108 \mathrm{~V}$, additional voltage is required to compensate for other losses in the diode bar current path. The Boost Converter is actually composed of two isolated flyback power stages which operate 180 degrees out of phase with each other. This yields an apparent switching frequency of $244 \mathrm{KHz}$. The alternating flyback networks work together to provide a high power current source for charging a large bank of capacitors. This $5.28 \mathrm{mF}$ capacitor bank, or "cap block assembly", is composed of a parallel combination of eight wet-slug tantalum $660 \mu \mathrm{F}, 150 \mathrm{~V}$ Mallory capacitors. The capacitor block stores the energy required for each interval of laser diode current pumping. At $114 \mathrm{~V}, 100 \mathrm{~A}$, and $200 \mu \mathrm{sec}$ pulse widths, the energy per pulse requirement can be calculated as $11.4 \mathrm{KW}$ x $200 \mu \mathrm{sec}=2.28 \mathrm{~J}$. The Boost Converter must replenish this energy following each laser pulse at a repetition rate of $40 \mathrm{~Hz}$. One unique element of the LDPE Boost Converter design is the efficient method used to perform this task while virtually eliminating the low frequency $40 \mathrm{~Hz}$ ripple from being reflected back to the spacecraft power bus. In high power, low-frequency laser drivers for spacecraft, one of the most challenging tasks is to provide the very large pulsing currents to the laser diodes (in this case $100 \mathrm{Amps}$ at $40 \mathrm{~Hz}$ ) while protecting the spacecraft power bus from the resulting reflected current ripple. For any continuous-mode analog control network, the active and/or passive filter networks that would be required to allow 
a traditional power supply to accomplish this rejection would make the system either too bandwidth limited or too massive. A better solution has been the utilization of a custom digital control network with discrete energy conversion levels. This has resulted in very low input current ripple (typically less than $50 \mathrm{~mA}$ ) when delivering $>10$ kilowatt pulses to the load at 40 Hz.

The large capacitance of the energy storage capacitor bank creates a significant challenge for the voltage control loop stability. A very large phase lag is present in the loop. Traditional compensation methods will not work in this application for a number of reasons, the primary one being that the resulting bandwidth would make the network far too slow to respond to system dynamics. Instead, the sense circuit was designed with a hysteresis network which maintains the capacitor bank voltage within a very small window instead of attempting to hold that voltage at a precise single value. Under steady state conditions, the normal $40 \mathrm{~Hz}$ ripple voltage on the capacitor bank, induced by the pulsing current to the laser diodes, remains within this regulation window. In this way, the network will only attempt corrections to the boost drive level if the capacitor voltage drops below or exceeds the preset window limits. When required, a digital up/down counter network with 11 bit resolution makes very slight adjustments in the magnitude of the cycle to cycle recharge current in the flyback stages of the Boost Converter.

The Thermal Control Board provides temperature regulation of the laser oscillator and the doubler crystal. The laser oscillator temperature must be very tightly regulated to a preset value. This regulation, typically $\pm 0.1^{\circ} \mathrm{C}$, is maintained by utilization of a TEC within the laser cavity at the oscillator diode mount. The Thermal Control Board provides a discrete control loop and FET bridge drive network interface to the TEC and associated thermistors located on the oscillator mount. The doubler temperature regulation requirement is less stringent, typically 
$\pm 0.5^{\circ} \mathrm{C}$. Due to the fact that the doubler temperature set point is always above the bench temperature during operation, doubler cooling is not required. A simple $2 \mathrm{~W}$ heater resistor (buried within the doubler crystal mount) was utilized to provide doubler temperature regulation. The Thermal Control Board also provides a hysteretic on/off control loop, a switchable current source for the heater resistor, and the interface to the associated thermistors on the doubler mount. The oscillator and doubler mounts each use two independent thermistors. For each mount, one thermistor is dedicated to the temperature control loop while the second thermistor is dedicated to temperature monitoring and telemetry. At each LDPE power on cycle, the oscillator temperature is driven to its set point within approximately one minute. In an effort to reduce the potential thermal stress on the doubler crystal, it was decided that the doubler temperature was to be brought up very slowly, less than $0.5^{\circ} \mathrm{C}$ per minute. In order to implement this additional requirement, the Thermal Control Board utilizes a very slow stepping counter reference voltage circuit to bring up the doubler temperature at each power on cycle.

The Control Electronics includes all of the digital interface networks and associated feedback control loops for regulation of laser drive current magnitude and pump pulse width duration, control of oscillator bypass current adjustment to maintain constant pump time of 200 $\mu$ sec, and the feedback control network for the Boost Converter operation. This includes a number of counters and timing functions, protection circuits, and regulation loops. The Control Electronics also provides the direct command and telemetry interface with the external GLAS instrument data system.

The primary diode power function of the LDPE is to deliver a $100 \mathrm{~A}, 200 \mu \mathrm{sec}$ pulse of current at $40 \mathrm{~Hz}$, to diodes that are electrically in series. Since the laser is not actively Qswitched, the timing of the pulse emission from the oscillator is actively controlled through the 
diode drive current. A by-pass FET diverts nominally $15 \mathrm{~A}$ of current around the oscillator diodes thereby further derating these diodes in current. When current is delivered to the diodes a counter counts the time until an internal photodetector detects the emission of the laser pulse. A feedback loop then adjusts the by-pass current to allow for more or less current to pass through the oscillator diodes to maintain a diode pump time of $200 \mu \mathrm{s}$. This loop is necessary to maintain the synchronization of the oscillator pulse emission to the maximum stored energy and gain of the amplifiers. Figure 29 shows a schematic of the current loop through the diode chain.

The total current through the amplifier chain is always tightly regulated to $100 \mathrm{~A}$. At the "beginning of life", the oscillator current is approximately $85 \mathrm{~A}$ with the difference, approximately $15 \mathrm{~A}$, bypassed around the oscillator. Over the course of the lifetime of the laser, as the diode stack efficiency slowly degrades, the amount of current bypassed around the oscillator diodes is gradually reduced as oscillator current is increased. This acts to hold the required "time to fire" at $200 \mu \mathrm{sec}$ while maintaining constant laser energy. This operation is represented as mode "A" in Figure 31. At first glance, it may seem that this technique would result in significant bypass network dissipation and reduced the overall electrical efficiency. Due to the fact that the oscillator stack is composed of only two diode bars, while the amplifier chain is composed of a series combination of 52 bars, the percentage of total compliance voltage and thus the associated power dissipation at the bypass network is actually a small fraction of the power delivered to the entire chain. This dissipation, in fact, turns out to be quite small in comparison with the total loss encountered by utilization of other regulation techniques. This includes even the originally considered implementation of a separate and independent oscillator current path. 
Late in laser lifetime, all of the available bypass current will have been redirected through the oscillator. At this point, represented as mode " $\mathrm{B}$ " in Figure 30, the pump time can no longer be maintained at $200 \mu \mathrm{sec}$. The drive pulse width will gradually increases (to a preset maximum of $244 \mu \mathrm{sec}$ ) as the laser energy slowly degrades. Eventually, the significant increase in prime power consumption and the reduction of transmitted laser energy will result in the condition where the actual "end of life" termination or turn off becomes necessary. The next laser would then be selected for continued operation of the GLAS instrument.

Figure 31 shows the power budget of the complete LDPE. The LDPE is about $83 \%$ efficient in delivering all necessary power to the laser from the spacecraft bus including, diode power regulation, and transmission losses.

\section{Laser Housing}

The overall opto-mechanical-thermal philosophy for this laser design was to use a single monolithic laser housing that served both as a stiff optical bench but also a robust thermal design to minimize thermal gradients across the box. A further constraint was the laser is intended to be operated with the optics cavity exposed to the space vacuum but had to be capable of holding 1 atmosphere pressure inside the optics cavity for a few weeks during some of the intended thermal vacuum tests at instrument and spacecraft level. The laser housing is essentially a thick optical bench with two box cavities on each side (made of 6061-T6 aluminum), one for the optics and one for the electronics. Keeping the electronics and the optics separated allowed for greater contamination control. Signal and power from the electronics cavity to the optics cavity was provided by internal feed throughs in the floor of the housing. The laser was then mounted to the instrument deck by three titanium flexure mounts. Other optical bench designs, such as kinematically mounted optical bench, were investigated but all of them were found not 
survivable through vibration or had thermal dissipation problems due to complex thermal pathways. Figure 32 is a solid model of the laser with the optics cavity lid removed. The lowest order resonance for the housing on the flextures was $216 \mathrm{~Hz}$. The electonics cavity was always vented through a screened hole in the box. The screen was for venting and RF emission suppression not for particulate filtration. The optics cavity was designed to vent to vacuum through a bust disc designed to rupture at 8 psi over pressure. During laser thermal vacuum (TVAC) testing the optics cavity was vented through a quick disconnect bypass. After TVAC testing, the bust disc was capped and the laser remains sealed through instument and observatory TVAC. After testing is complete, the bust disc is uncapped ("red tag" item), and the laser vents during launch.

The laser is all conductively cooled and the $100 \mathrm{~W}$ of heat generated is conducted to one side wall of the laser housing where a variable conductance heat pipe transfers the heat to the instrument thermal radiator. Since a single heatpipe is used to maintain the laser temperature this dictated the amplifier positions on a common side wall of the laser housing. The other heat sources of FET heatsink, oscillator TEC, and doubler, had to be designed to minimize gradients. The monolithic design minimizes interfaces which tend to be the most difficult points to model particularly for vacuum systems. Figure 33 and Figure 34 show the thermal model for the laser housing.

\section{Contamination Control}

Contamination control was classified in two areas, particulates and nonvolatile residues (NVR). Particulate contamination requirements were set at Mil-std level 50 as defined by MIL-STD1246. Although absolute verification is difficult, meeting the standard was accomplished by process and visual inspection. Laser parts processing and assembly was conducted in two 1000 
$\mathrm{ft}^{2}$ class 1000 cleanrooms. Witness pates for particulates and NVR's were verified on a monthly basis. Critical optical subassembly work was conducted in class 100 flow benches and parts stored in cleaned, covered stainless steel containers. Optical subassemblies were inspected by using phase contrast microscopy and white light scattering. After laser assembly, high intensity UV lights were used for inspection in conjunction with a HEPA vacuum to clean up any observed particulates.

The NVR requirement was set at $\mathrm{A} / 2$ per Mil-Std-1246 where $\mathrm{A}$ level $=1 \mu \mathrm{g} / \mathrm{cm}^{2}$. This was the level we felt we could verify to rather than a hard requirement based on known optical damage mechanisms form NVR's. NVR control was achieved by precision cleaning, verification of precision cleaning and vacuum bake-outs. Metallics were ultrasonically cleaned with aqueous detergent, deionized water, ethanol or IPA, and/or other solvents. Polymeric piece parts like wires, feed-throughs, insulators and stand-offs, were solvent cleaned and were prebaked in vacuum oven at $10^{-3}$ Torr.

Verification of the precision cleaning process was conducted by analyzing hexane rinses (50 $\mathrm{ml}$ typical) of parts by evaporating the hexanes and measuring the mass of the NVR. The NVR was then transferred by using chloroform solvent to a $\mathrm{KBr}$ disc and analyzed using an FTIR spectrometer. Solvent control samples were also ran along with the verification rinses. The measurement uncertainty of the mass measurement process was $0.1 \mathrm{mg}$. Therefore, a go/nogo criteria was set at $0.1 \mathrm{mg}$ or less for an acceptable level of NVR. A failed rinse sample meant the parts had to be re-cleaned and verified before being passed to the next level of assembly. This process was quite burdensome and had a yield of about $75 \%$ pass rate for known clean control samples. The pass rate was $60 \%$ for cleaned flight parts. If we divide $0.1 \mathrm{mg}$ by the mass of a typical $50 \mathrm{ml}$ hexane rise we get an NVR concentration of $3 \mathrm{ppm}$. If we assume $1 \mathrm{ml}$ 
of solvent remains on a $100 \mathrm{~cm}^{2}$ part the NVR concentration would be $0.1 \mu \mathrm{g} / \mathrm{cm}^{2}$, or $\mathrm{A} / 10$. Despite the lack of precision of this method it was a direct attempt to verify meeting the NVR standard.

In addition to measuring the mass of the NVR a compositional determination of the NVR was conducted by FTIR. The FTIR analysis is much more sensitive in detecting the presence of silicones and hydrocarbons. Figure 35 shows a sample spectrum from the FTIR of the hexanes verifying solvent. This spectrum was obtained by evaporating a full $1000 \mathrm{ml}$ of solvent rather than the $50 \mathrm{ml}$ verification rinse. The largest peak at $2900 \mathrm{~cm}^{-1}$ is a residual hydrocarbon peak that is in all hexanes, even high quality spectroscopic grade. The amount of residual hydrocarbons is also lot to lot dependent. Therefore a single lot of hexanes was procured and used for all the verification rinses. For the $50 \mathrm{ml}$ samples the acceptance criteria was set at $<$ $2.0 \%$ absorption at $2900 \mathrm{~cm}^{-1}$. Calibration runs with known thicknesses of hydrocarbons (parafilm) were run to determine the absorption coefficient of the main peaks. Using an absorption coefficient of $820 \mathrm{~cm}^{-1}$ for the main $2900 \mathrm{~cm}^{-1}$ peak, a $1 \%$ absorption represents a concentration of $4.5 \times 10^{-2} \mu \mathrm{g} / \mathrm{cm}^{3}$ or about $50 \mathrm{ppb}$ per $1 \%$ absorption. So for our $2 \%$ criteria, the rinse hydrocarbon concentration of the hexanes was about $0.1 \mathrm{ppm}$. If $1 \mathrm{ml}$ of solvent remains on the part surface area of $100 \mathrm{~cm}^{2}$ then the residue was $5 \times 10^{-4} \mu \mathrm{g} / \mathrm{cm}^{2}$ or A/1000.

A good region to look for the silicone signature was in the region form 780 to $830 \mathrm{~cm}^{-1}$ and a peak at $1700 \mathrm{~cm}^{-1}$. The criteria for passing the rinse was "below detection limit" for silicones, which was about $0.1 \%$. Figure 36 shows a sample with a large measurable amount of silicone NVR of $0.6 \mathrm{mg}$ was measured and absorption coefficients calculated. Our detection limit of $0.1 \%$ represents $3 \mu \mathrm{g}$ of silicones in a $50 \mathrm{ml}$ rinse representing about $6 \times 10^{-2} \mu \mathrm{g} / \mathrm{cm}^{3}$, or $60 \mathrm{ppb}$. If the rinse was collected from a $50 \mathrm{~cm}^{2}$ part, the silicone level would be about $\mathrm{A} / 20$. 
There are some problems however in really using this spectroscopic method to make a quantitative determination of the contamination level of the parts. First, one has to assume that the hexane rinse process dissolves all the residual contamination so that the NVR can be measured. Second, one has to assume the NVR transfer process to the $\mathrm{KBr}$ disc is uniform and repeatable so that the FTIR is really measuring all the NVR to obtain the peaks. For these reasons and others, we did not make a quantitative determination of the delivered contamination level but were able to say our contamination detection was very sensitive and that all parts passed this cleaning and verification process. This FTIR process was mostly useful in identifying the signature of the contaminant, such as presence of silicones, rather than quantitatively determining the cleanliness level.

Following precision cleaning and verification, the contamination control plan called for staged vacuum bake-outs at the part, subassembly and final assembly levels. Piece parts and materials were first baked out in high temperature vacuum ovens at $10^{-3}$ Torr. Table 2 shows the material, bake temperature and duration.

After subassemblies such as pump heads, bonded optics and cabling were completed and tested for performance, a $10^{-6}$ Torr high-vacuum bake-out was conducted at $65^{\circ} \mathrm{C}$ for $72 \mathrm{hrs}$. Final laser assemblies were also baked out at high vacuum. The laser electronics were integrated into the housing before installation and alignment of the optics. The electronics were baked out at $60^{\circ} \mathrm{C}$ for over 14 days. The high vacuum chamber was monitored by a quadrapole mass spectrometer and the criterion set for the end of bake-out was no mass detected above 40 amu and the total ion current had stabilized to affixed level. After the laser was finally assembled a "lid-off" bake-out was performed at $55^{\circ} \mathrm{C}$ for about 60 hours again to chamber pressures $<10^{-6}$ Torr. Figure $37 \mathrm{a}, \mathrm{b}$, show the mass spectra for the laser at the beginning (a) and end (b) of the 
laser high vacuum bake-out and Figure 38 shows the total ion current of the bake-out, which has leveled off and by the spectrum consists almost entirely of water. We do not have a quantitative assessment of the outgassing rates at these levels. Chamber pressures achieved were typically 2 $-3 \times 10^{-6}$ Torr. After completion of this final bake-out, the laser was sealed and box leak rate was measured. The laser assembly was now ready for formal thermal vacuum and vibration testing and qualification.

\section{Environmental Tests}

Upon completion of the flight laser assembly and final bake-out, the lasers went through a series of environmental tests. Environmental testing of the GLAS space flight lasers included vibration and thermal-Vacuum (TVAC) tests as well as electromagnetic interference (EMI) and electromagnetic compatibility (EMC) tests.

The EMI/EMC tests were done using the GLAS engineering test unit (ETU) laser. The ETU was assembled and tested prior to the actual flight lasers build. The ETU is identical to the flight laser in all aspects except the components are considered flight spare quality. The first test which consisted of characterizing the laser EMI/EMC as well as DC magnetic properties did not involve the testing of the integrity of the flight laser assembly process, thus the ETU was used as a "like-kind" to minimize handling of the actual flight lasers. The vibration and TVAC tests were performed on the actual flight lasers built by the GLAS laser team.

Figure 39 shows the duration of each of the three flight laser build processes and tests. At the beginning and end of each of the processes or tests, TCP was done to ensure the laser performance remained the same. A typical TCP involved measurement of parameters shown in Table 3, also shown are the parameters being monitored during instrument level tests using 
Bench Test Equipment (BTE) as well as telemetry data received from the satellite while operating in-orbit.

\section{Bench Test Equipment}

The GLAS Bench Test Equipment (BTE) measures the following GLAS laser transmitter characteristics:

- Power - Average power of fundamental (1064 nm) and frequency doubled (532 nm) light.

- Spatial - Far field profile (divergence and circularity), boresight, pointing jitter

- Temporal - Q-switch pulse full width at half maximum (FWHM)

- Spectral - Center wavelength (Lidar channel), linewidth

Figure 40 shows the layout of the BTE during TVAC test. In addition, many other laser functions are monitored such as laser temperatures, prime power, diode drive currents, and box pressure.

\section{BTE Data Acquisition Software}

The BTE data acquisition (DAQ) software was written under the LabView environment (National Instrument Inc.). All test instruments were connected via GPIB and RS-232 cables. Each cycle the DAQ software acquired the vital signs of the laser health as well as performance data. The DAQ software commanded the laser temperature set points via a Neslab water circulating chiller/heater. A software thermal interlock protected the Laser by disabling prime power if the Oscillator diode or Laser Reference Temperature reached an unacceptable limit.

All data was displayed at the end of each inquiry cycle ( $\sim 10$ seconds $)$ and saved to a data file every five minutes (can be varied according to application). 


\section{Power Measurement}

The average power of the GLAS fundamental $(1064 \mathrm{~nm})$ and frequency doubled (532 $\mathrm{nm})$ laser radiation were measured with two volume calorimeters (Scientech, Model 38-0401). The 1064 $\mathrm{nm}$ and the $532 \mathrm{~nm}$ laser beams were separated by a harmonic separator and each beam was then incident on the corresponding volume calorimeter. The energy of the laser radiation was calculated by dividing the measured average power with the measured repetition rate of the laser. The volume calorimeter had a spectral response between $400 \mathrm{~nm}$ to $1200 \mathrm{~nm}$, with $<1 \%$ precision and $5 \%$ accuracy.

The transmission losses through the BTE vacuum chamber window, beam pick-off wedge, periscope, and harmonic separator were measured and used to correct the measured power to create a "corrected" true power.

\section{Temporal Measurement}

The GLAS laser $Q$-switch pulse, full-width-at-half-maximum (FWHM) was measured by scattering a portion of the laser beam used for spatial characterization off a white card and into an InGaAs PIN photo-detector. Only the $1064 \mathrm{~nm}$ light (altimeter channel) pulse FWHM was measured. A high pass optical filter with cutoff wavelength at $730 \mathrm{~nm}$ was used to block the 532 $\mathrm{nm}$ radiation. Additional optical attenuators (ND filters) were used to adjust the electrical signal from the photo-detector on the oscilloscope to within a range of 50 to $300 \mathrm{mV}$. The photodetector (Opto-Electronics, model PD-50) had a rise time of $35 \mathrm{psec}$ and could resolve optical pulses to $50 \mathrm{psec}$. The detector output was processed with a Tektronics TDS-650 1-GHz bandwidth digital oscilloscope.

\section{Spectral Measurement}


Approximately $3.7 \%$ of the total light intensity (both $1064 \mathrm{~nm}$ and $532 \mathrm{~nm}$ ) or $1.2 \%(50 \mathrm{~mW})$ of the $532 \mathrm{~nm}$ laser power was reflected from the second surface of an uncoated optical wedge and used for spectral analysis by a Burleigh pulsed wavemeter Model WA4500. The light was collected and directed to a single mode optical fiber via an aspherical lens. Coupling efficiency was estimated to be $<10 \%$. The fiber was purposely located beyond the focal plane of the coupling lens to minimize misalignment sensitivity during TVAC cycling. In addition, neutral density filters and variable diameter apertures were used to limit the amount of light incident on the fiber end. This helped to prevent damage due to high field intensity from the focused spot. A low pass optical filter ensured only the $532 \mathrm{~nm}$ radiation (Lidar channel) was captured in the fiber. Estimated power at the exit end of the optical fiber was $<5 \mathrm{~mW}$.

The light was injected into the Burleigh Pulsed Wavemeter (Burleigh Instrument, WA4500) via the fiber input port. The WA4500 contained two etalons A \& B, (A - provided coarse data was a Fizeau etalon and B - provided fine data was a Fabry-Perot etalon and the spectral resolution of the etalons were $75 \mathrm{GHz}$ and $15 \mathrm{GHz}$, respectively) to determine the wavelength of the incident signal. Absolute accuracy of WA4500 was \pm 1 pm @ $700 \mathrm{~nm}$, or \pm 0.76 pm @ 530 nm. Instantaneous wavelength measurement was acquired and a statistical analysis was done to the data upon completion of the test. The procedure was as follows: a histogram was generated using the collected data with bin size equaled to the GLAS laser oscillator free spectral range (FSR) at $532 \mathrm{~nm}$ (approximately $2 \mathrm{~nm}$ ). A Lorentzian line shape was fit to the histogram. The center wavelength and the FWHM, which indicated the mode hop excursion of the GLAS laser oscillator, were determined.

\section{Spatial Measurement}


In the BTE setup an expanded ( $25 \mathrm{~mm}$ diameter) $\mathrm{HeNe}$ reference laser beam was directed to the reference mirror (through an uncoated optical wedge and vacuum chamber window) on the GLAS laser alignment plate. The reference HeNe beam was adjusted such that it retro-reflected along its incident path.

Approximately 4\% of the total light intensity (both $1064 \mathrm{~nm}$ and $532 \mathrm{~nm}$ ) and the retroreflected $\mathrm{HeNe}$ reference beam were reflected from the first surface of an uncoated optical wedge were used for spatial analysis. The beam was reflected from a second uncoated wedge and incident normal to an off-axis parabolic (OAP) mirror. The OAP mirror (Space Optics research Labs, Model:OAP157.48-23.555-08Q/MMOA) was made of Zerodur (scratch/dig of 60/40) had a focal length of $3997.6 \mathrm{~mm}$, off axis distance of $598.5 \mathrm{~mm}$ (off-axis angle equals $8.5^{\circ}$ ) and surface accuracy of 1/16 P-V@632 nm. At the focal plane of the OAP mirror a CCD monochromatic camera (Cohu, Model 6700) captured the far field patterns of the GLAS laser beam and the reference HeNe beam. This setup allowed the reference HeNe laser beam and the GLAS laser beam to share common optics thus eliminating the problem of mechanical jitter of individual optical mounts. The following spectral parameters were characterized through this setup: beam divergence, boresight, centroid jitter and circularity.

The images on the CCD camera were captured and analyzed by BeamView software (Coherent, Inc.). The parameters shown in Table 5 were measured using the corresponding algorithms on the BeamView application:

The CCD camera had a spectral response ranging from $190 \mathrm{~nm}$ to $1100 \mathrm{~nm}$. The sensor pixel size was $17.4 \mu \mathrm{m}(\mathrm{H}) \times 16.9 \mu \mathrm{m}(\mathrm{V})$. A high pass filter passed only the $1064 \mathrm{~nm}$ and 633 
$\mathrm{nm}(\mathrm{HeNe})$ light. A polarizer and waveplate were used to maximize the beam intensity on the CCD without saturation. Background correction was performed prior to each acquisition.

\section{Vibration Test}

The vibration test was performed on all flight lasers upon completion of each. The test consisted of sinusoidal and random vibration testing to verify the workmanship and integrity of the Laser Transmitter Assembly (LTA). The LTA was exposed to the expected transient and random vibration of a DELTA II 7320 Launch Environment (designated launch vehicle). The test was performed at the facility within the GSFC Engineering Services Division. The Acceleration Spectral Density (ASD) curves for the vibration tests along the thrust (X), lateral (Y) and Longitudinal ( $Z$ ) axes are shown in Figure 41, Figure 42, and Figure 43 respectively. The total duration per axis was 1 minute. The equivalent Grms levels were:

Full Input Levels (Acceptance Levels)

- Thrust Axis (X): 7.93 Grms 1 Minute Duration

- Lateral Axis (Y): 6.83 Grms 1 Minute Duration

- Longitudinal Axis: 6.79 Grms 1 Minute Duration

Figure 44 shows the GLAS flight laser SN2 on the vibration table during one of the tests.

Thus far none of the environmental tests were active, meaning that the lasers were not in operation during the test duration. The remaining thermal vacuum (TVAC) tests required the lasers to be in operation during majority of the tests.

\section{Thermal Vacuum (TVAC) Test}

Per NASA's General Environmental Verification Specification (GEVS), the flight laser is required to perform within the system requirement over four operational cycles with 6 hour 
dwells at the minimum and maximum operational temperatures $\left(10^{\circ} \mathrm{C}, 35^{\circ} \mathrm{C}\right), 6$ hour cold and hot survival soaks $\left(0^{\circ} \mathrm{C}, 40^{\circ} \mathrm{C}\right)$, and hot and cold starts $\left(10^{\circ} \mathrm{C}, 35^{\circ} \mathrm{C}\right)$ at the minimum and maximum voltages $(26.4 \mathrm{~V}$ and $34 \mathrm{~V})$. The LTA was also characterized at the nominal operational temperature $\pm 2^{\circ} \mathrm{C}$, and a 36 hour continuous operational test was performed at the nominal operating temperature. A typical TVAC test temperature profile is shown in Figure 45.

Since instrument and spacecraft level TVAC testing will be performed with a sealed, pressurized (16 psid) LTA, a single cycle with operational and survival dwells, and hot and cold starts at minimum and maximum voltage was performed followed by a 24 hour operational dwell at the nominal operating temperature.

The LTA was vacuum tested in the SLTC TVAC chamber with a water filled heat pipe simulator controlled with a Neslab chiller. This heat pipe is used to simulate the reference temperature of the laser when in orbit. The alignment plate, which is used to provide a mechanical reference to the laser transmitter for boresight and output beam alignment, was maintained at $20^{\circ} \mathrm{C}$, to simulate a zero CTE optics bench, for the entire test with an additional Neslab chiller. The entire test was monitored with a mass spectrometer to verify cleanliness.

\section{Environmental Test Results}

Here we showed some of the sample test results from environmental testing of GLAS flight laser SN2. Figure 46 shows the 1064 and $532 \mathrm{~nm}$ pulse energy as a function of reference temperature (heat pipe temperature). The laser emits maximum energy at a reference temperature of $\sim 33^{\circ} \mathrm{C}$. During Laser start-up conditions, the power meter response transients can be seen in the data at reference temperatures of $11^{\circ} \mathrm{C}$ and $35^{\circ} \mathrm{C}$. The drop in IR data seen in the start-up at $10^{\circ} \mathrm{C}$ was due to the Doubler slowly coming to temperature and thereby increasing its conversion 
efficiency from IR to Green. A hysteresis loop consistently appeared below $21^{\circ} \mathrm{C}$. The lower path was followed going cold and the upper path was followed while warming.

Figure 47 shows the behavior of laser SN2 when sealed and pressurized with 16 psid during the last part of the TVAC testing. The spatial measurement (boreshight, divergence and circularity) of the same laser during TVAC at reference temperature of $33^{\circ} \mathrm{C}$ in vacuum and 1.5 psid and 16 psid are shown in Figure 48. Note that the divergence of the laser beam met the requirement in vacuum as described in previous section (by defocusing the telescope secondary).

Figure 49 shows the doubled wavelength measurements of laser SN2 in TVAC tests under vacuum and pressurized conditions. The wavelengths of the laser change as reference temperatures varied during TVAC cycling. Figure 50 shows the laser power and reference temperature of SN2 throughout the all-vacuum portion of TVAC testing. The graph shows the first cycle stepping through the specified temperature range up to Hot Survival $\left(40^{\circ} \mathrm{C}\right)$ then down to Cold Survival $\left(\approx 0{ }^{\circ} \mathrm{C}\right)$, hot and cold starts at $35^{\circ} \mathrm{C}$ and $10^{\circ} \mathrm{C}$, followed by three operational cycles from $10^{\circ} \mathrm{C}-35^{\circ} \mathrm{C}$. There appeared to be an energy drop at the $33^{\circ} \mathrm{C}$ plateau after Hot Start. This could be evidence of an amplifier pump diode bar shunt. The energy didn't repeat itself after operational cycle 1 at $33^{\circ} \mathrm{C}$ but did repeat at $10^{\circ} \mathrm{C}$. Otherwise the laser power appeared stable over temperature cycling. The bar shunt event is deemed acceptable and no action was taken to replace the pump laser array. Infant mortality of a single bar is expected and acceptable during subsystem and system level environmental testing prior to launch.

All three flight lasers completed environmental tests without any changes in performance. Table 6 summarizes the TVAC tests and delivery dates of all three GLAS flight lasers. Upon delivery of the GLAS flight lasers and integration into the spacecraft. Instrument level tests continued for an additional period of time. Subsystem level and instrument level tests on all 
three flight lasers totaling over 400 million shots or about $11 \%$ of the projected mission life. The total accumulated shots (see Table 7) during subsystem and instrument levels environmental testing were unprecedented.

\section{Summary}

The Geoscience Laser Altimeter System on NASA's ICESat mission has been operating in space for over $3-1 / 2$ years. The lasers so far have emitted a cumulative number of shots exceeding 1 billion. At the time of this writing, Laser 3 currently has emitted more pulses in space than any other pulsed solid state lasers with more than 700 million shots fired from space. The GLAS laser transmitter was conceived, designed and built using 1990's technology. The in-space operation since 2001 has been an invaluable learning experience for future space laser instruments design and development. Indeed, the GLAS laser design has inspired future missions such as the Mercury Laser Altimeter ${ }^{21}$ (MLA) on board of MESSENGER and Lunar Orbiter Laser Altimeter for the Lunar Reconnaissance Orbiter ${ }^{22}$ (LRO) to be launched in late 2008. GLAS is a pioneering instrument and the instrument performance is truly extraordinary. The GLAS lasers' pulsewidth ( $<6 \mathrm{~ns})$, energy $\left(>100 \mathrm{~mJ}\right.$, total), beam quality $\left(\mathrm{M}^{2} \sim 2\right)$, and stability have helped enable $2.4 \mathrm{~cm}$ precision, $5 \mathrm{~cm}$ accuracy altimetry measurements from a 600 $\mathrm{km}$ orbit, in a size, weight and efficiency within mission constraints. Despite the earlier unexpected loss of Laser 1, a larger than anticipate degradation rate in Laser 2, the GLAS lasers continue to collect high resolution vertical profiles of the Earth's atmosphere and land surface. With the current projections on the lifetime of Laser 3, it is still possible the GLAS instrument will meet or exceed prelaunch expectations. For an overview of the scientific results from ICESat see the special issues of Geophysical Research Letters. ${ }^{23}$ 


\section{Acknowledgement}

The authors would like to acknowledge the support and dedication of all staffs and engineers at

the now defunct SLTC. The author would also like to thank J. Abshire and the GLAS instrument team for their hard work in developing the GLAS lasers. 


\section{References}

1. Abshire, J.B, X. Sun, E. A. Ketchum, R. S. Afzal, P. S. Millar, "The Geoscience Laser Altimeter System (GLAS) for the ICESat Mission," OSA Conference on Lasers and Electro-Optics, San Francisco, CA, May 2000.

2. Abshire, J.B, X. Sun, H. Riris, J. M. Sirota, J. F. McGarry, S. Palm, D. Yi, and P. Liiva, “Geoscience Laser Altimeter System (GLAS) on the ICESat Mission: On-orbit measurement performance," Geophysical Research Letters, Vol. 32, L21S02, doi:10.1029/2005GL024028, 2005.

3. Zwally, H. J., B. Schutz, W. Abdalati, J. Abshire, C. Bentley, A. Brenner, J. Bufton, J. Dezio, D. Hancock, D. Harding, T. Herring, B. Minster, K. Quinn, S. Palm, J. Spinhirne, R. Thomas, "ICESat's laser measurements of polar ice, atmosphere, ocean, and land," Journal of Geodynamics, 34 (2002) 405-445.

4. Schutz, B. E., H. J. Zwally, C. A. Shuman, D. Hancock, and J. P. DiMarzio (2005), "Overview of the ICESat Mission," Geophys. Res. Lett., 32, L21S01, doi:10.1029/2005GL024009.

5. Sirota, J. M., S. Bae, P. Millar, D. Mostofi, C. Webb, B. Schutz, and S. Luthcke (2005), "The transmitter pointing determination in the Geoscience Laser Altimeter System," Geophys. Res. Lett., 32, L22S11, doi:10.1029/2005GL024005.

6. Afzal, R. S. , J. L. Dallas, A. Lukemire, W. Mamakos, A. Melak, B. Schroeder, A. W. Yu, "The Geoscience Laser Altimeter System Laser Transmitter," OSA Conference on Lasers and Electro-Optics Digest, CMJ2, San Francisco, CA 2000. 
7. Afzal, R. S., J. L. Dallas, A. Lukemire, W. Mamakos, A. Melak, L. Ramos-Izqueirdo, B. Schroeder, A. W. Yu, "Space Qualification of the Geoscience Laser Altimeter System," OSA Conference on Lasers and Electro-Optics Digest, CWN4, Long Beach, CA 2002.

8. Afzal, R. S., "Mars Observer Laser Altimeter: Laser Transmitter," Applied Optics, ( 33), 15, 20 May, 1994, p. 3184.

9. Afzal, R. S., "Space Operation of the MOLA Laser," OSA Advanced Solid State Laser Topical Meeting, Davos, CH, 2000.

10. Smith D.E., M.T. Zuber, H.V. Frey, J.B. Garvin, J.W. Head, D.O. Muhleman, G.H. Pettengill, R.J. Phillips, S.C. Solomon, H.J. Zwally, W.B. Banerdt, T.C. Duxbury, M.P. Golombek, F.G. Lemoine, G.A. Neumann, D.D. Rowlands, O. Aharonson, P.G. Ford, A.B. Ivanov, C.L. Johnson, P.J .McGovern, J.B. Abshire, R.S. Afzal, X.L. Sun, “Mars Orbiter Laser Altimeter: Experiment summary after the first year of global mapping of Mars," Journal of Geophysical Research-Planets, 106 (E10): 23689-23722, OCT 25 2001.

11. Afzal, R. S., A. W. Yu, W. A. Mamakos, "The GLAS Laser Transmitter Breadboard," OSA TOPS Vol. 10, Advanced Solid State Lasers, p. 102 Orlando, FL, Jan. 27 - Jan. 29, 1997.

12. Afzal, R. S., M. D. Selker, "A simple high efficiency, TEM00, diode laser pumped, QSwitched Laser," Opt. Lett., Vol. 20, No. 5, p.46, March 1, 1995

13. Afzal, R. S, A. W. Yu, J. J. Zayhowski, and T. Y. Fan, "Single-Mode, High Peak-Power, Passively Q-Switched Diode Pumped Nd:YAG Laser," Optics Letters, Vol. 22, No. 17, p. 1314, Sept 1, 1997. 
14. Dallas, J. L., R. S. Afzal, and M. A. Stephen, "Demonstration and Characterization of a Multi-Billion Shot, 2.5 mJ, 4 ns, Q-Switched, Nd:YAG Laser," Applied Optics, Vol. 35, No. 9, p. 1427, 20 March 1996

15. Stephen, M. A, J. L. Dallas and R. S. Afzal, "Multi-billion shot, High-Fluence Exposure of Cr4+:YAG Passive Q-switch," SPIE Proceedings from 29th Annual Boulder Damage Symposium, Vol. 3244, Boulder, CO, p. 517, Oct. 6, 1997.

16. Stephen, M. A., M. Krainak, and J. L. Dallas, "Quasi-CW Laser Diode Bar Life Tests," SPIE Proceedings from 29th Annual Boulder Damage Symposium, Vol. 3244, Boulder, CO, p. 598, Oct. 6, 1997.

17. Krainak, M., R.S. Afzal, M. Stephan, G. Browder, J. Haden, and N. Carlson, "Performance Tests of Quasi-CW Diode Pump Arrays Conducted or Sponsored by NASA Goddard Space Flight Center," 1997 Digest of the LEOS Summer Topical Meetings: Advanced Semiconductor Lasers and Applications, 1997, p. 78.

18. Xiao, G., M. Bass, “A Generalized Model for Passively Q-switched Lasers Including Excited State Absorption in the Saturable Absorber," IEEE J. Quantum. Electron., Vol. 33, No. 1, January 1997, p. 41.

19. Lowdermilk, W. H., J. E. Murray, “The Multipass Amplifier: Theory and numerical analysis," J. Appl. Phys., Vol. 51, No. 5, May 1980, p. 2436 - 2444.

20. Barth, Janet and E.G. Stassinopoulos, "Space Radiation Exposure of the GLAS Mission," NASA GSFC X-900-93-06, Aug 1993.

21. Krebs, Danny J., A.M. Novo-Gradac, S.X. Li, S.J. Lindauer, R.S. Afzal, and A.W. Yu, "Compact, passively Q-switched Nd:YAG laser for the MESSENGER mission to Mercury," Appl. Opt., Vol. 44, p. 1715-1718, 2005. 
22. See website: http://lunar.gsfc.nasa.gov/ on LRO mission details.

23. Results from the Ice, Cloud, and land Elevation Satellite (ICESat) Mission, Geophysical Research Letters, Vol. 32, No. 21 and 22, 2005. (Also see the ICESat web site: http://icesat.gsfc.nasa.gov/) 
IST and LRS

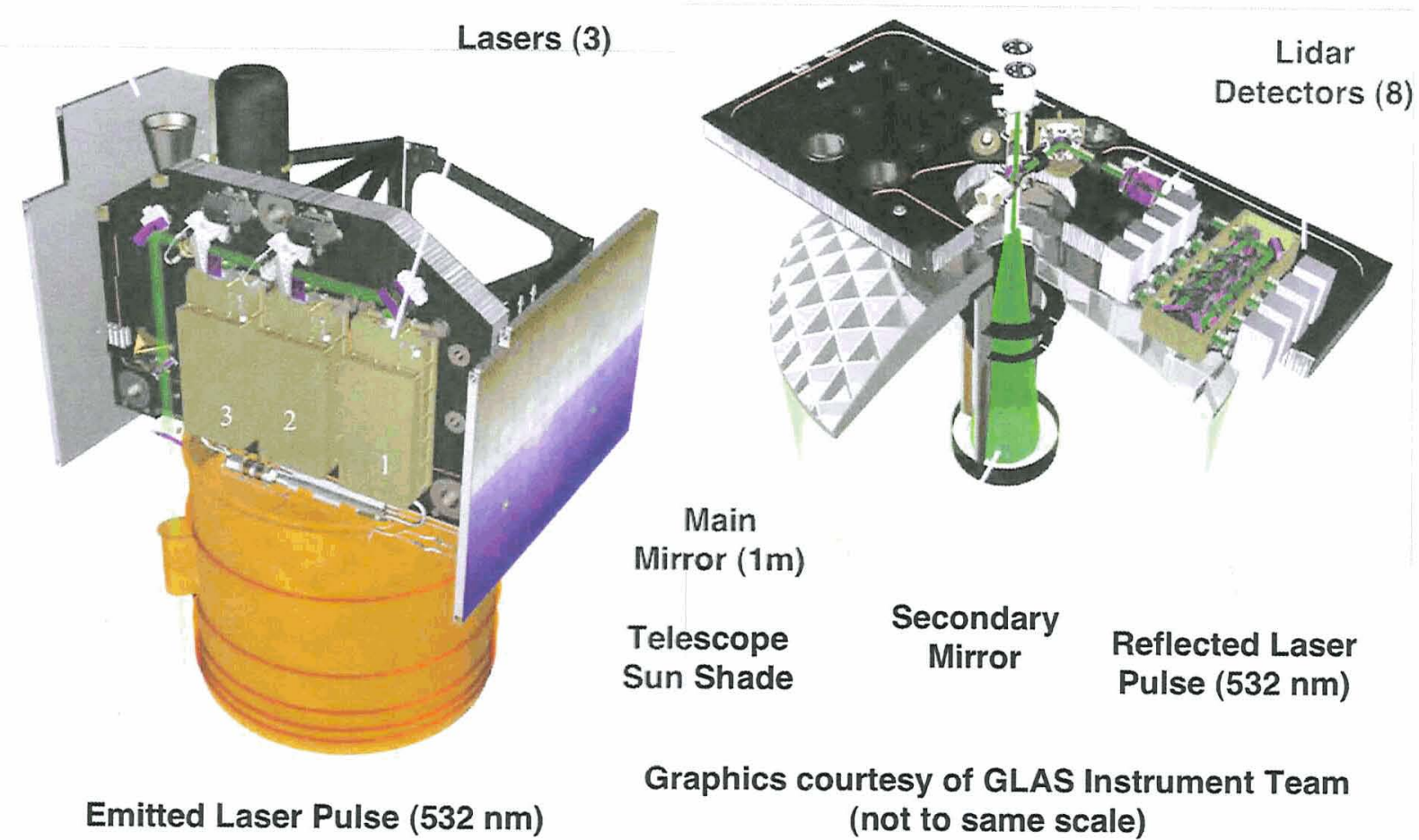

Figure 1. Graphic showing the location of the lasers in relation to the other elements of the instrument optical path. 


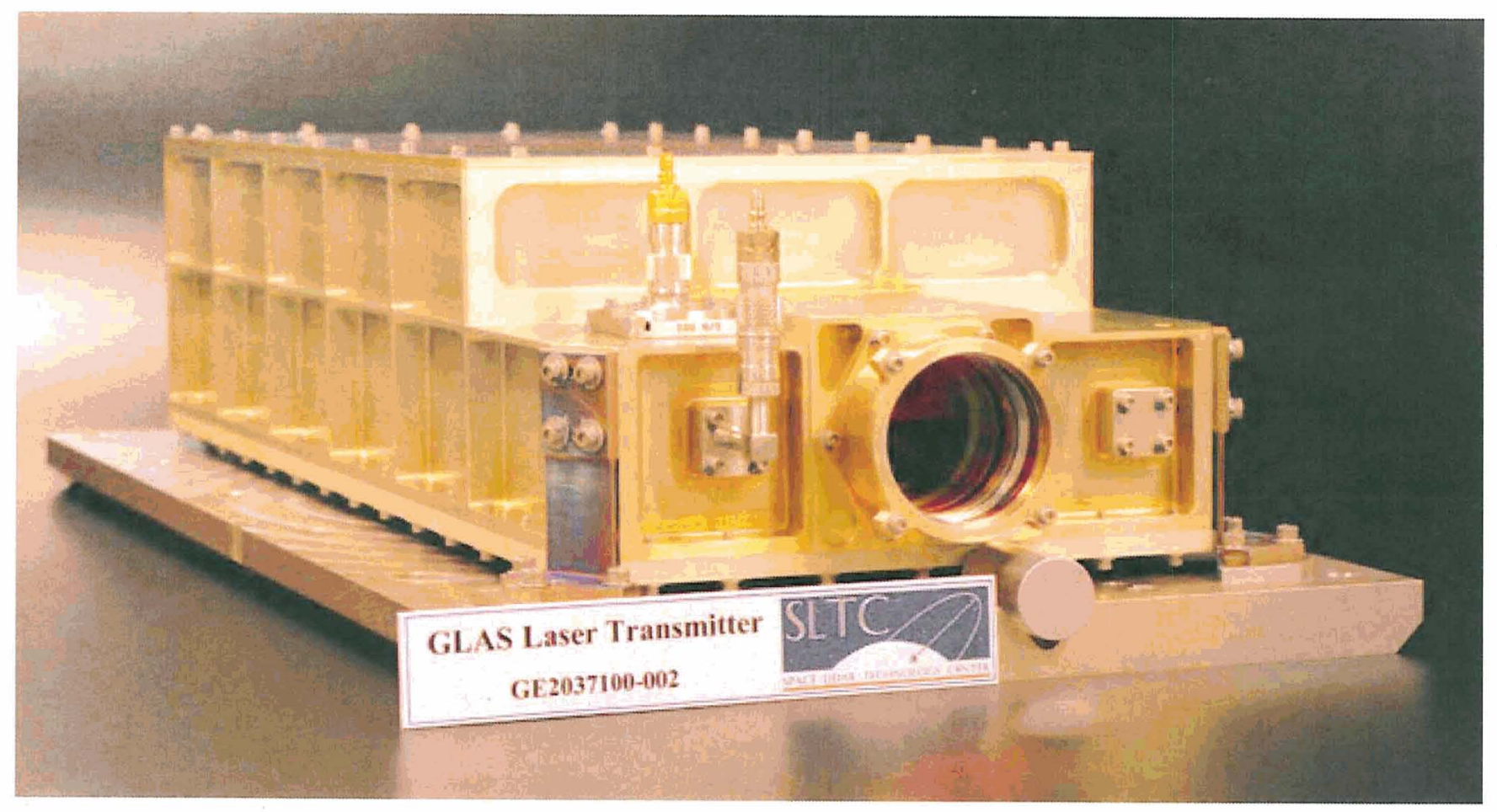

Figure 2. External photograph of the GLAS laser serial number 2. Visible is the output port of the laser beam, the mounting flexures, quick disconnects (remove before flight) for venting and purging with air, and a reference mirror used to align the pointing of the laser beam mounting feet. 


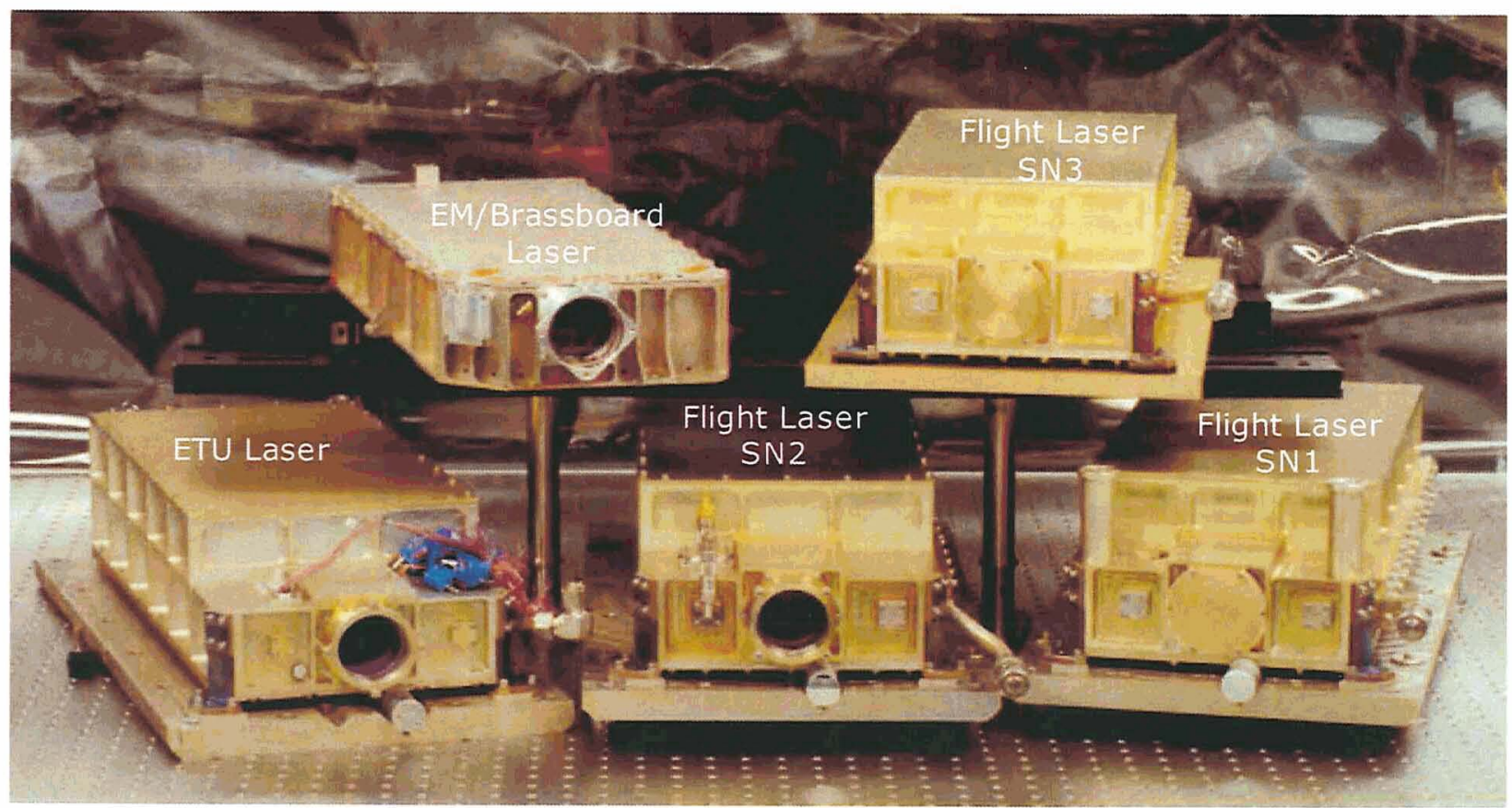

Figure 3 Collection of the laser hardware developed for GLAS. Visible is the EM then reconfigured into a brassboard test, ETU with additional instrumentation from flight, and three flight lasers SN1, SN2, and SN3. Not shown is Laser SN4 which was assembled from flight spare parts and assemblies in January 2003 about the same time as the launch of ICESat. 


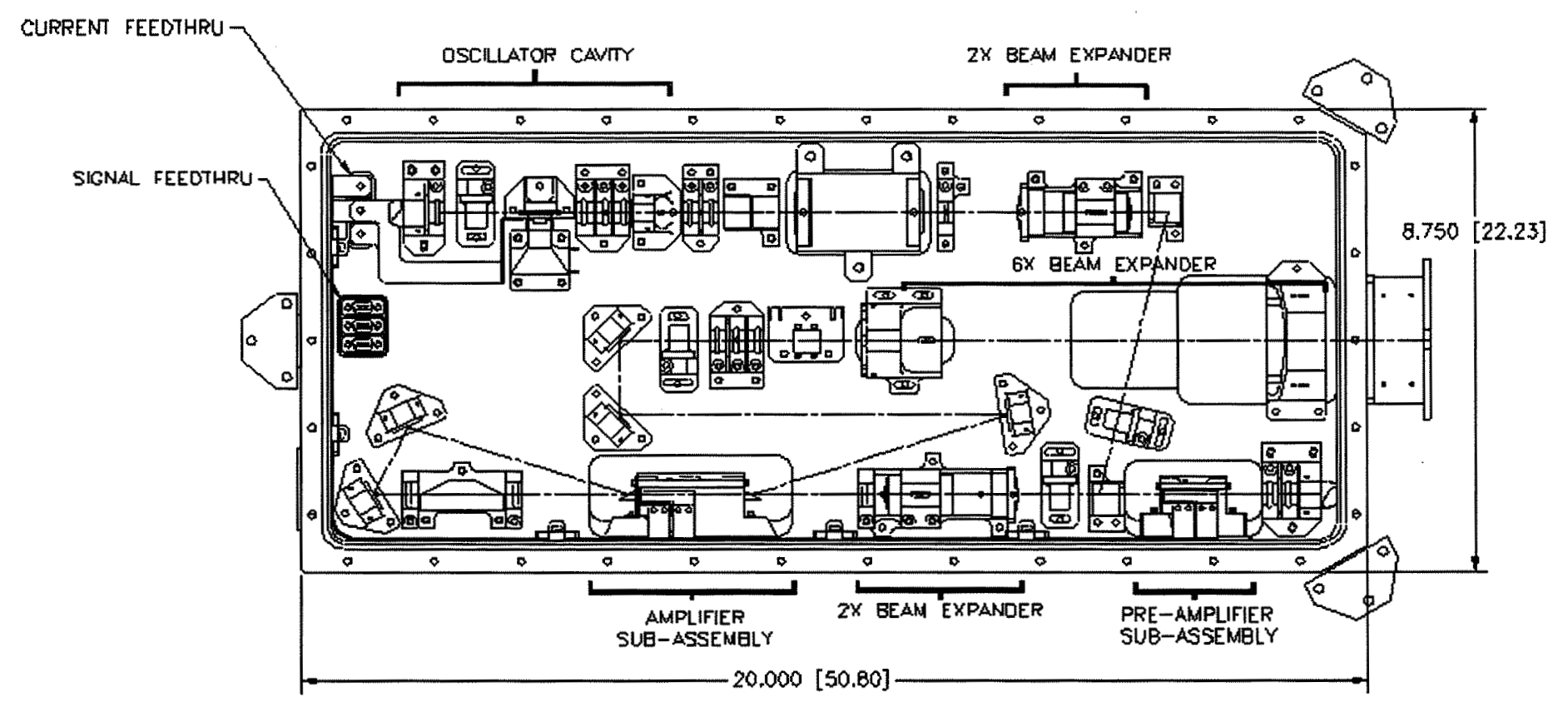

Figure 4. Schematic of the optical layout in the laser cavity. 


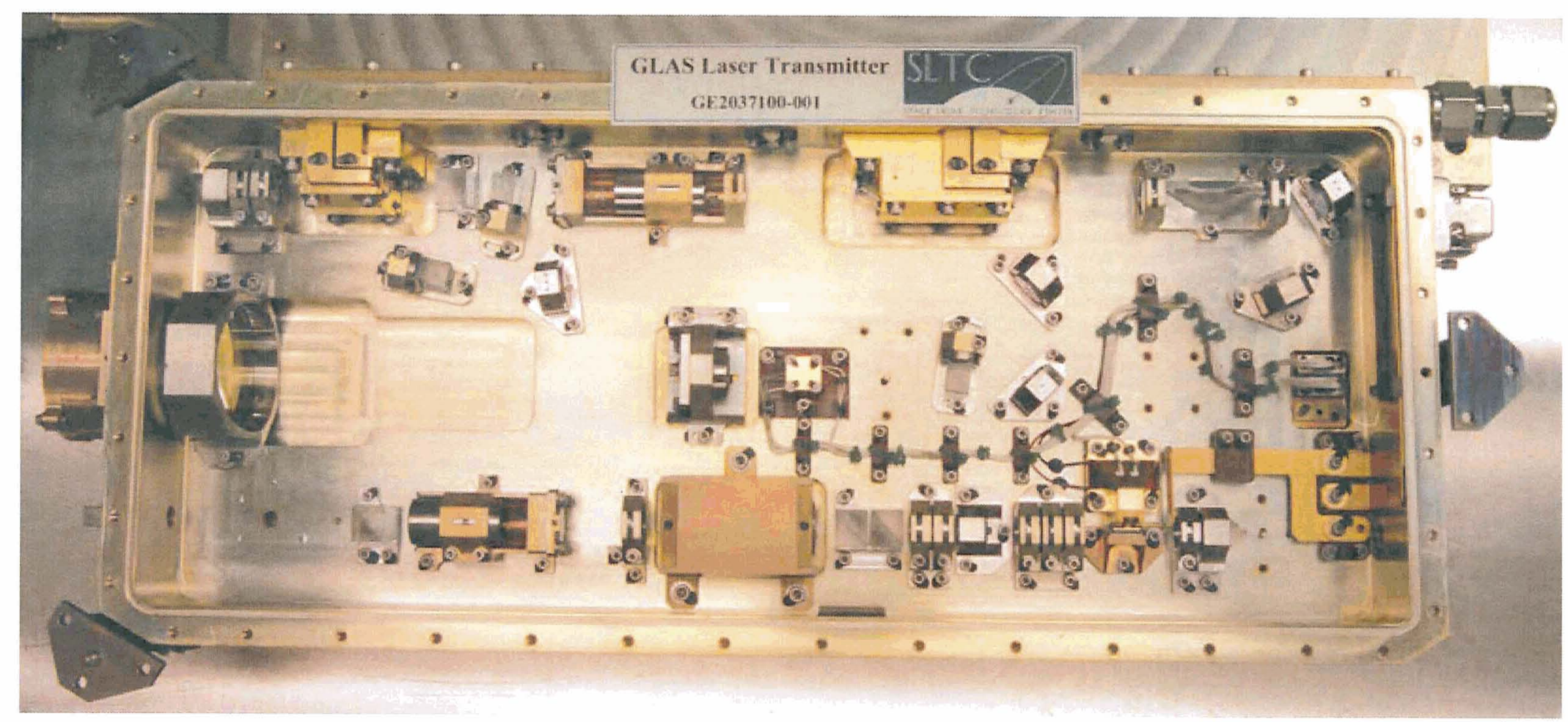

Figure 5. Photograph the optics cavity of a flight laser. 


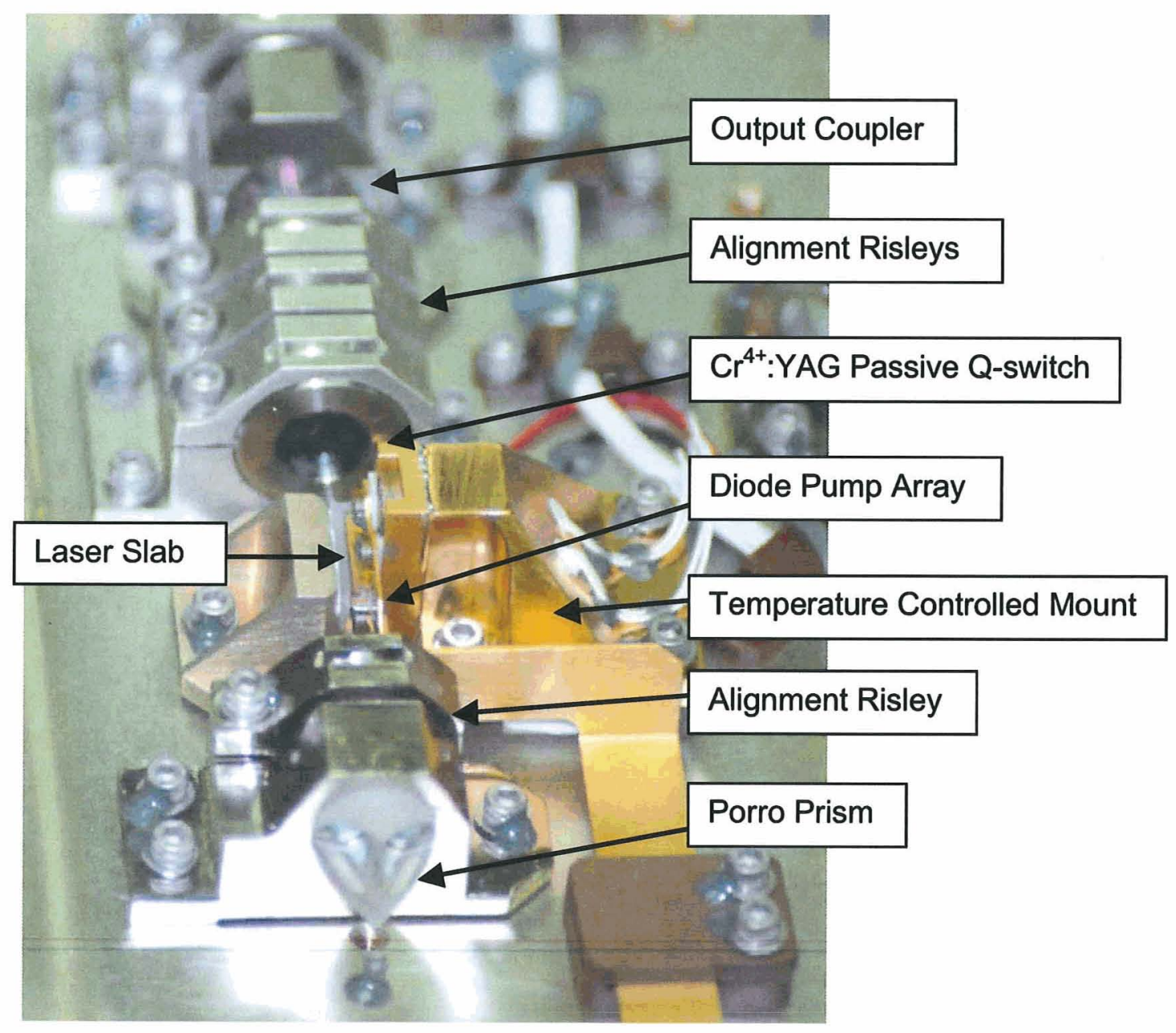

Figure 6. Photograph of the flight laser oscillator. 


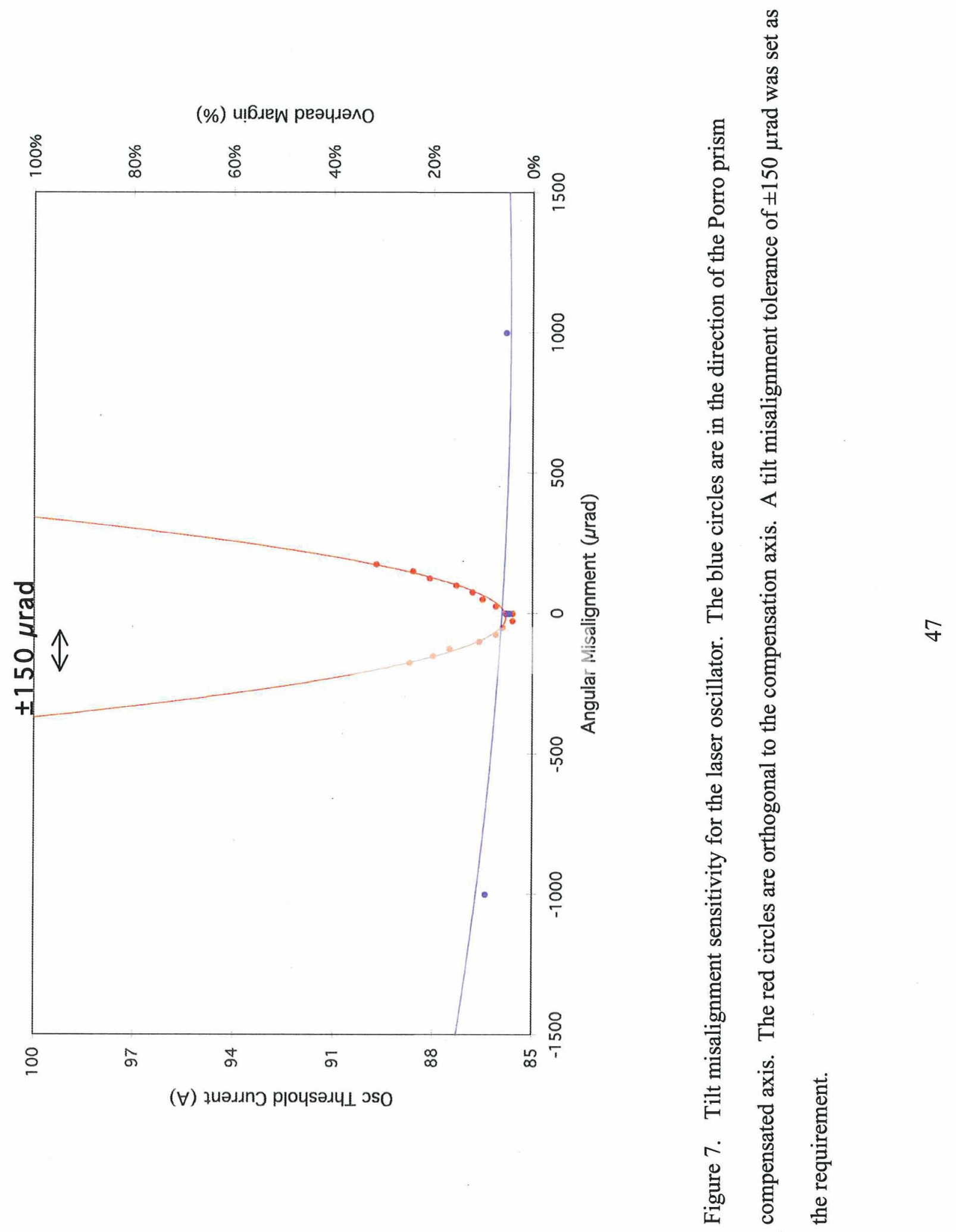


Threshold Current vs. Temperature

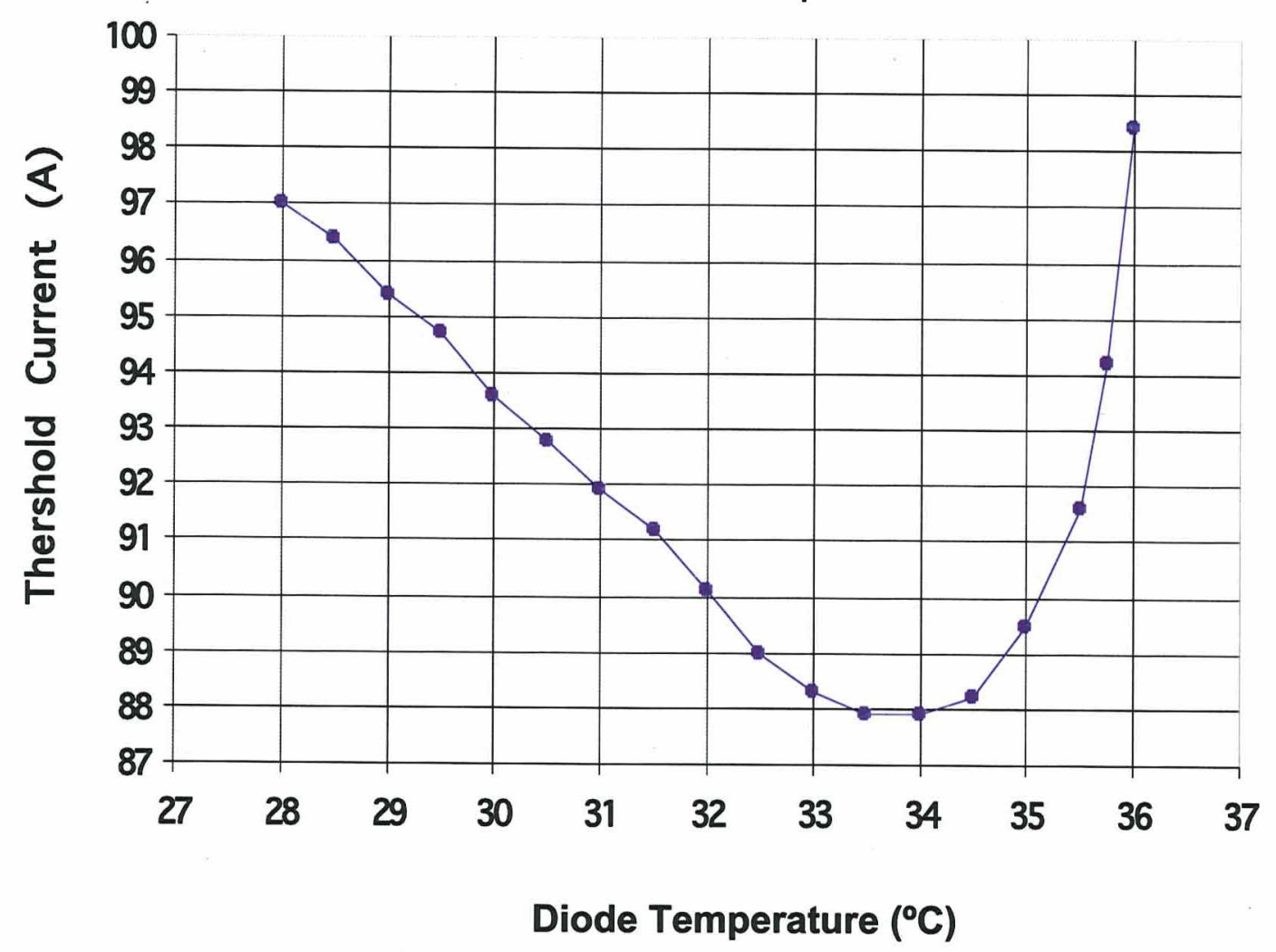

Figure 8. Oscillator threshold current as function of pump diode temperature. For this case the diode set point temperature was set at $31.8^{\circ} \mathrm{C}$. 


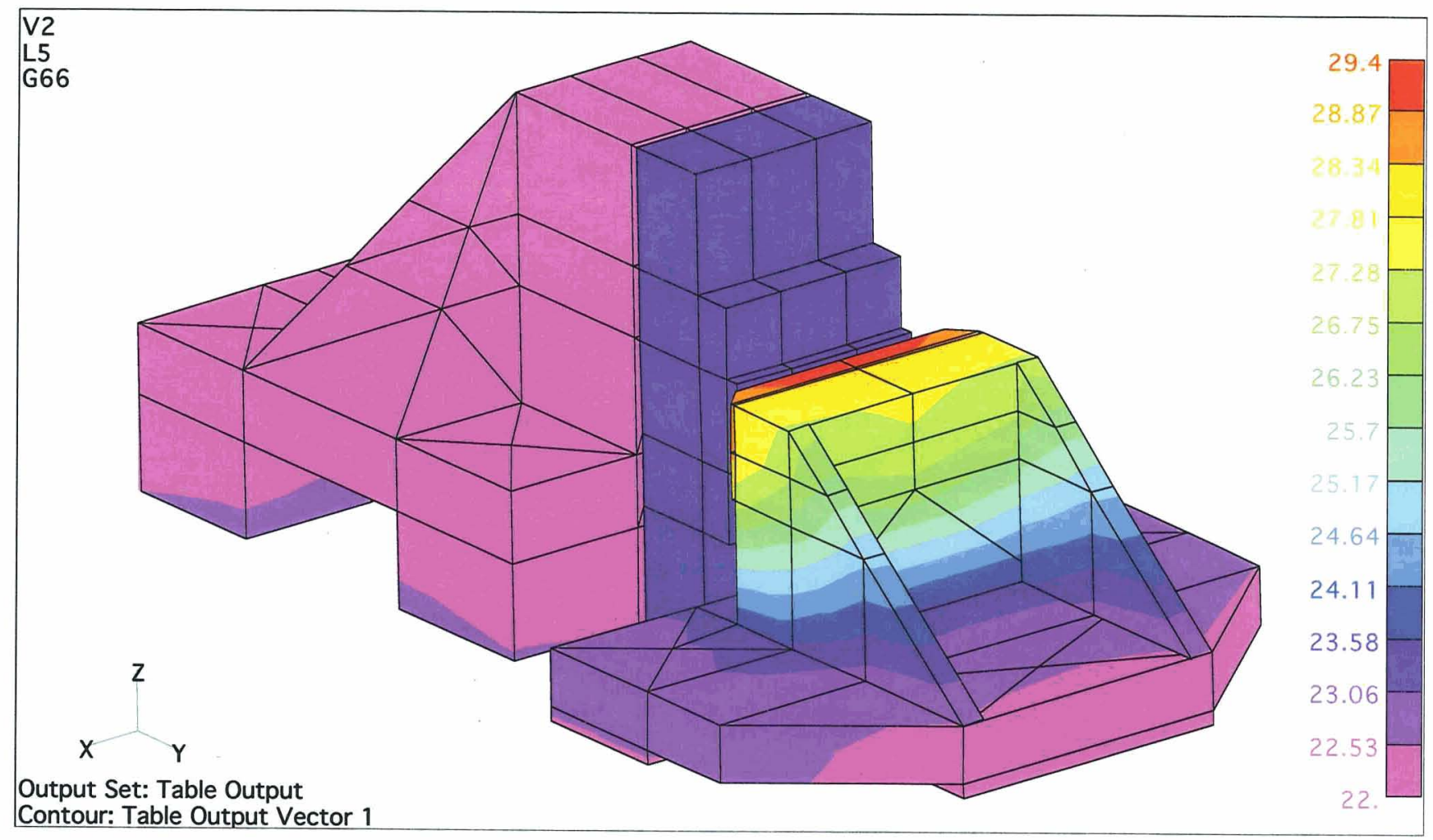

Figure 9. Thermal predictions for the oscillator gain module. The temperature ranges from a low of $22^{\circ} \mathrm{C}$ to the hottest slab temperature of $29.4^{\circ} \mathrm{C}$. The diode is dissipating about $1.8 \mathrm{~W}$, the slab about $0.3 \mathrm{~W}$ and about $0.9 \mathrm{~W}$ is radiated into the laser housing in florescence and unabsorbed diode pump light. 


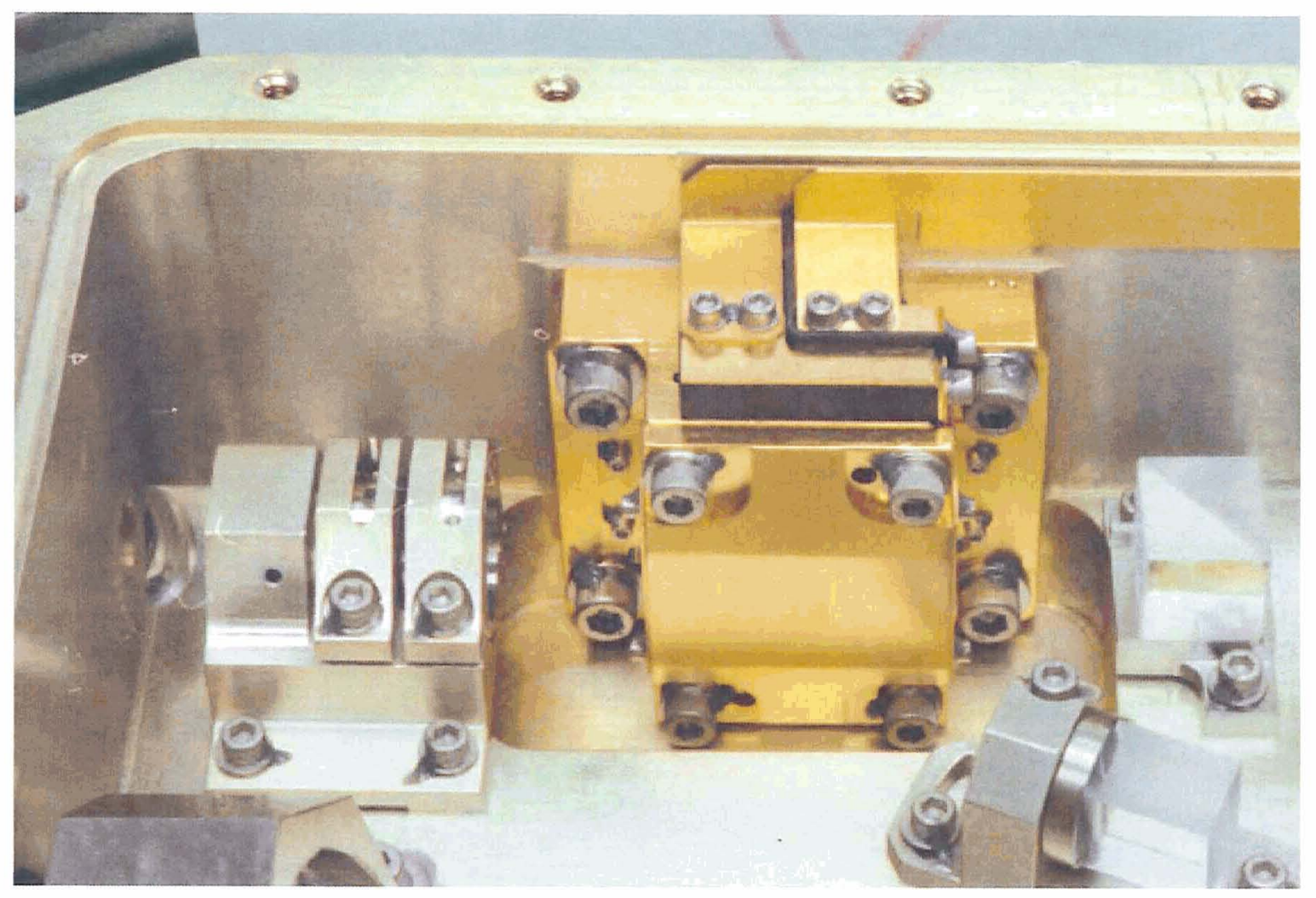

Figure 10. Preamplifier section of the laser. Visible are the preamplifier gain module, in and out coupling polarizer and waveplate/Risley/Porro mount. 


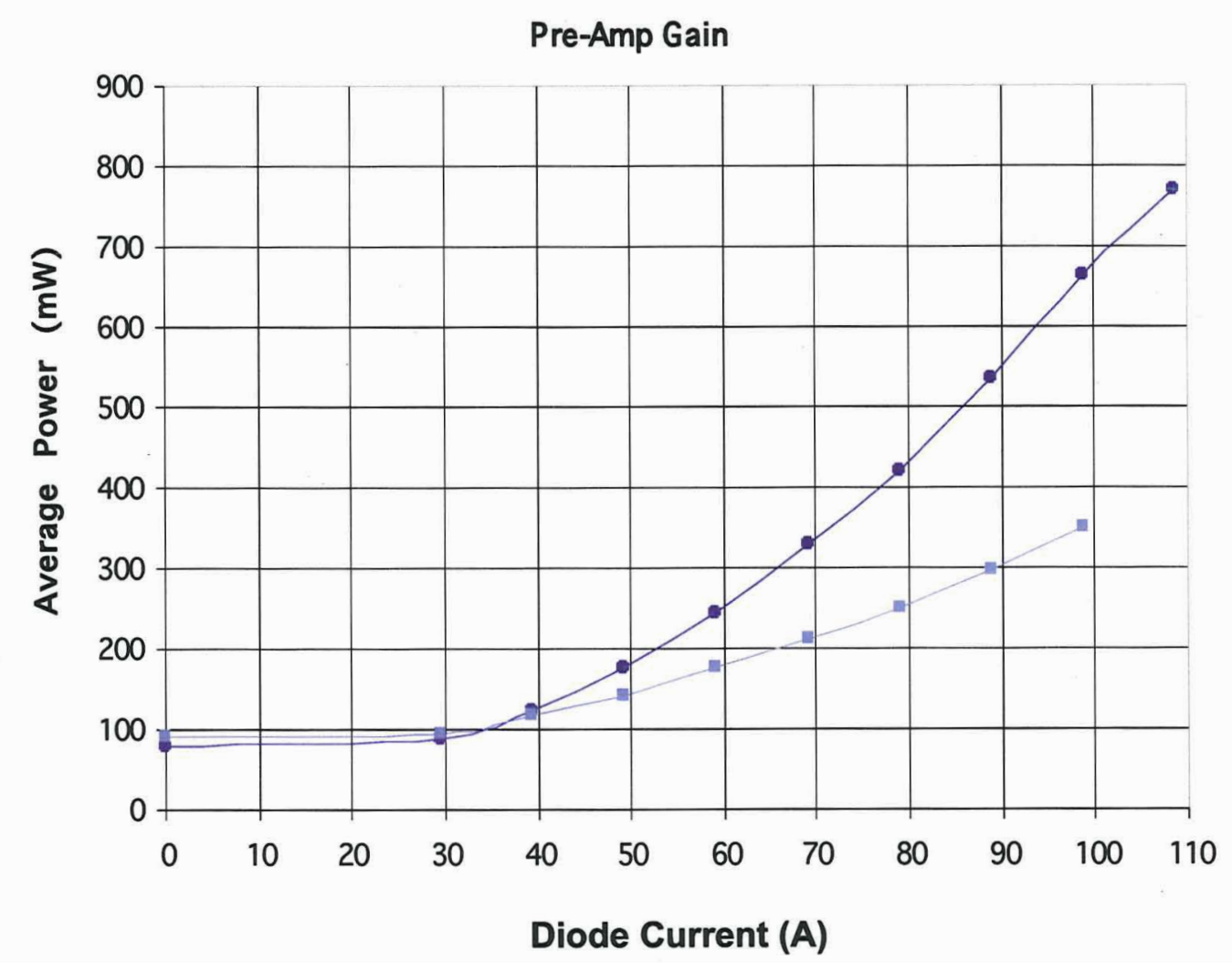

Figure 11. Output power of the single and double pass preamplifier operating at $40 \mathrm{~Hz}$. The input was the oscillator beam and the measurement includes all the in-coupling and out-coupling losses into the gain module. Light blue squares are single pass and dark blue circles are double pass. 


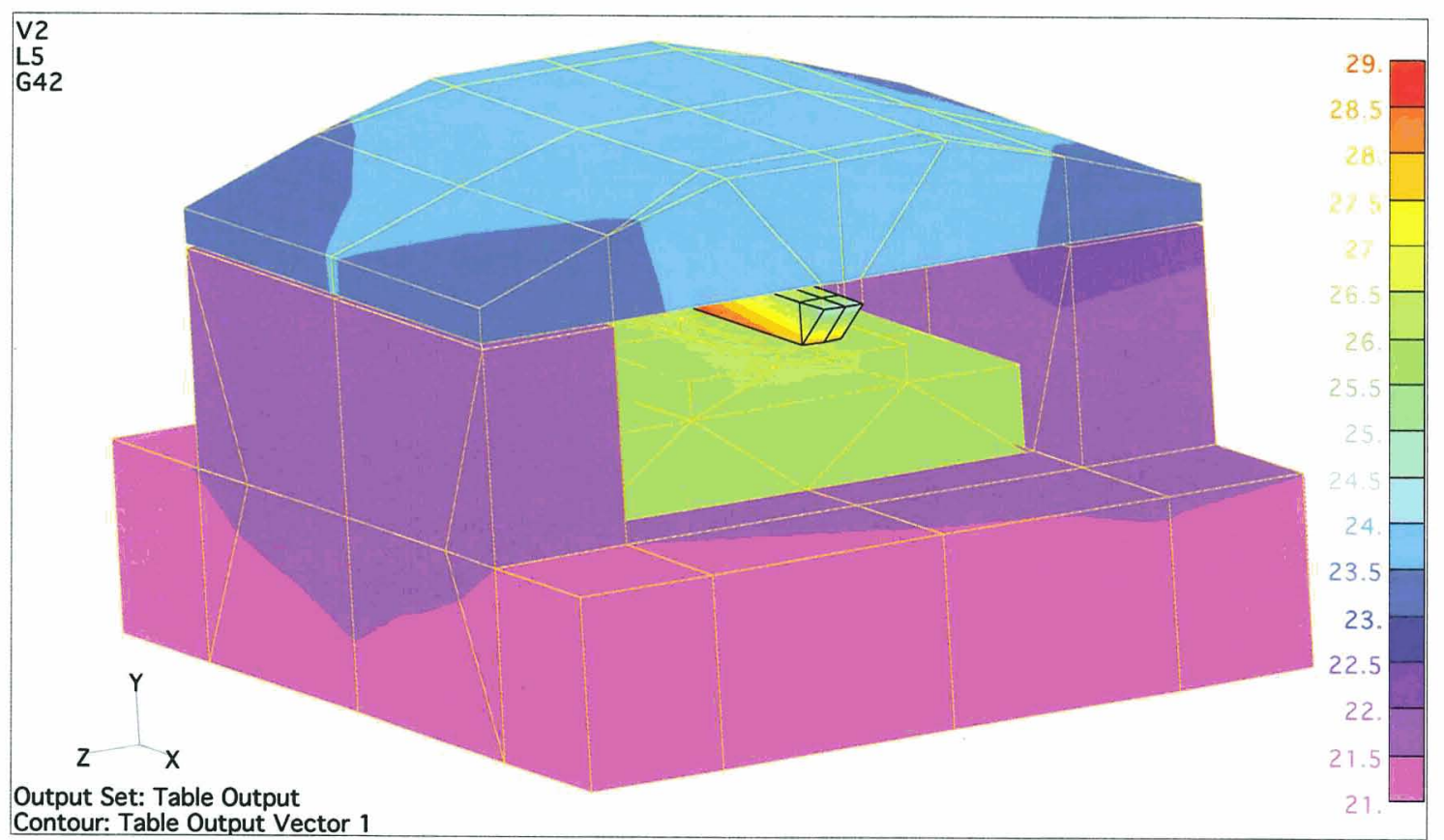

Figure 12. Thermal predictions for the preamplifier gain module. The temperature ranges from a low of $21^{\circ} \mathrm{C}$ to the hottest slab temperature of $29^{\circ} \mathrm{C}$. The diodes are dissipating about $7.1 \mathrm{~W}$, the slab about $1.6 \mathrm{~W}$ and about $3.0 \mathrm{~W}$ is radiated in florescence and unabsorbed diode pump light. End caps are installed onto the end of the pump chamber (not shown) to capture the radiation in the pump module. 


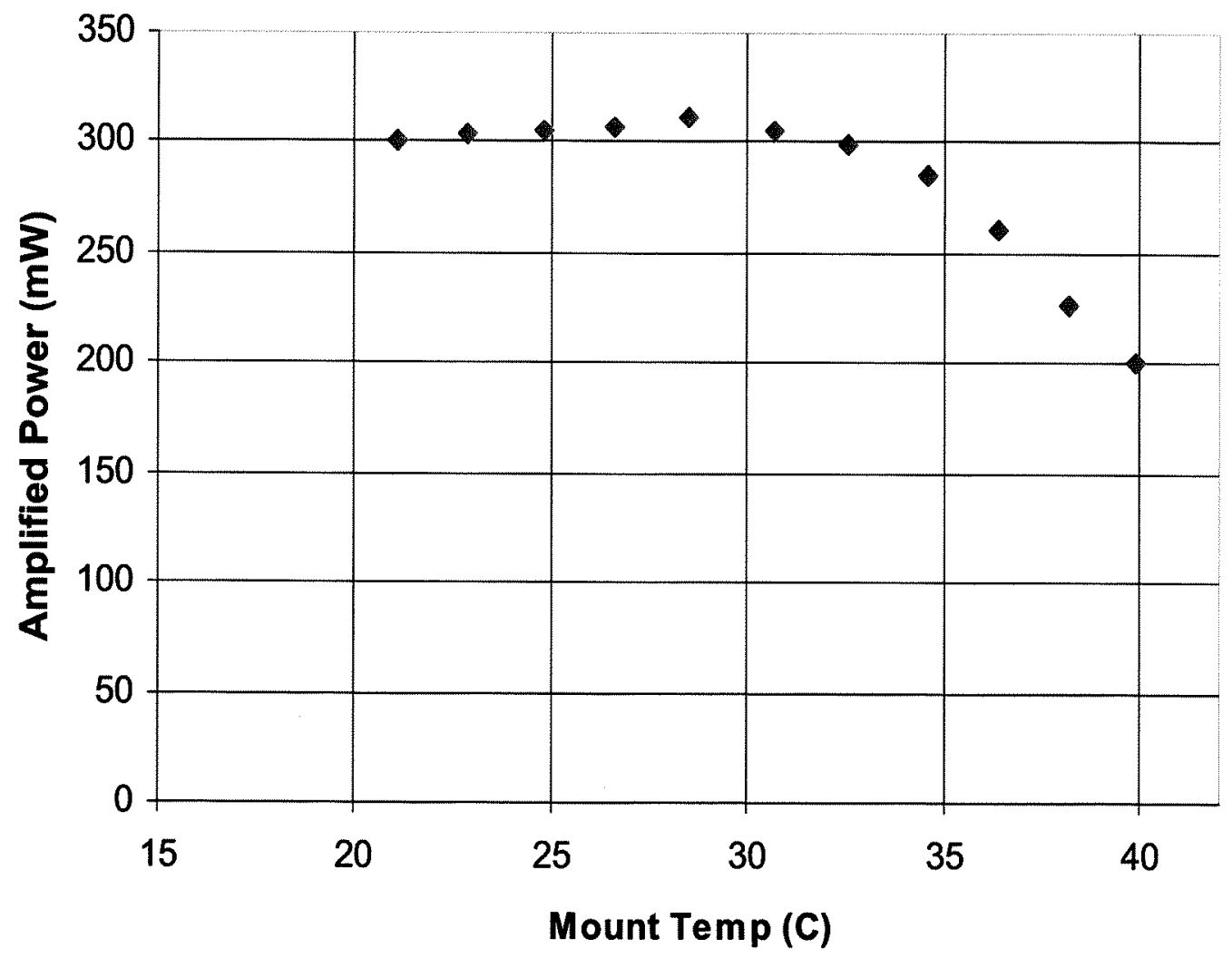

Figure 13. Preamplifier single pass gain with mount temperature. The input laser was a replica oscillator beam at $1.5 \mathrm{~mJ}$ and 40 $\mathrm{Hz}$. 


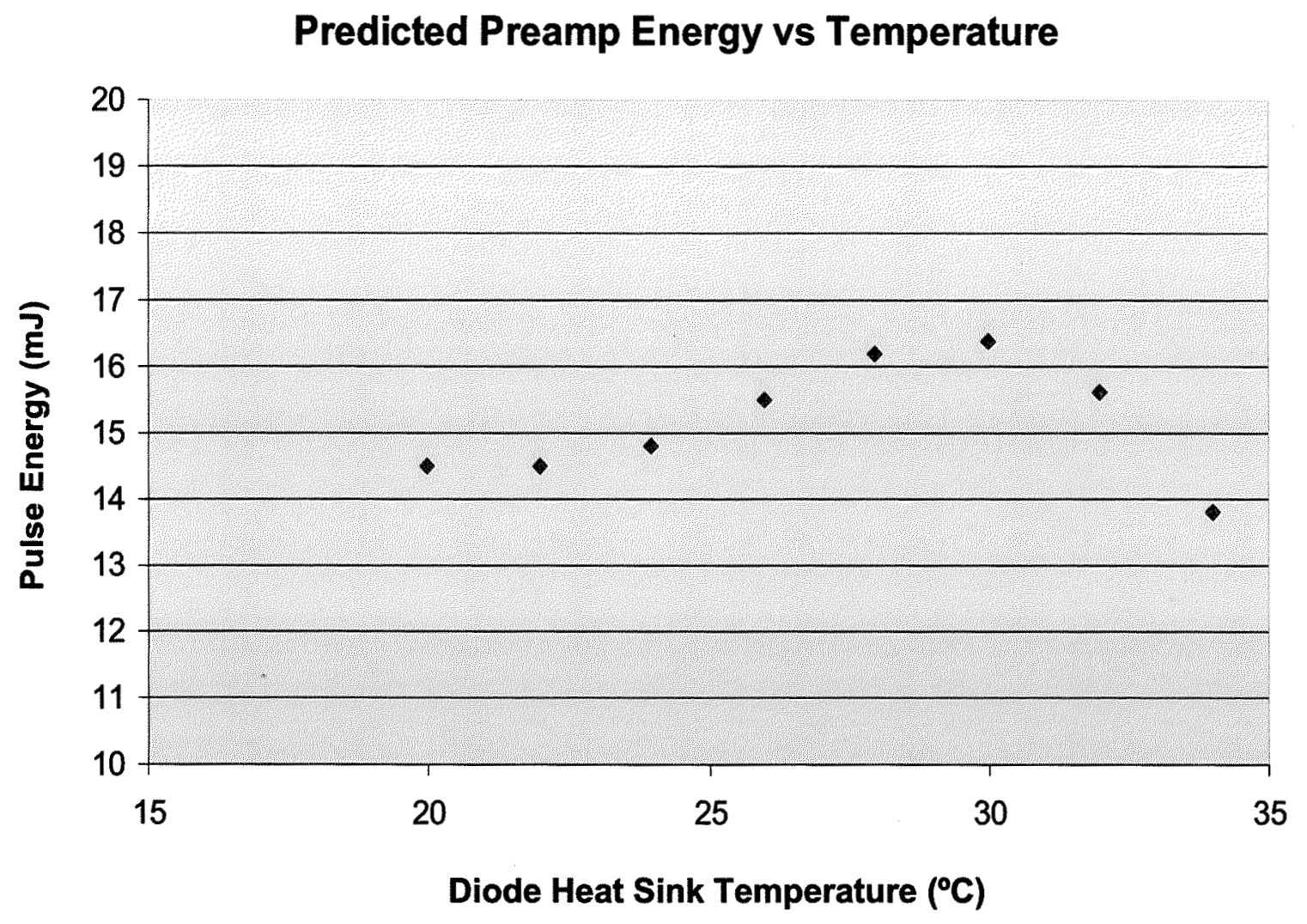

Figure 14. Predicted pulse energy after the preamplifier stage. The calculation was based on actual measured values of the flight components such as slab losses, diode power and wavelength. 


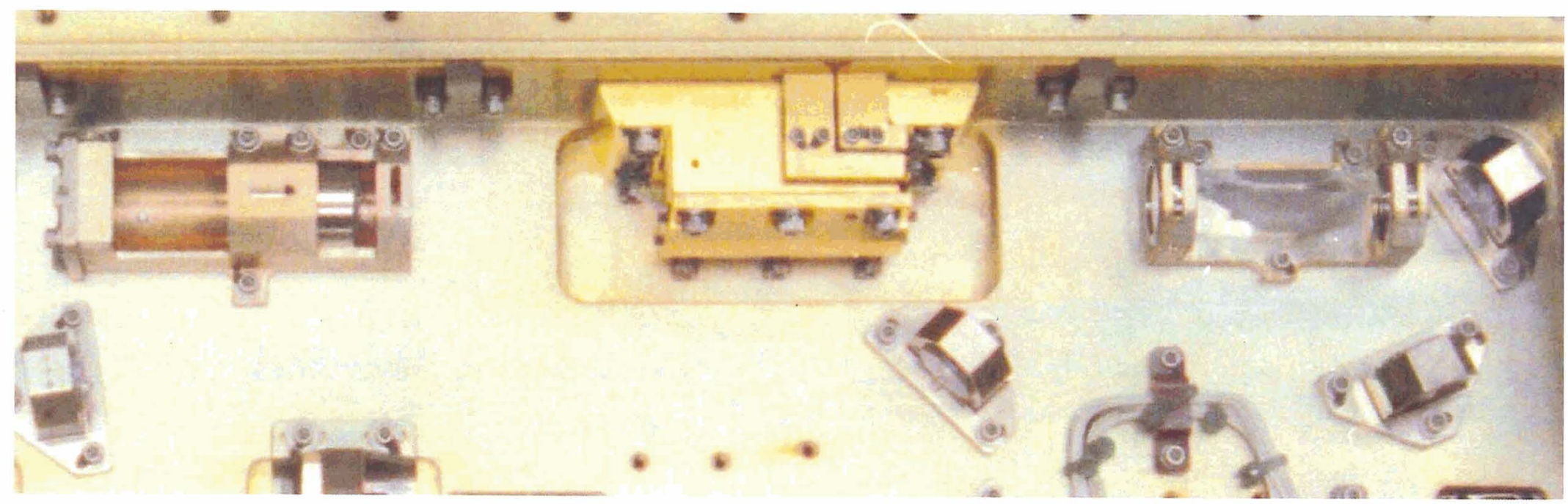

Figure 15. Power amplifier section of the laser. Visible is the input beam expander assembly, the amplifier gain module, dove prism assembly, and turning optics. 


\section{DoubleSinglePass Amplifier Gain}

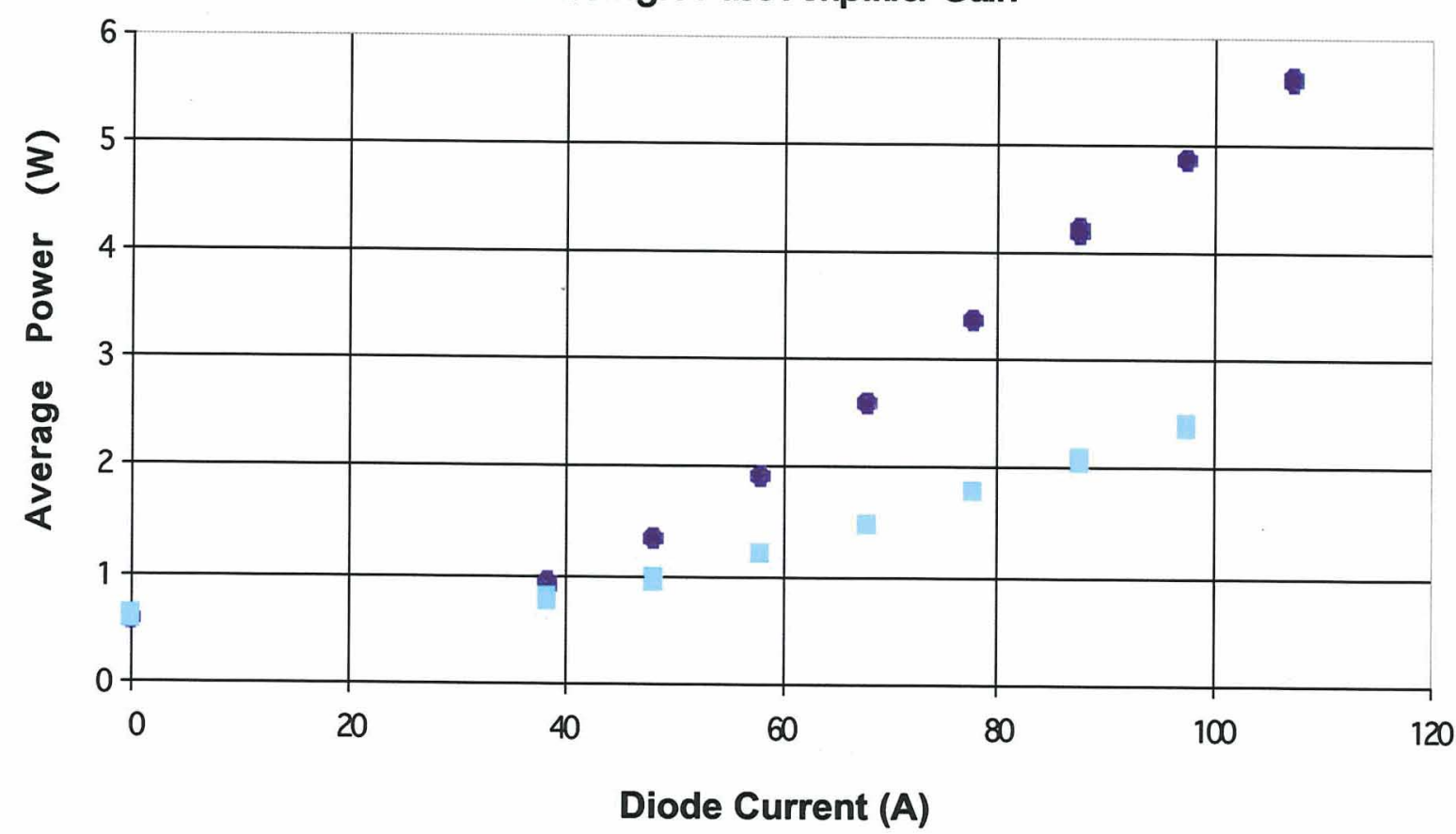

Figure 16. Output power of the single and double pass preamplifier operating at $40 \mathrm{~Hz}$. The input was the beam exiting the preamplifier operating at $100 \mathrm{~A}$. The measurement includes all the in-coupling and out-coupling losses into the gain module. Light blue squares are single pass and dark blue circles are double pass. 


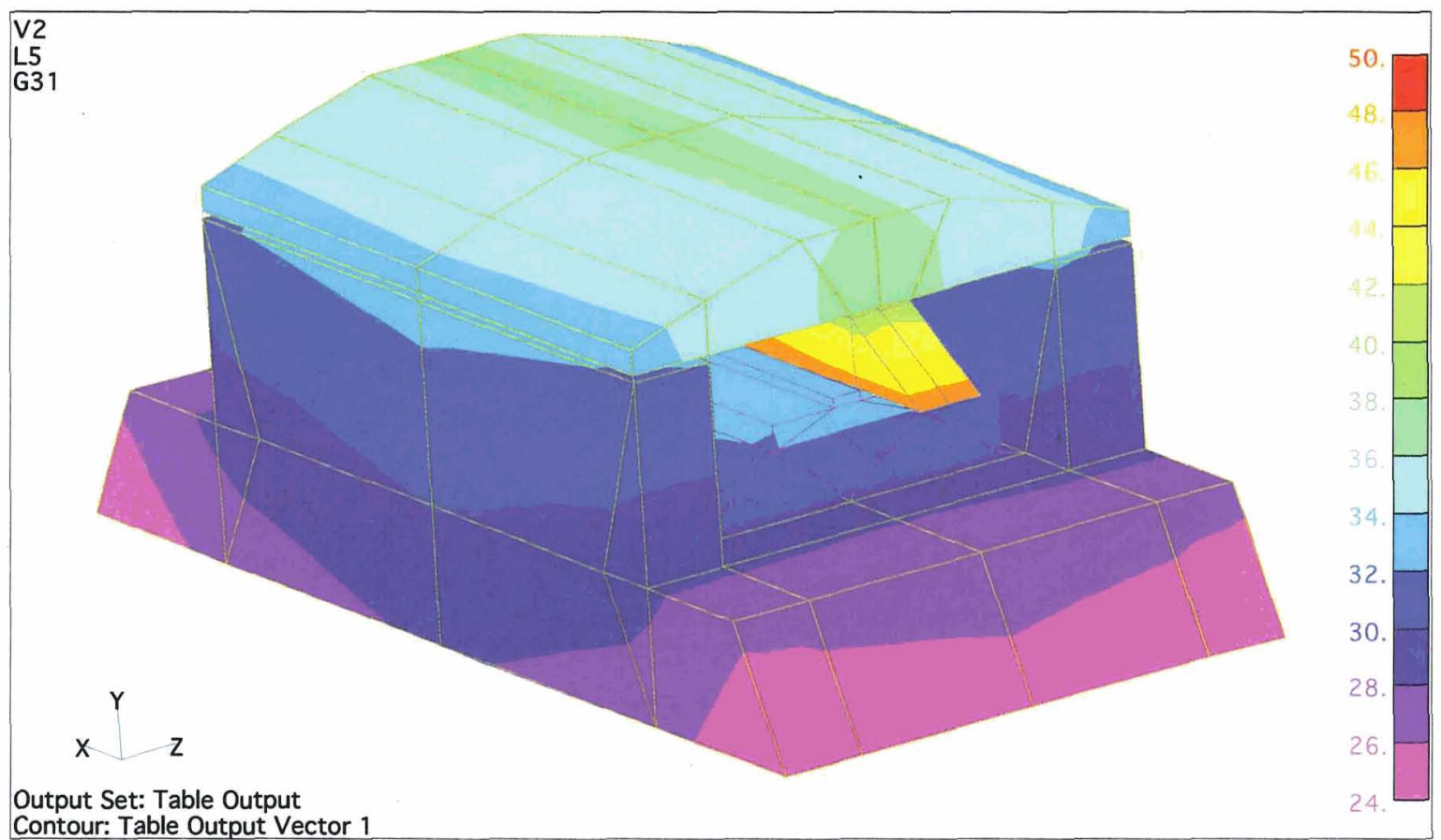

Figure 17. Thermal predictions for the power amplifier gain module. The temperature ranges from a low of $24^{\circ} \mathrm{C}$ to the hottest slab temperature of $50^{\circ} \mathrm{C}$. The diodes are dissipating about $39.1 \mathrm{~W}$, the slab about $10.2 \mathrm{~W}$ and about $14.1 \mathrm{~W}$ is radiated in florescence and unabsorbed diode pump light. End caps are installed onto the end of the pump chamber (not shown) to capture the radiation in the pump module. 


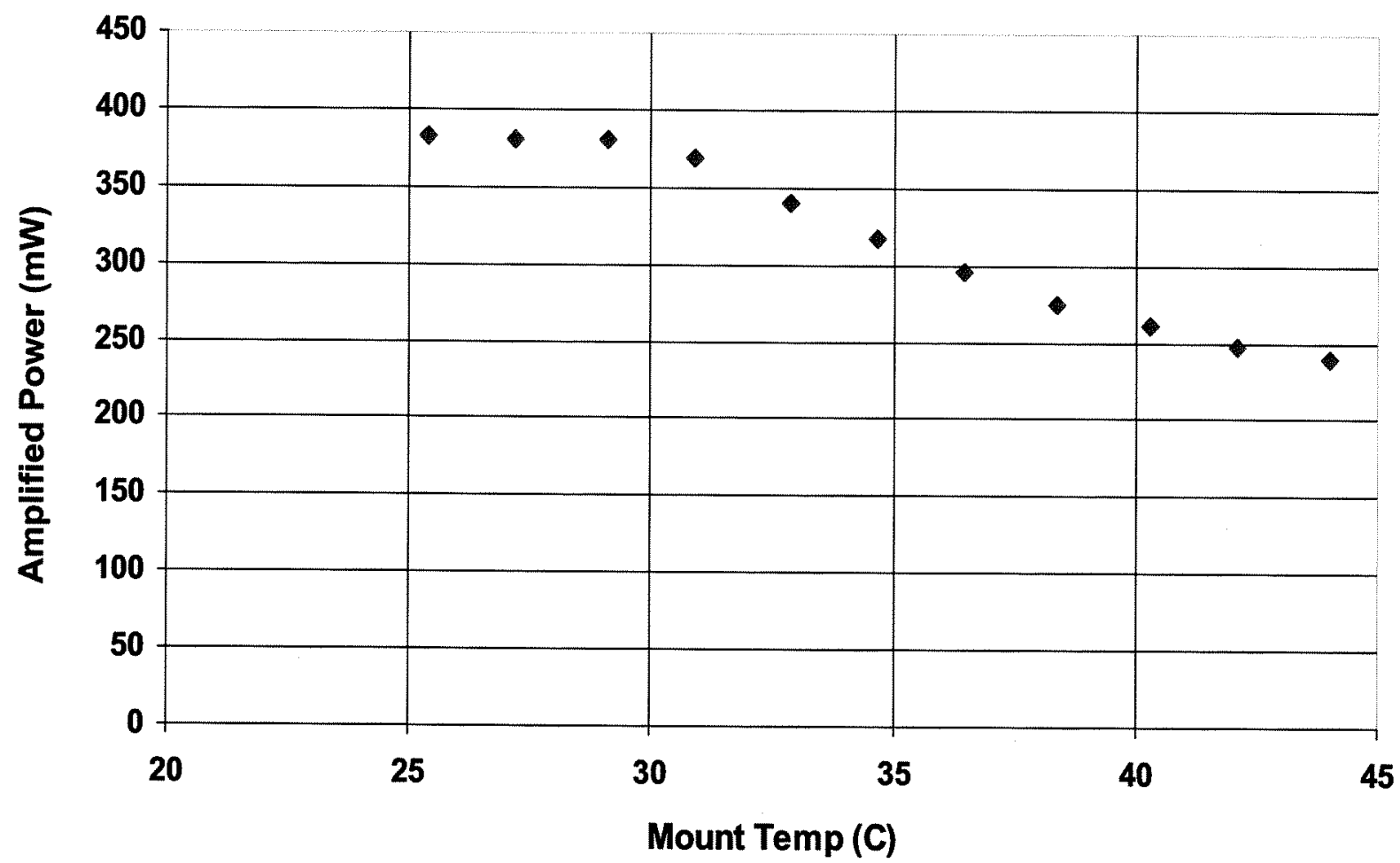

Figure 18. Temperature dependence of the amplifier single pass gain. The input laser was a replica oscillator beam at $1.5 \mathrm{~mJ}$ and $40 \mathrm{~Hz}$. 


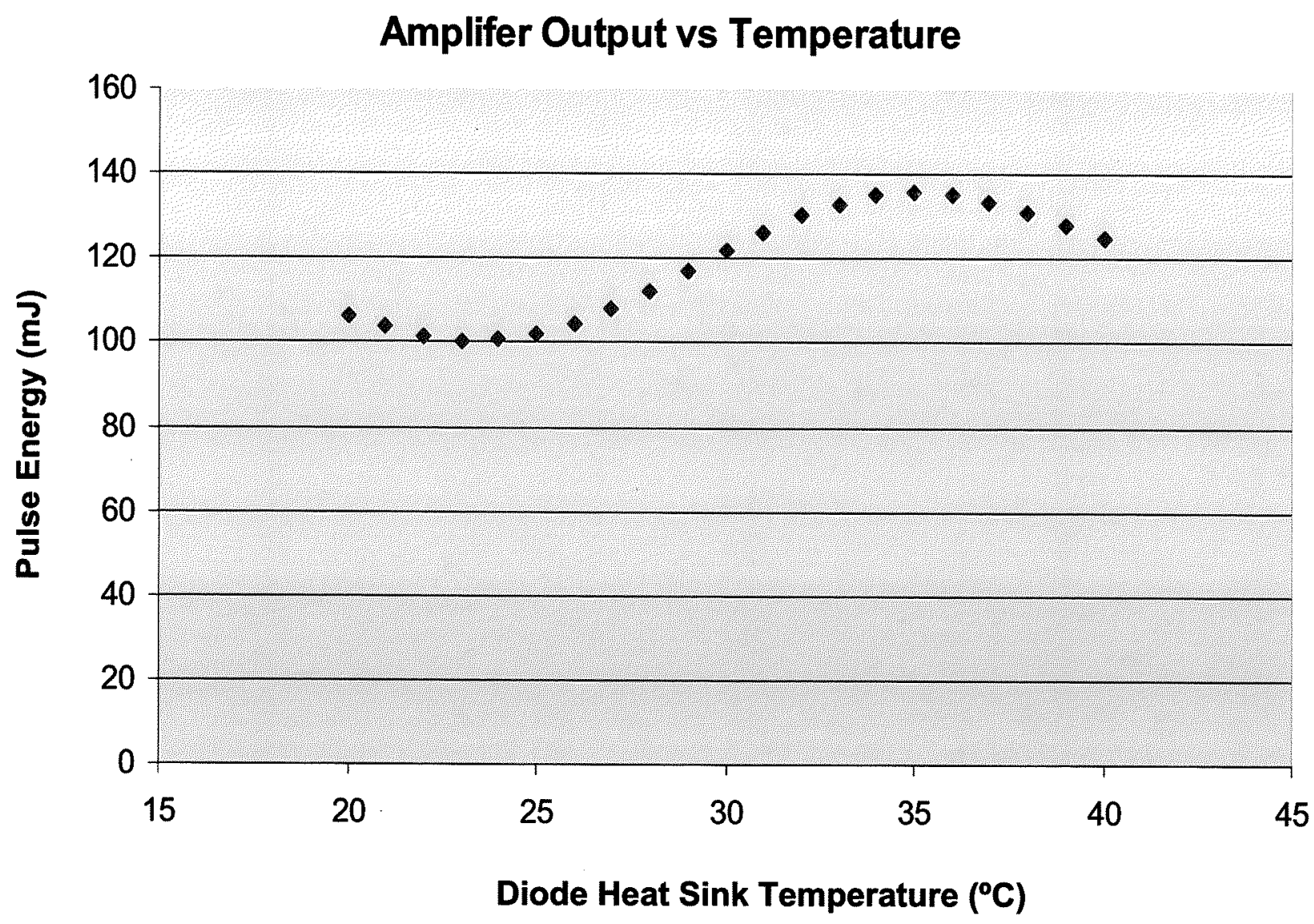

Figure 19. Predicted pulse energy after the amplifier stage. The calculation was based on actual measure values of the flight components such as slab losses, diode power and wavelength. 


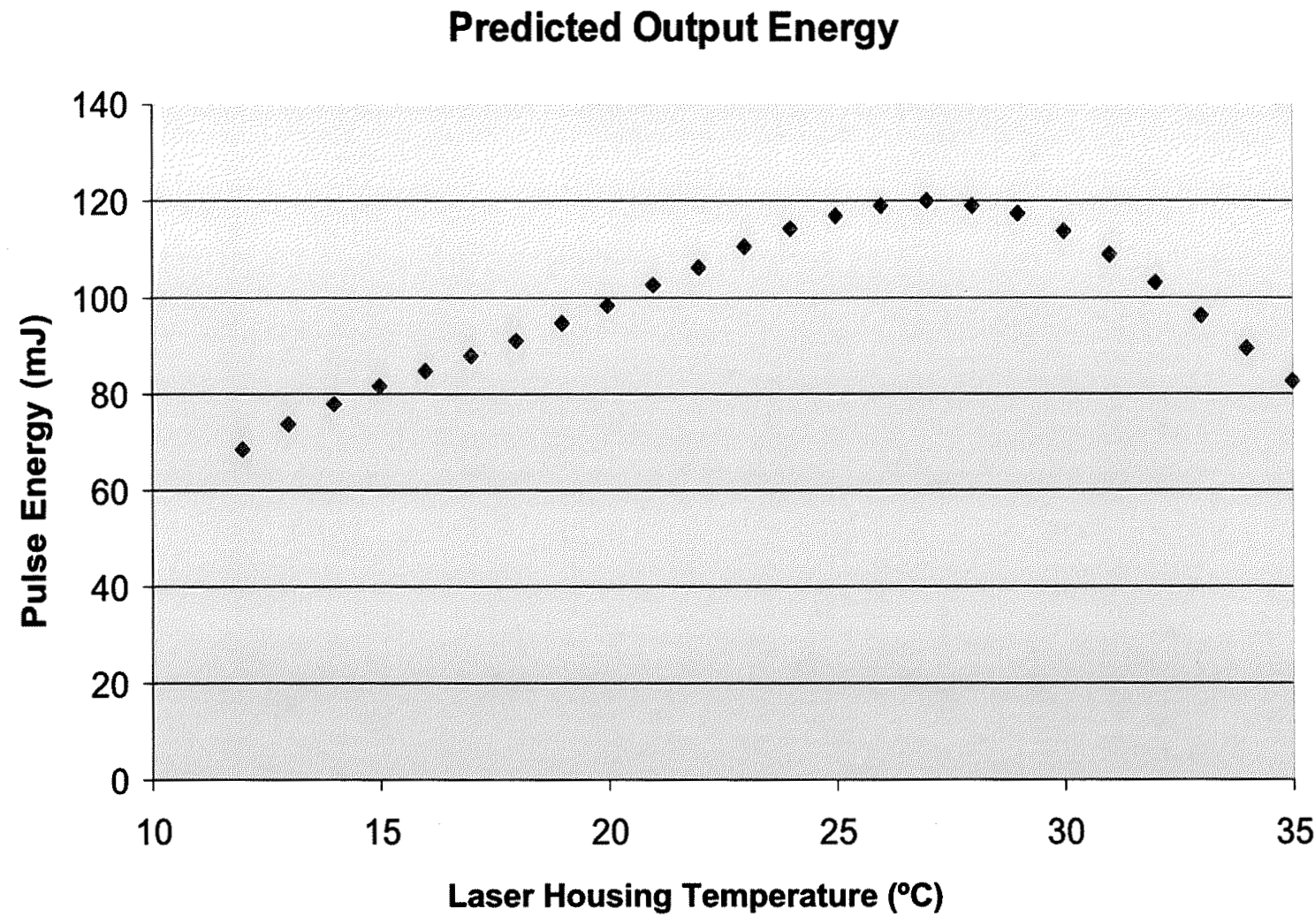

Figure 20. Predicted total laser pulse energy as a function of laser housing temperature. This prediction is based on an ensemble averaged measured wavelength and power from the flight diode arrays. 


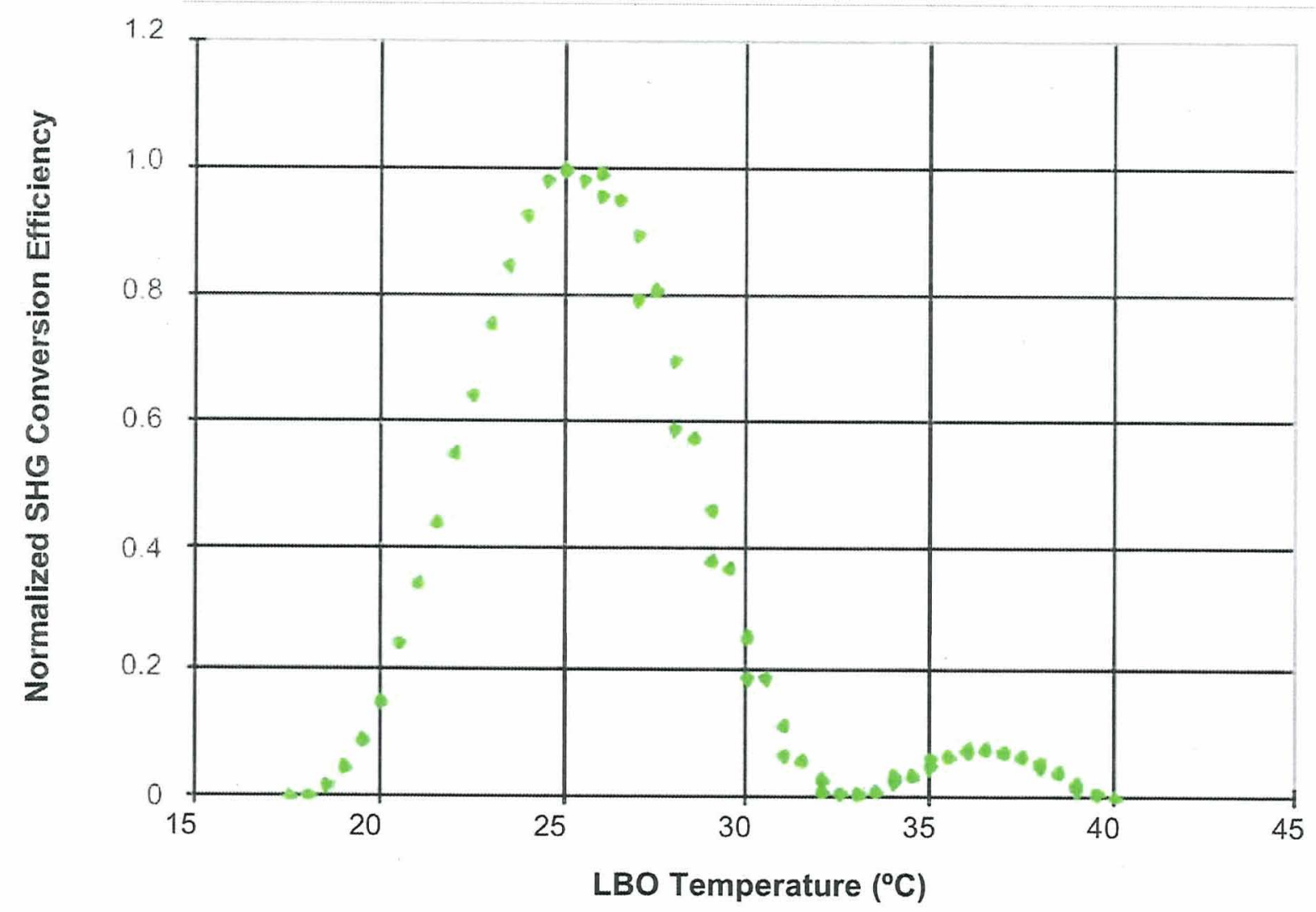

Figure 21. Normalized second harmonic conversion efficiency as a function of crystal temperature. 


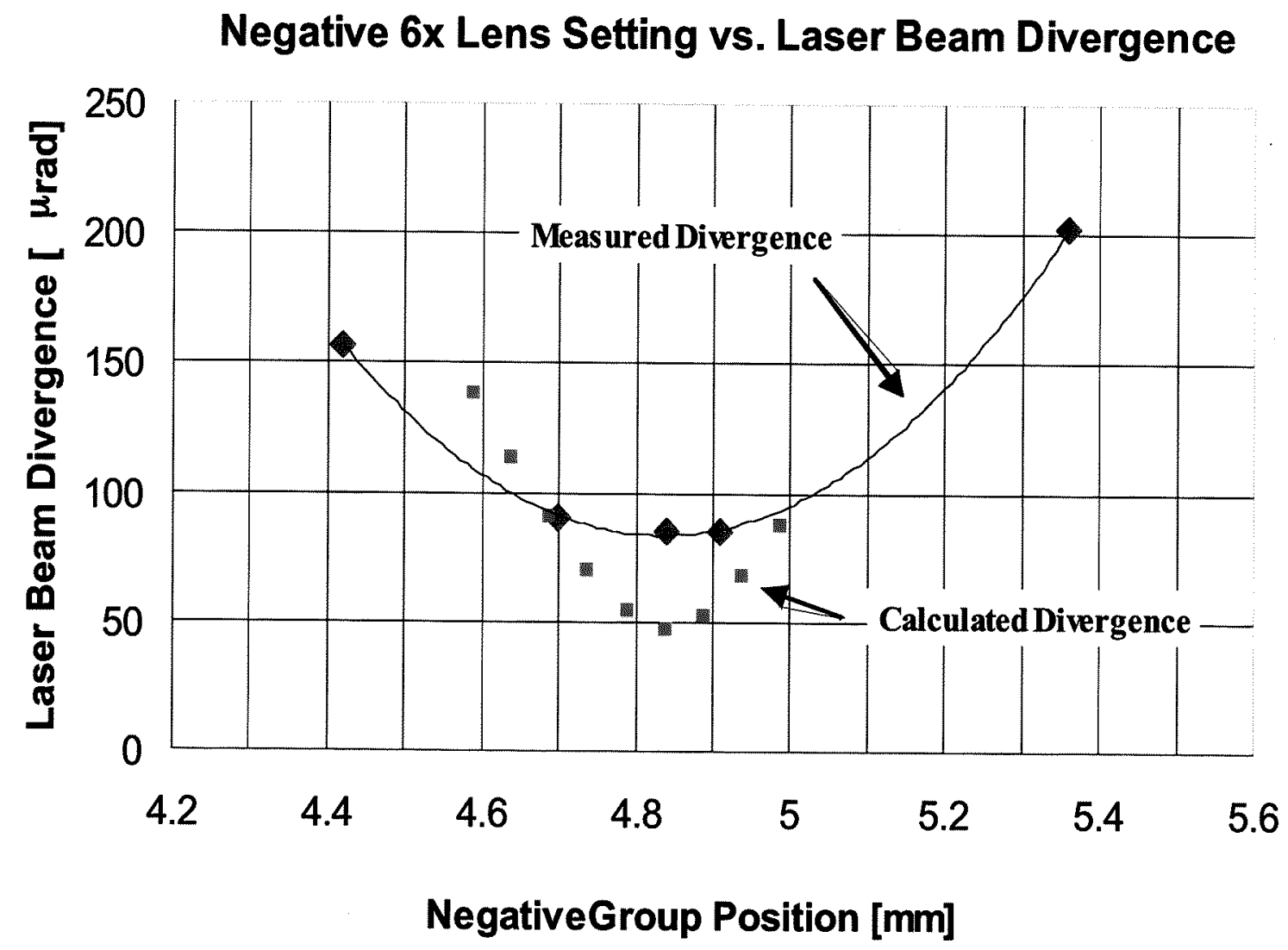

Figure 22. Laser Beam divergence $(1064 \mathrm{~nm})$ as a function of relative position of the negative lens group. Blue diamonds are measured values and red squares are calculated from a diffraction limited Zemax model. 


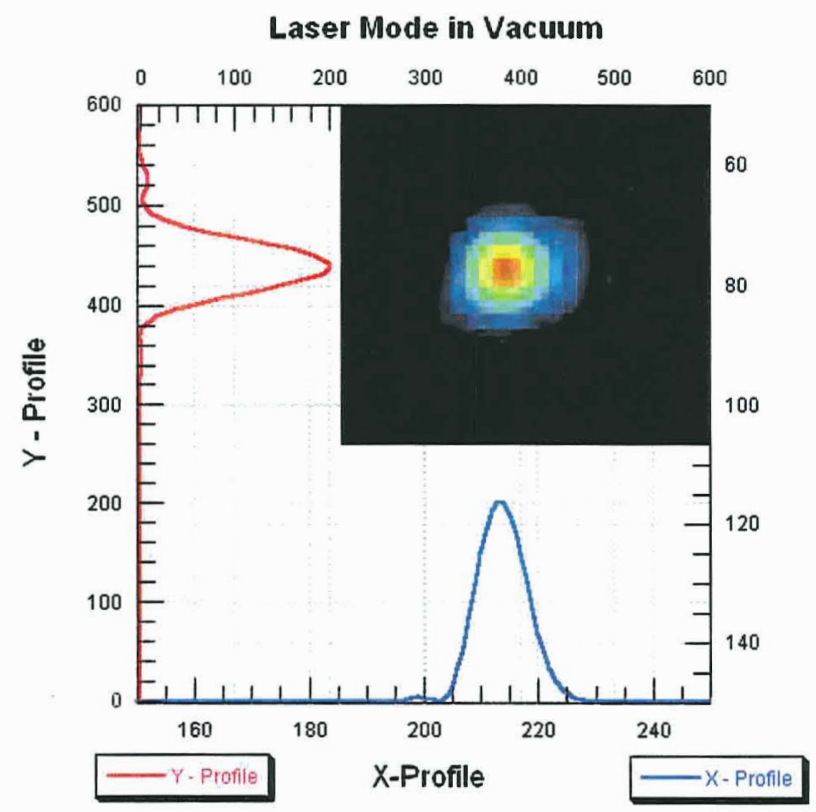

(a)

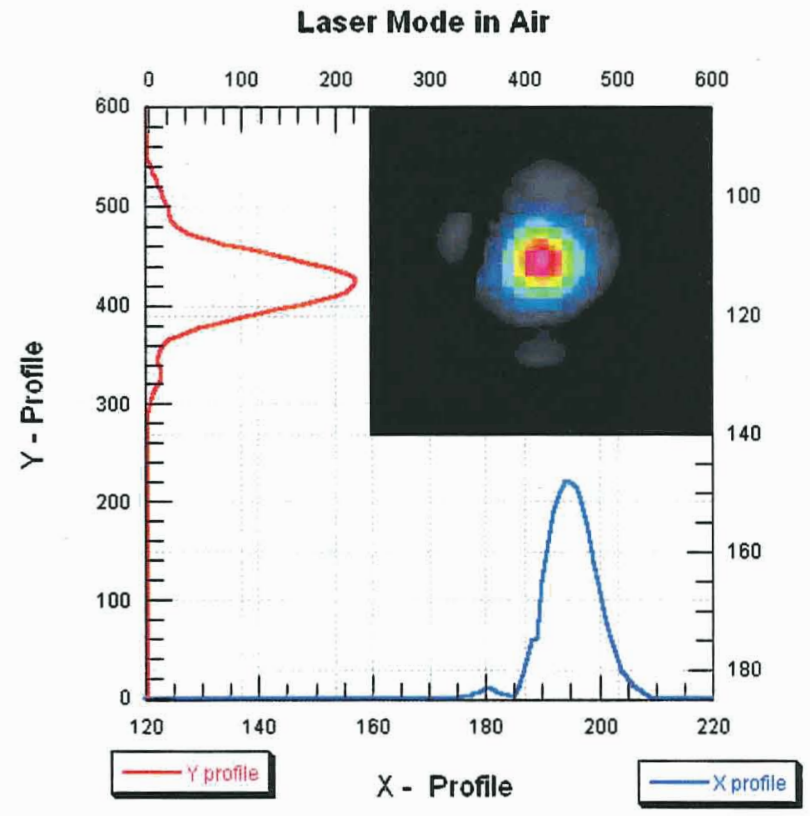

(b)

Figure 23. (a) Far-field laser beam profiles in air with $190 \mu \mathrm{rad}$ defocus. The beam divergence is $94 \mu \mathrm{rad}$; (b) Far-field laser beam profiles in vacuum. The beam divergence is $71 \mu \mathrm{rad}$. 
90

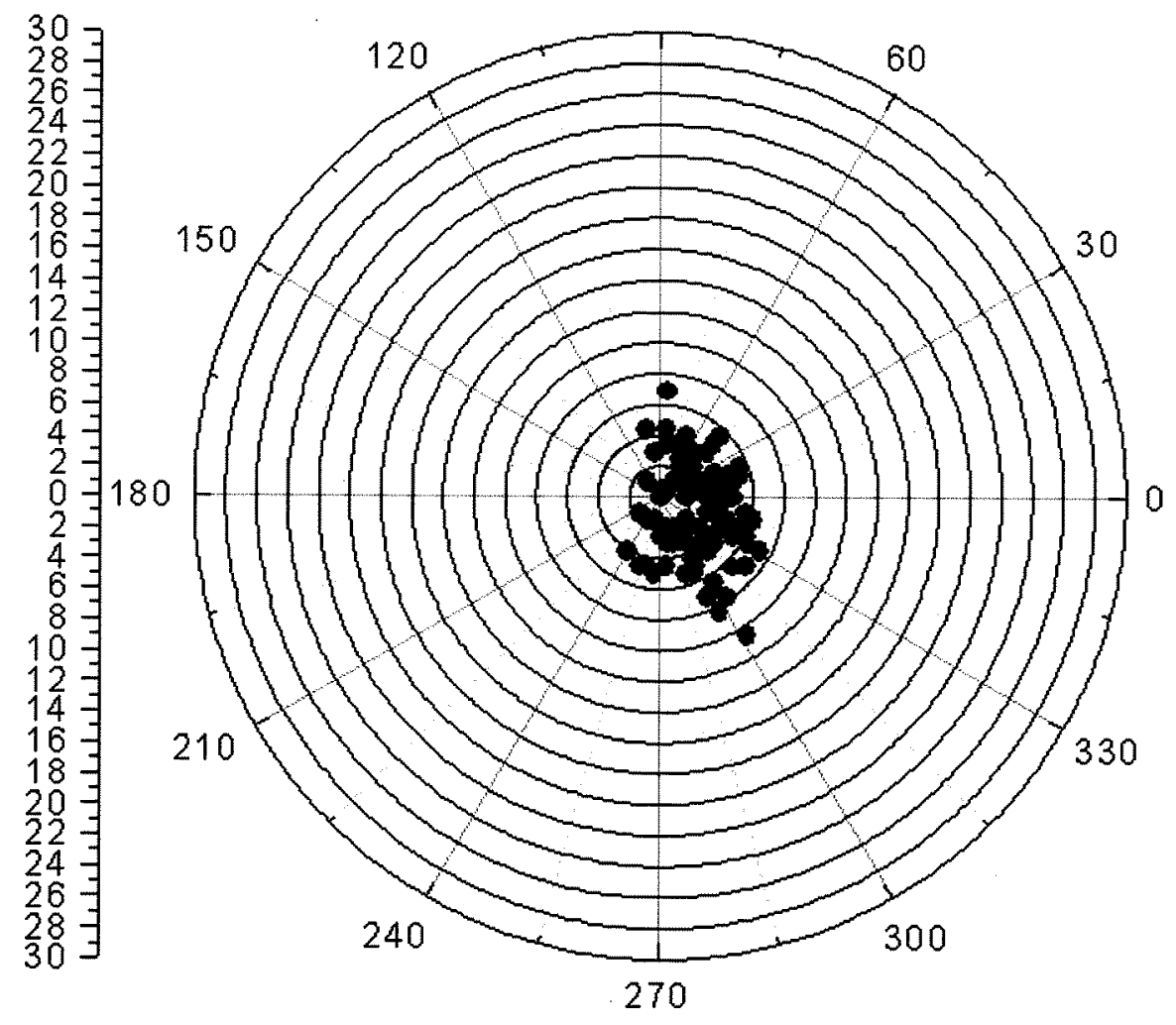

Figure 24. Plot of the laser pointing jitter. The target plot shows 100 individual laser energy centroids plotted on a circular plot with each circle representing a $2 \mathrm{mrad}$ division. The $1 \sigma$ jitter was $2 \mathrm{mrad}$ with a maximum of $10 \mathrm{mrad}$. 


\section{Laser Energy vs. Pump Current}

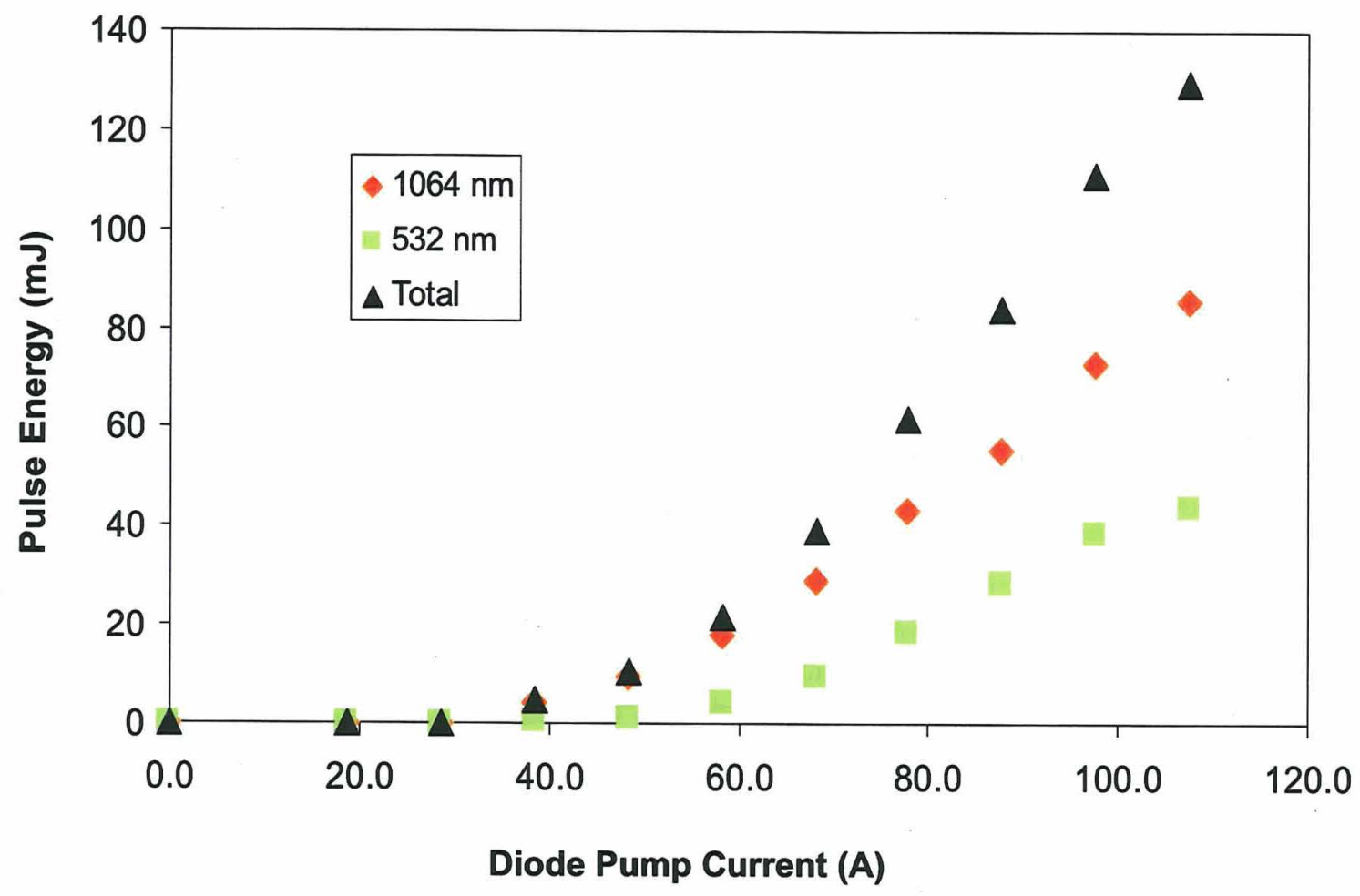

Figure 25. Laser output pulse energy in the final configuration before converting the laser over to its internal electronics. The laser oscillator current is maintained to emit a pulse at $200 \mu \mathrm{sec}$ and the current to the preamplifier and amplifier were adjusted to obtain this curve. 


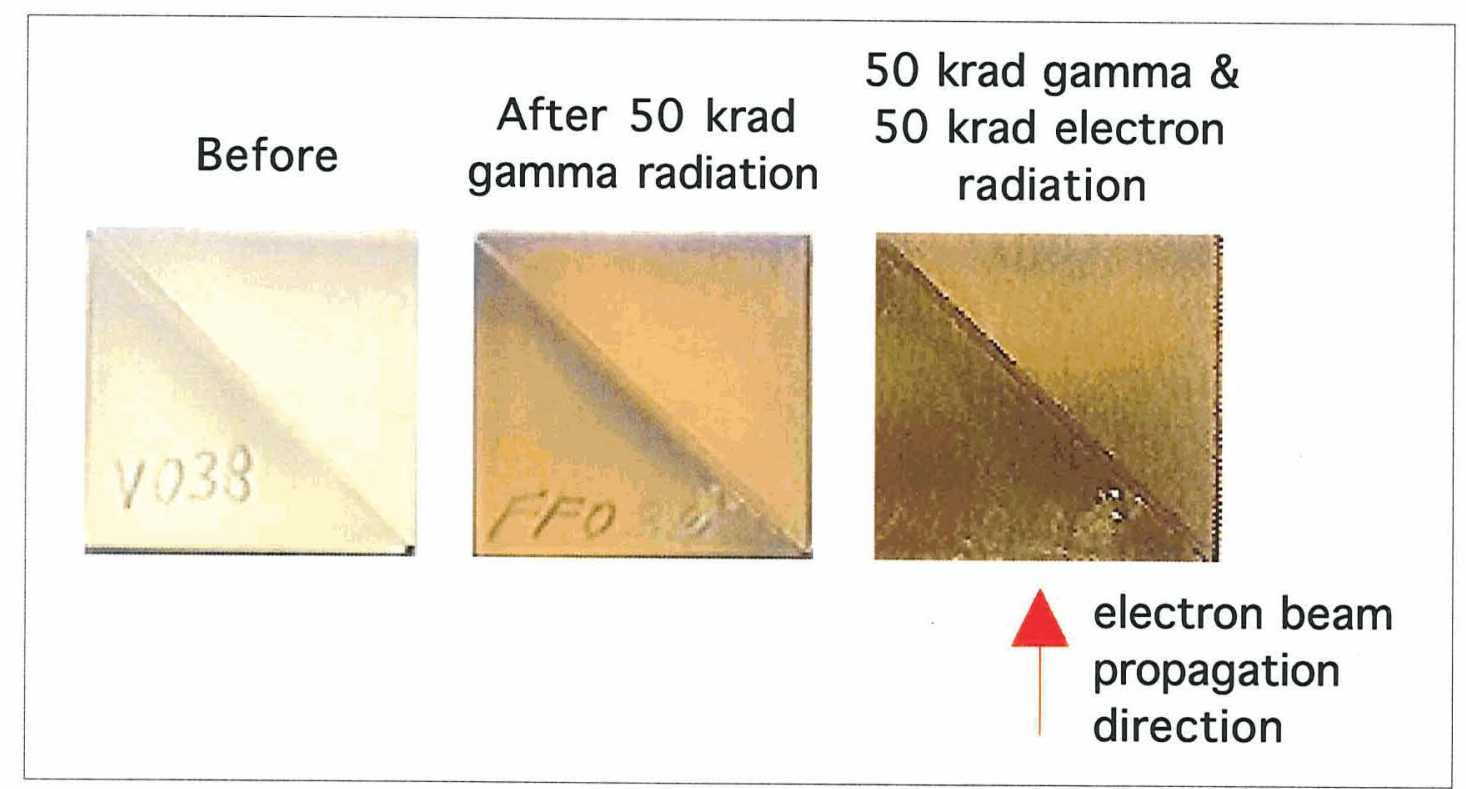

Figure 26. Photographs of the BK7 glass air-spaced polarizers after gamma and electron radiation exposures. 


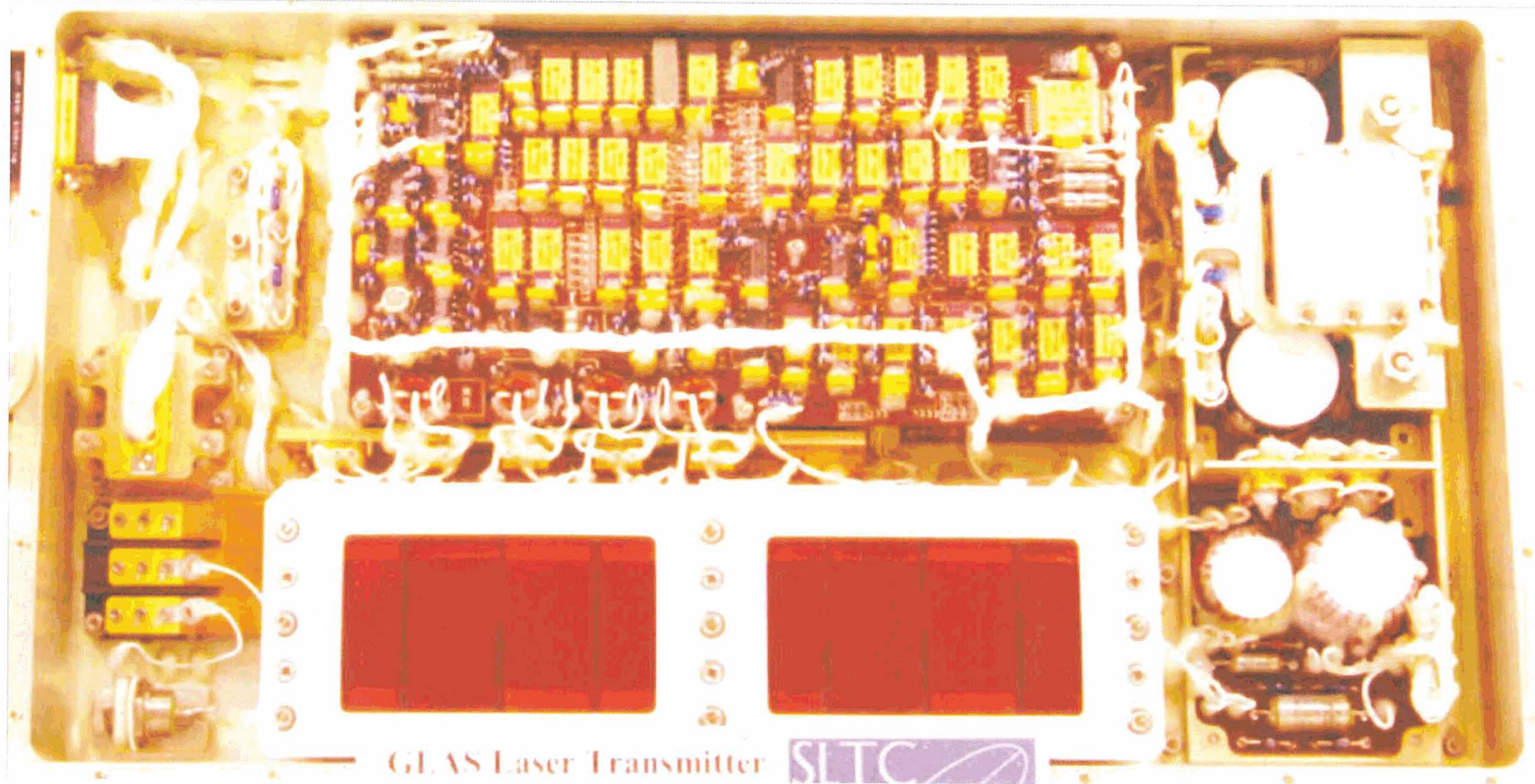

Figure 27. Photograph of the GLAS laser flight electronics. 
BOOST CONVERTER

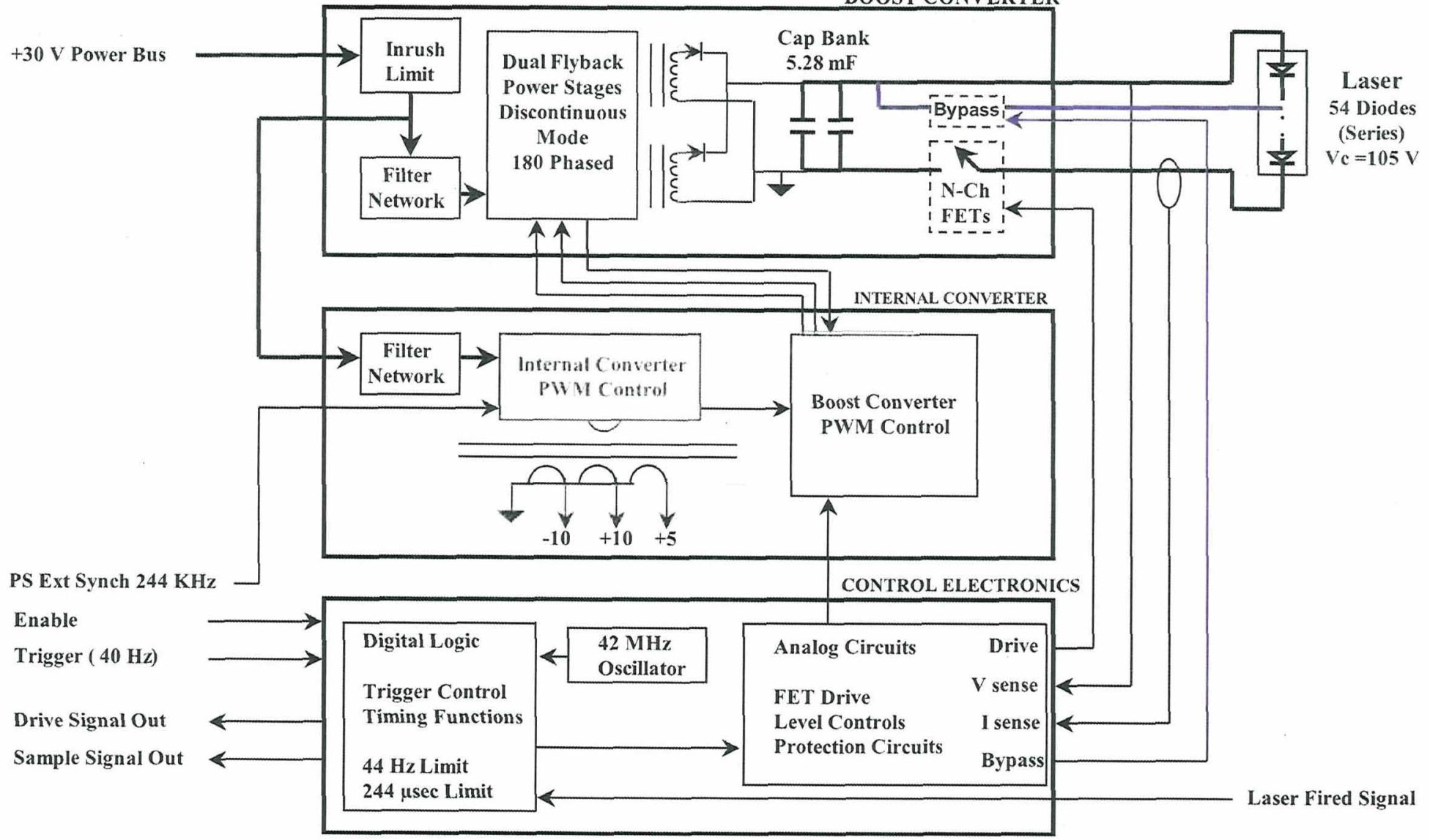

Figure 28. LDPE block diagram. 


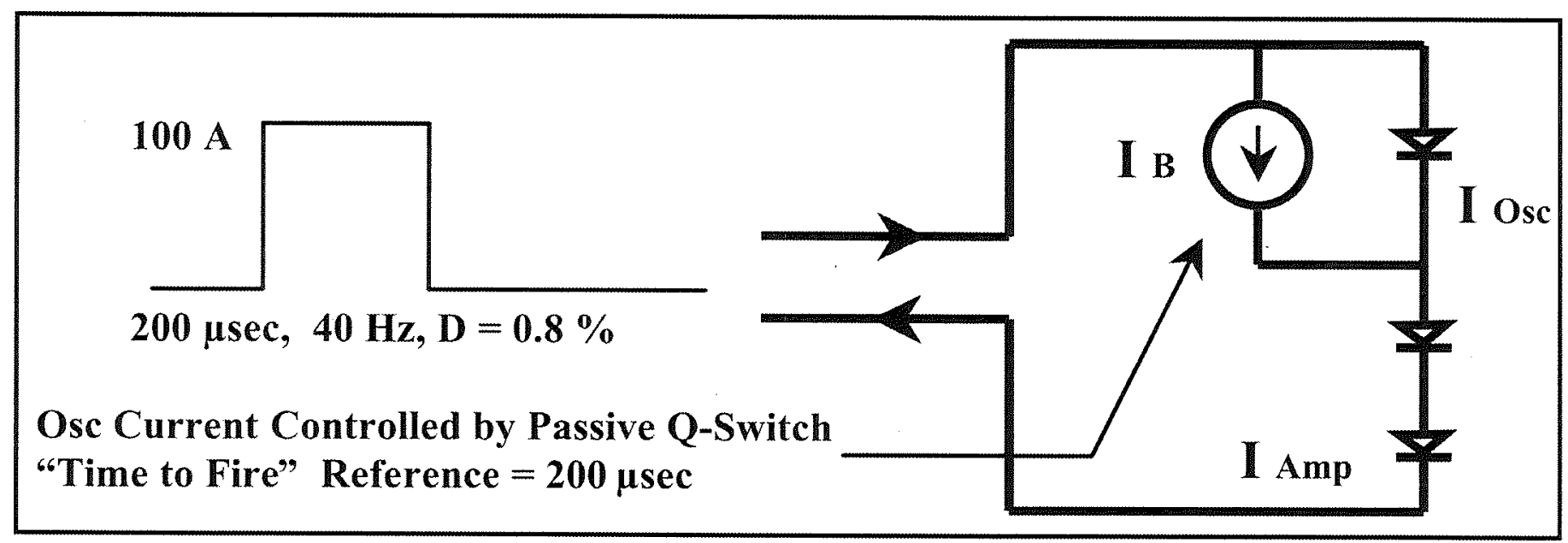

Figure 29. Schematic of current loop of the LDPE. $I_{B}$ is the by-pass current. 


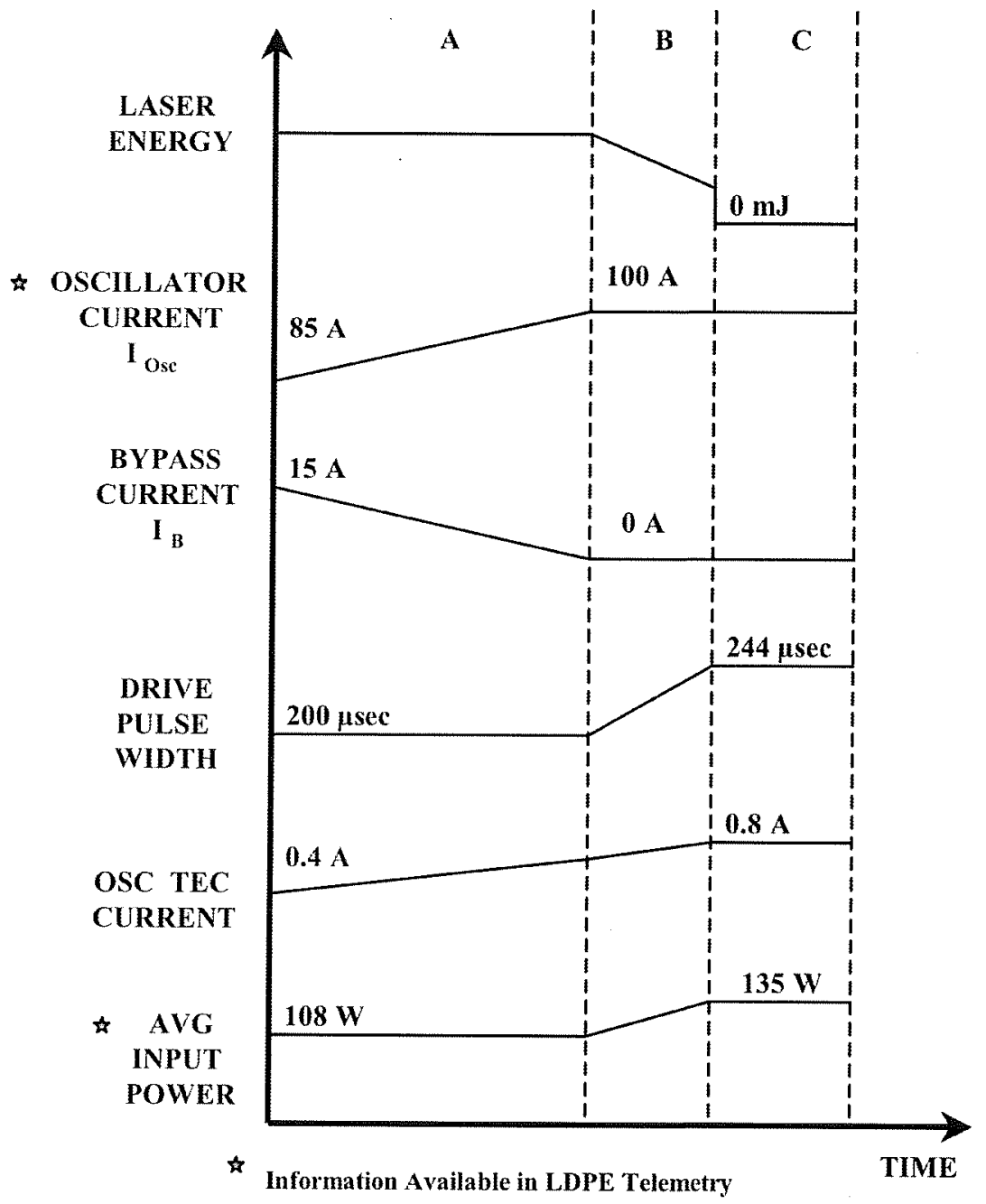

Figure 30. Operational modes across laser lifetime. 


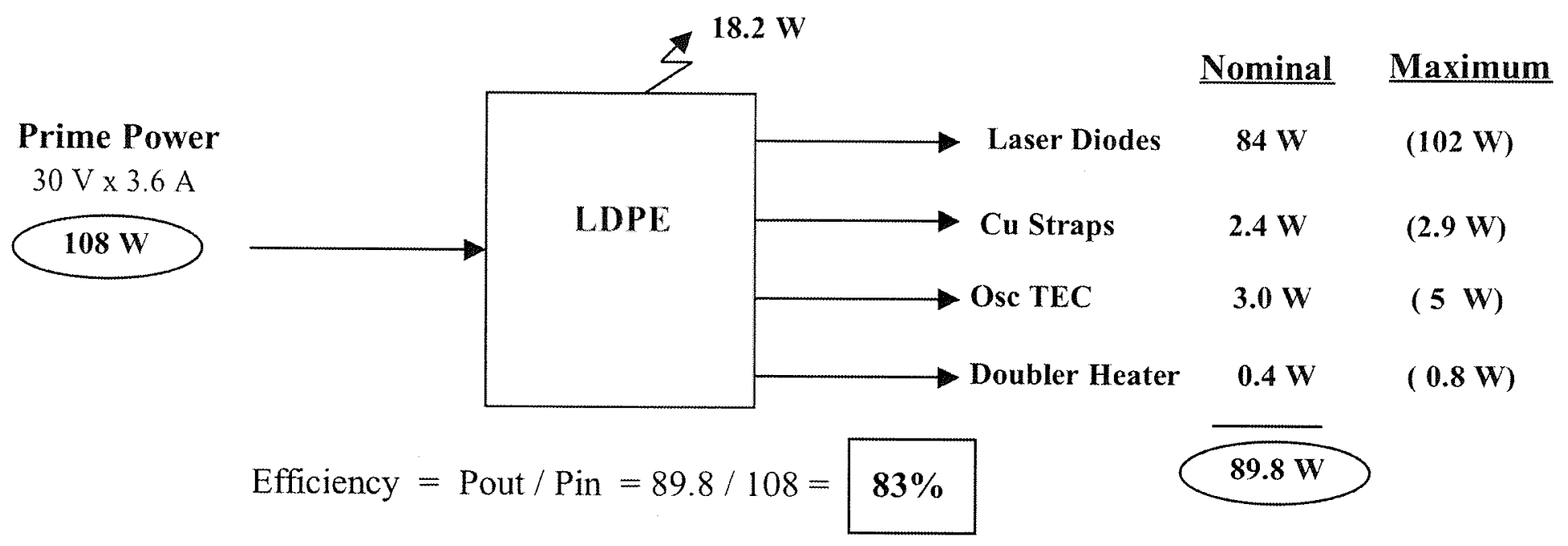

Figure 31. LDPE power budget. 


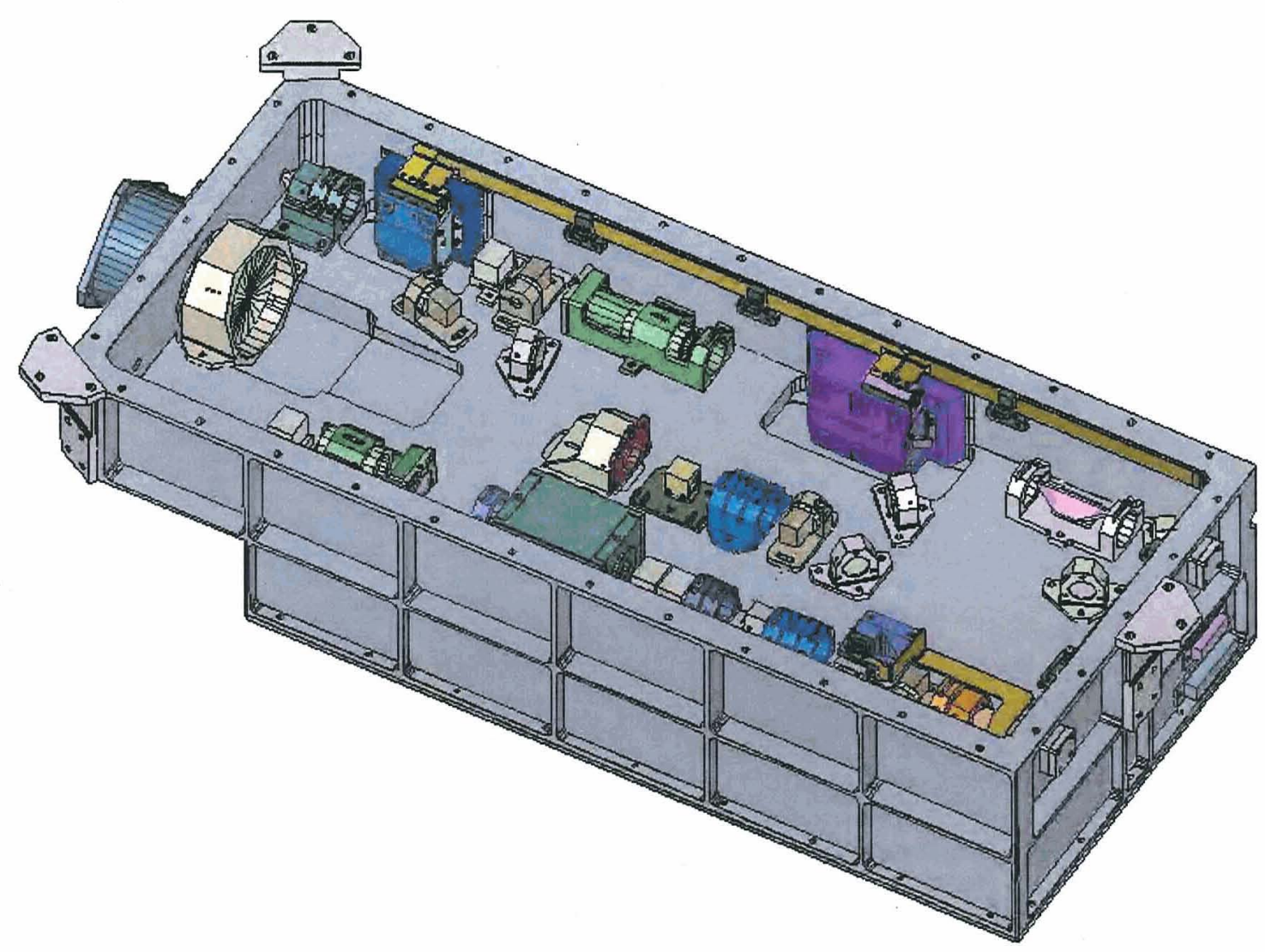

Figure 32. Solid model of the laser housing with optical cavity lid removed. Visible are the locations of the optical mounts, mounting flexures and signal and power feed throughs. 


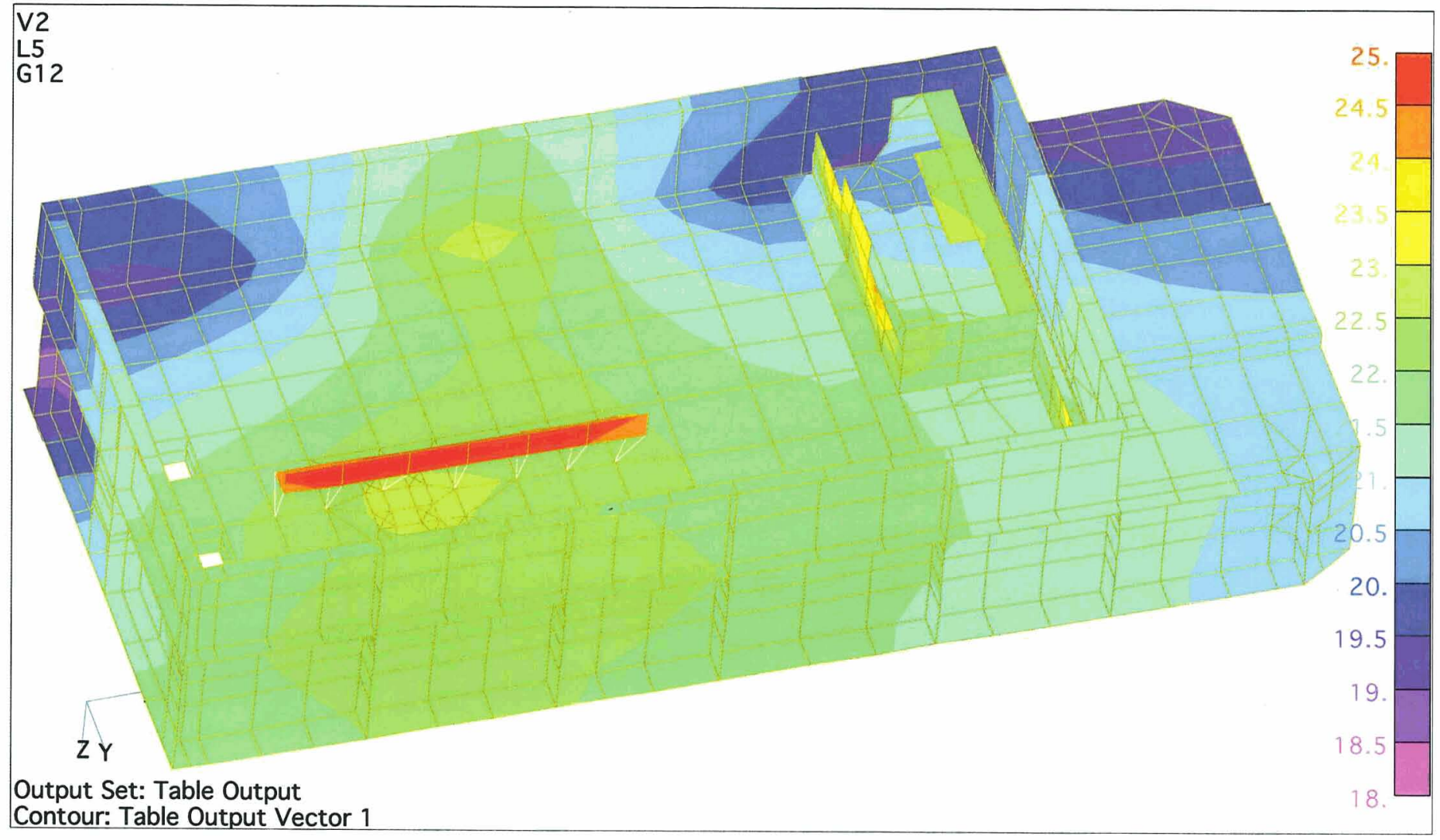

Figure 33. Temperature predictions for the laser housing electronics cavity. The highest temperatures are FET heat sink. The heat pipe coolant was maintained at $18^{\circ} \mathrm{C}$. 


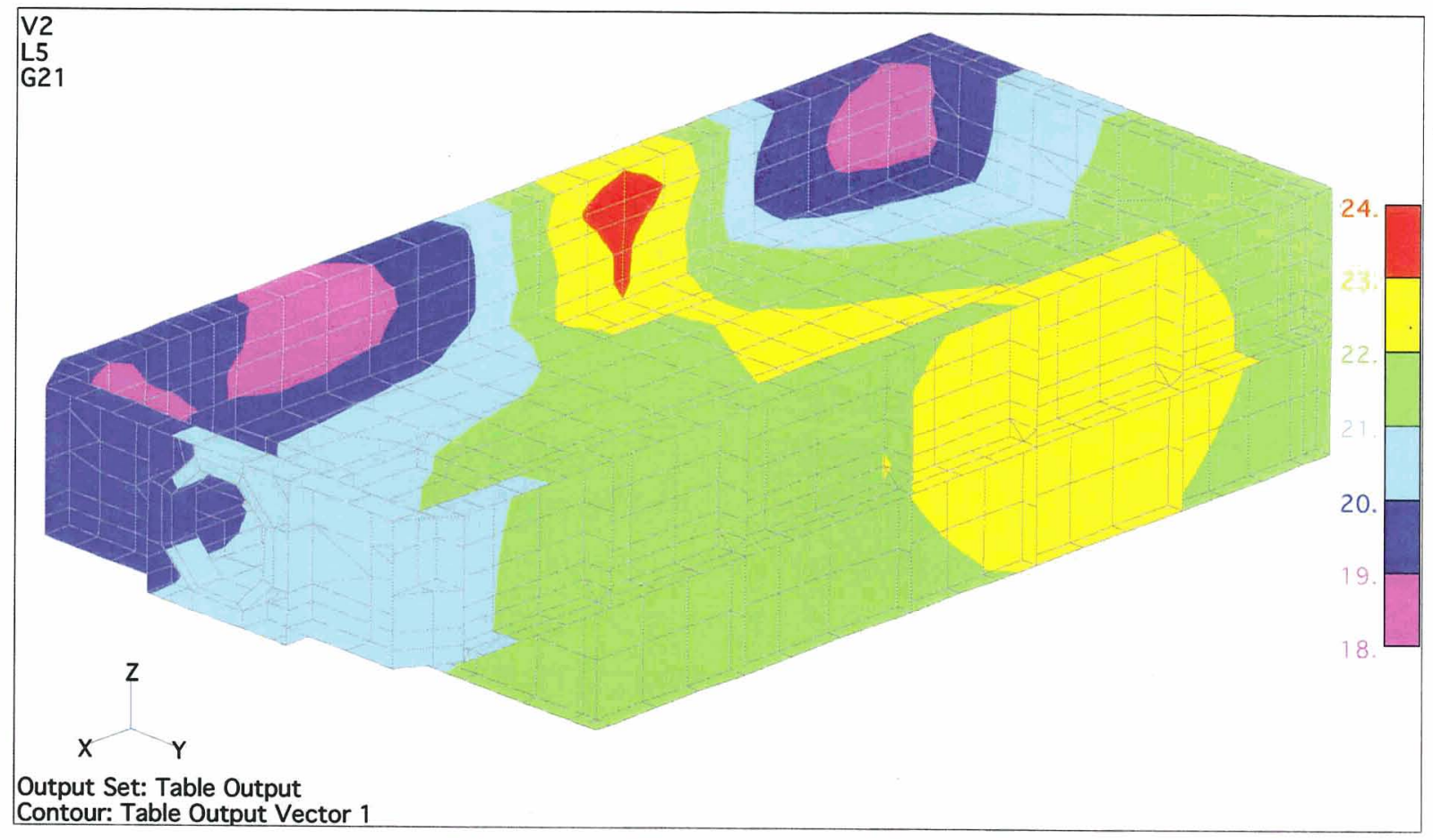

Figure 34. Temperature predictions for the laser housing optics cavity. The highest temperatures are underneath the amplifier.

There is only a $1^{\circ} \mathrm{C}$ temperature gradient across the oscillator which is the most alignment sensitive. The heat pipe coolant was maintained at $18^{\circ} \mathrm{C}$. 


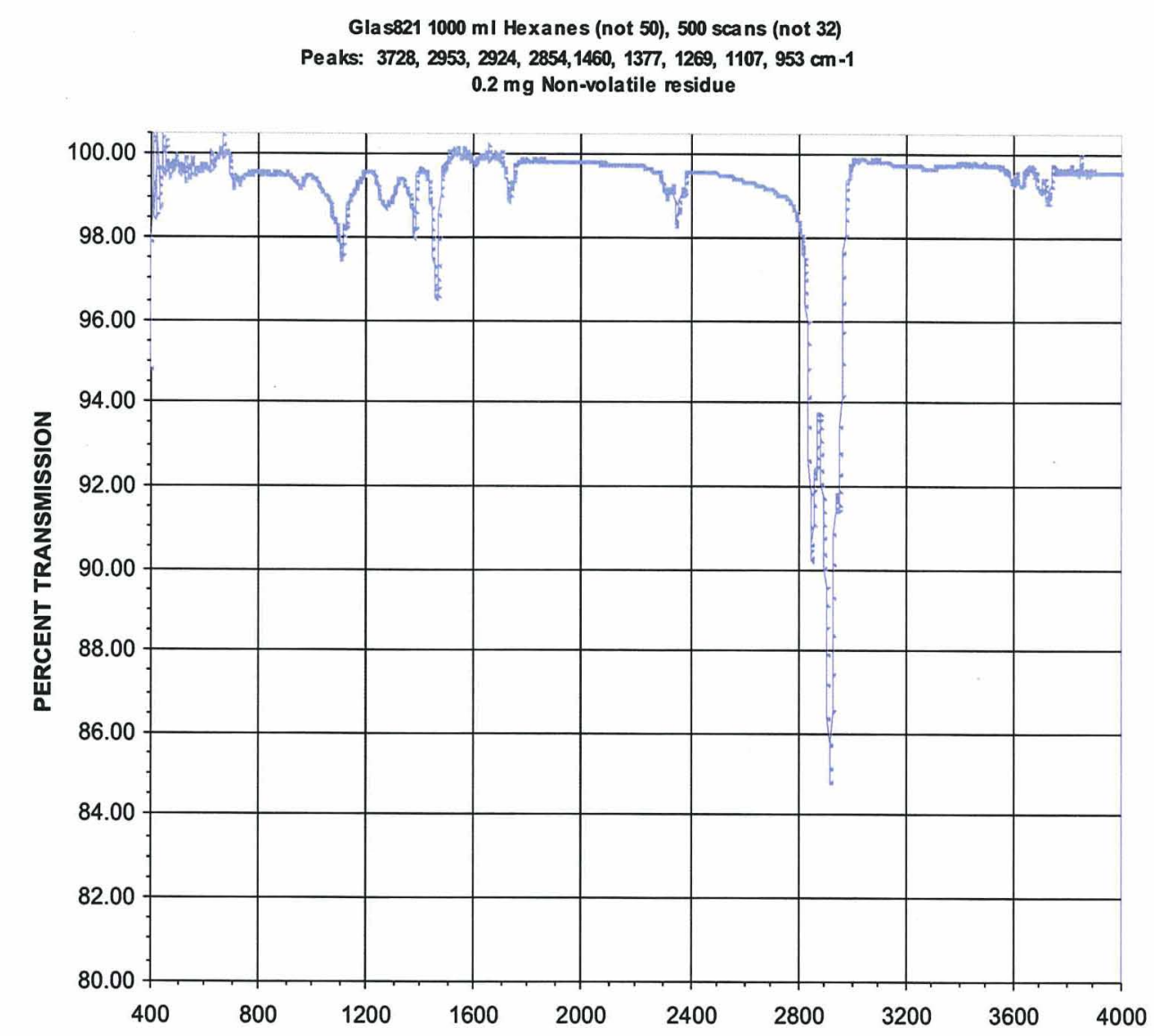

Figure 35. NVR FTIR spectrum from evaporated hexanes. 
Silicone Absorption Spectra

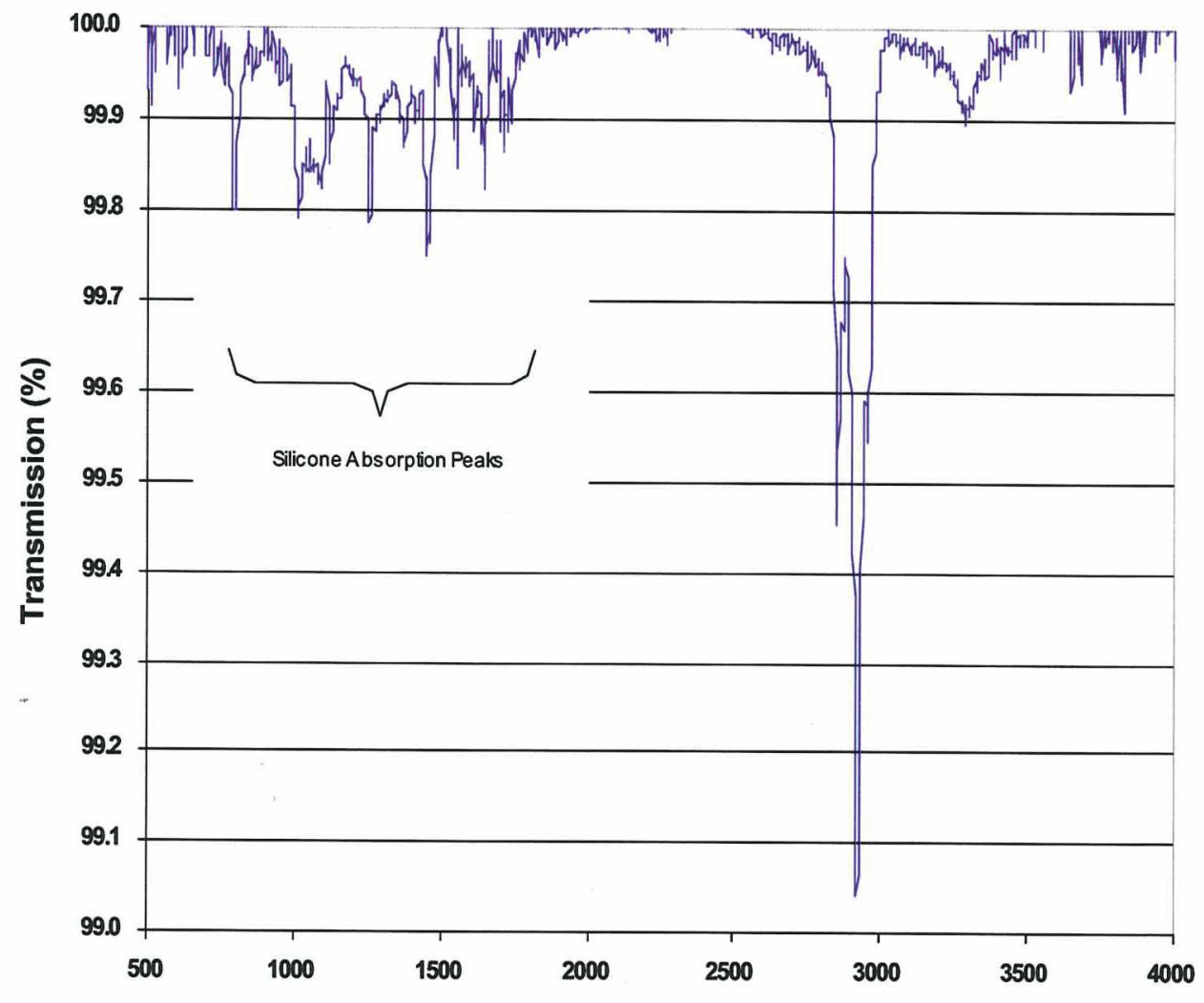

Figure 36. NVR FTIR spectrum from a sample rinse showing silicone absorption peaks. 

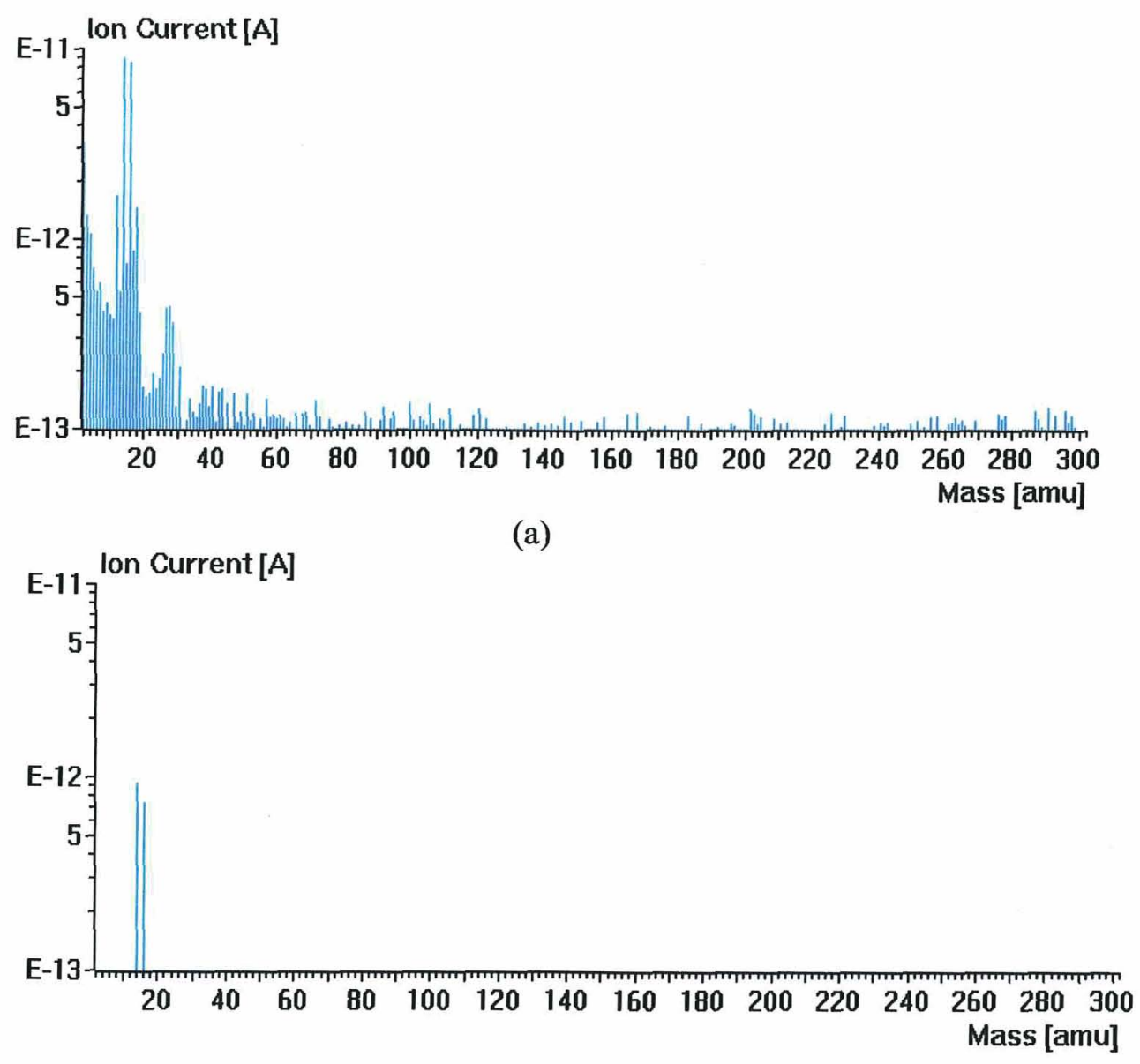

(b)

Figure 37. Example of mass spectra of Laser 3 at the beginning (a) and end (b) of the whole laser assembly final bake-out. This was the second bake-out of Laser 3 after a rework from a failed diode array in the power amplifier. By the end of bake-out only water is detected 


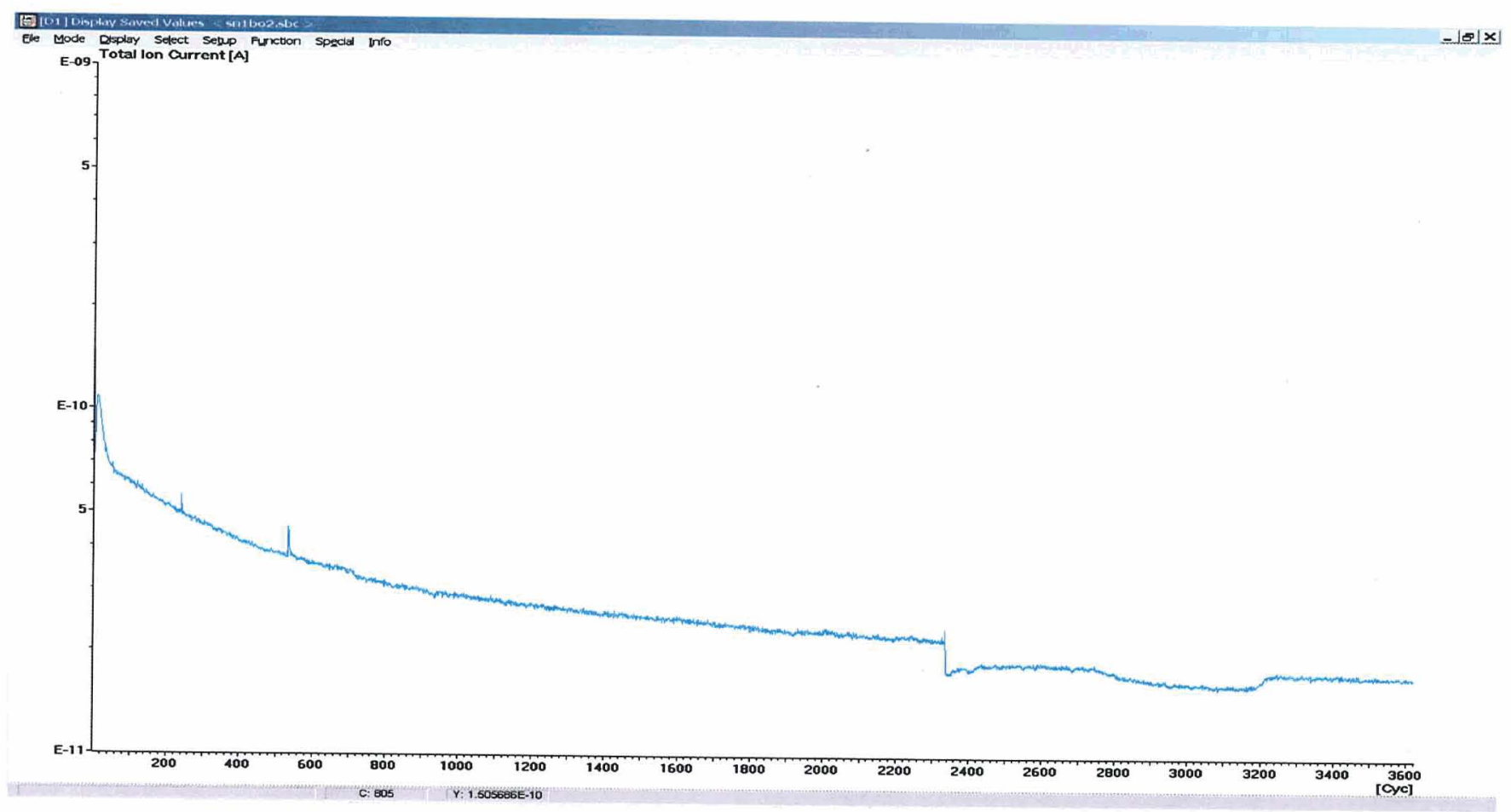

Figure 38. Example of total ion current from the mass spectrometer showing the leveling off of the ion current by the end of the bake-out. The Mass Spectrometer is a Balzer Quadrupole Mass Analyzer with Faraday Cup and Channeltron Multiplier; model QMS 200 M3, bakeable to $300 \mathrm{C}$; Mass Range 1 - $300 \mathrm{amu}$, with a high sensitivity ion source and dual Thoriated Iridium filaments. The above trace was recorded at the mass specs. highest resolution while on a log scale. 
- $\quad$ SUB-ASSEMBLY BUILD

\section{MILESTONES}

\section{LASER TRANSMITTER 1}

DURATION

6 WEEKS

- LASER ASSEMBLy

- VIBRATION TESTING

- $\quad$ BAKE-OUT LASER ASSEM.

- tVAC

- SHIP/DOCUMENT

TOTAL

\section{WEEKS}

\section{PROCESSSES}

PARTS VERIFICATION

OPTICS BONDING

AMPLIFIER HEAD INTEGRATION \&TEST (I\&T)

LASER HARNESSES (OSC, DOUBLER)

LT HOUSING PREASURE TEST

ELECTRONICS/HOUSING I\&T

ELECTRONICS BAKE-OUT

OPTICS BAKE-OUT

1 WEEK BUILD, TCP, STAKE ALL SCREWS WITH LOW-OUTGASSING EPOXY

1 WEEK TCP, VIBRATION TEST, TCP

1 WEEK BAKE-OUT, VERIFICATION, TCP

3 WEEKS $\quad 4$ OP CYCLES,

NON-OP, COLD START IN VACUUM,

OPINON-OP CYCLE PRESSURIZED

1 WEEK FINAL STAKING, HP REMOVAL DATA REDUCTION

- LASER 2, 3 DELIVERED AT 4-6 WEEK INTERVALS DUE TO VAC. CHAMBER AVAILABLITY

Figure 39. Duration of each of the assembly and testing milestones for the GLAS flight lasers. 

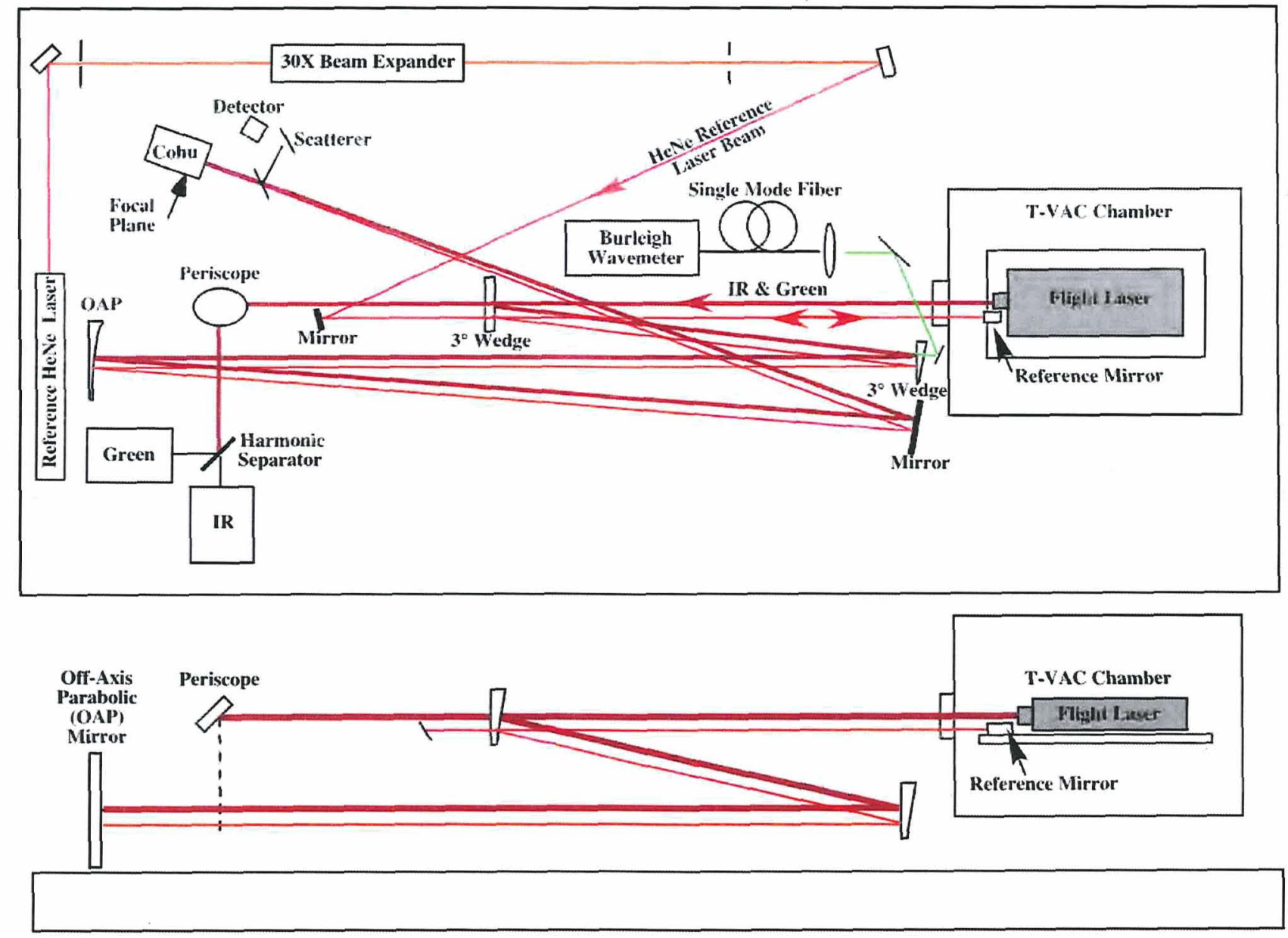

Figure 40. Layout of the BTE during TVAC tests. 


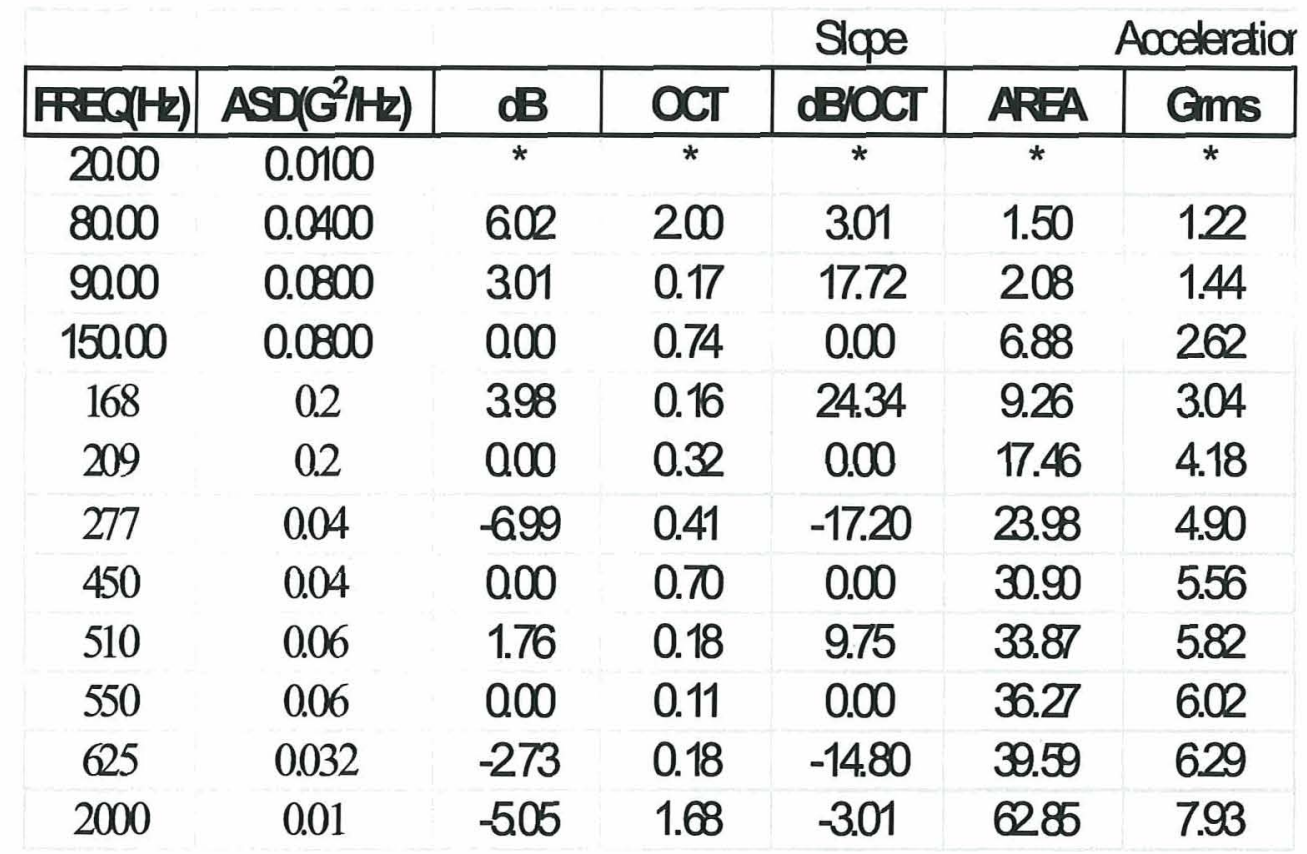

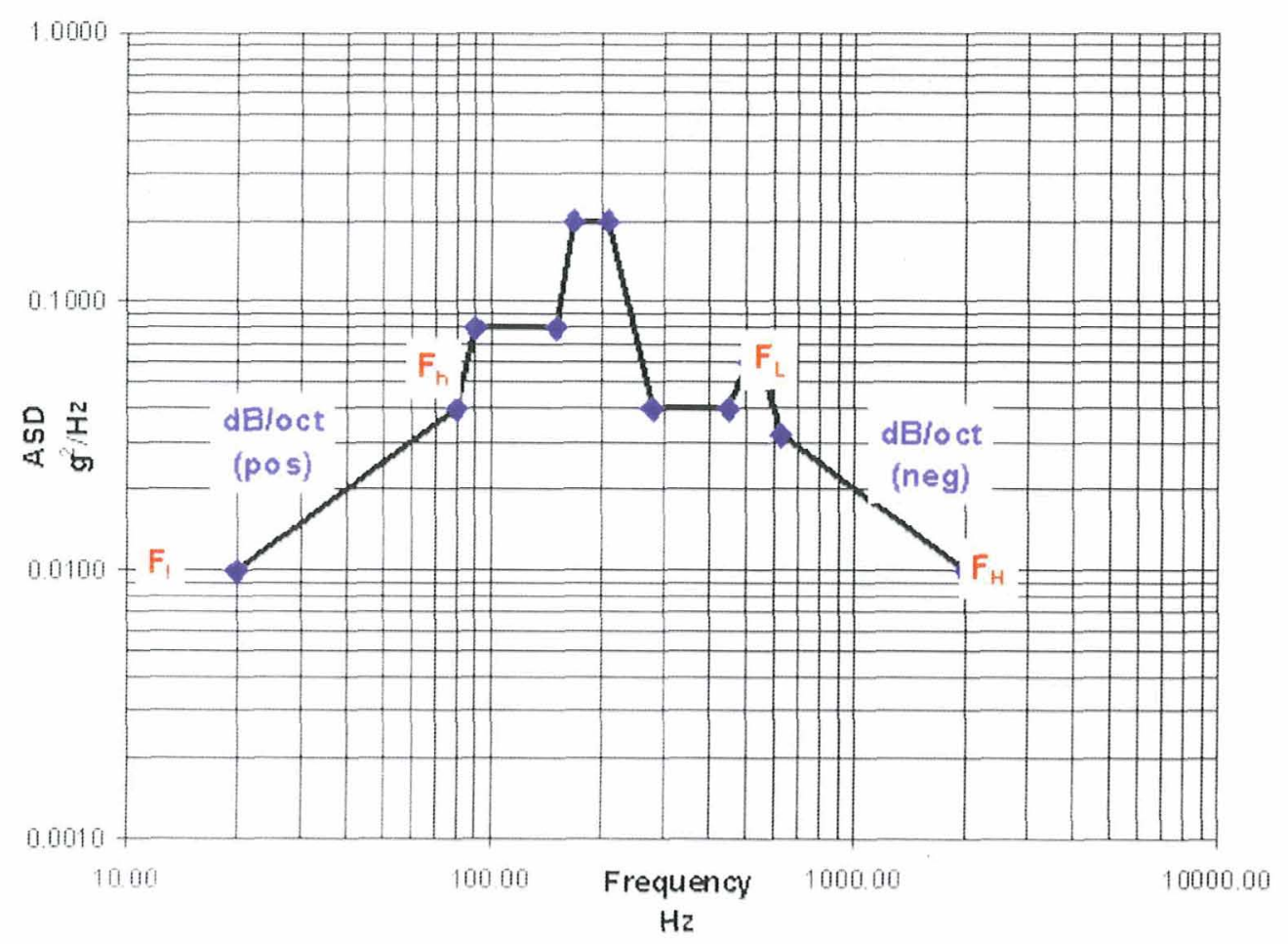

Figure 41. ASD of Random Full Input Level along the X-Axis, Thrust 


\begin{tabular}{|c|c|c|c|c|c|c|}
\hline \multicolumn{2}{|c}{} & \multicolumn{3}{c}{ Slope } & \multicolumn{2}{r|}{ Acceleratior } \\
\hline FREQ(Hz) & ASD $\left(\mathbf{G}^{\mathbf{2}} / \mathbf{H z}\right)$ & $\mathbf{d B}$ & OCT & dB/OCT & AREA & Gms \\
\hline 20.00 & 0.0100 & $*$ & $*$ & $*$ & ${ }^{*}$ & $*$ \\
\hline 40.00 & 0.0400 & 6.02 & 1.00 & 6.02 & 0.47 & 0.68 \\
\hline 500 & 0.04 & 0.00 & 3.64 & 0.00 & 18.87 & 4.34 \\
\hline 2000 & 0.01 & -6.02 & 2.00 & -3.01 & 46.59 & 6.83 \\
\hline
\end{tabular}

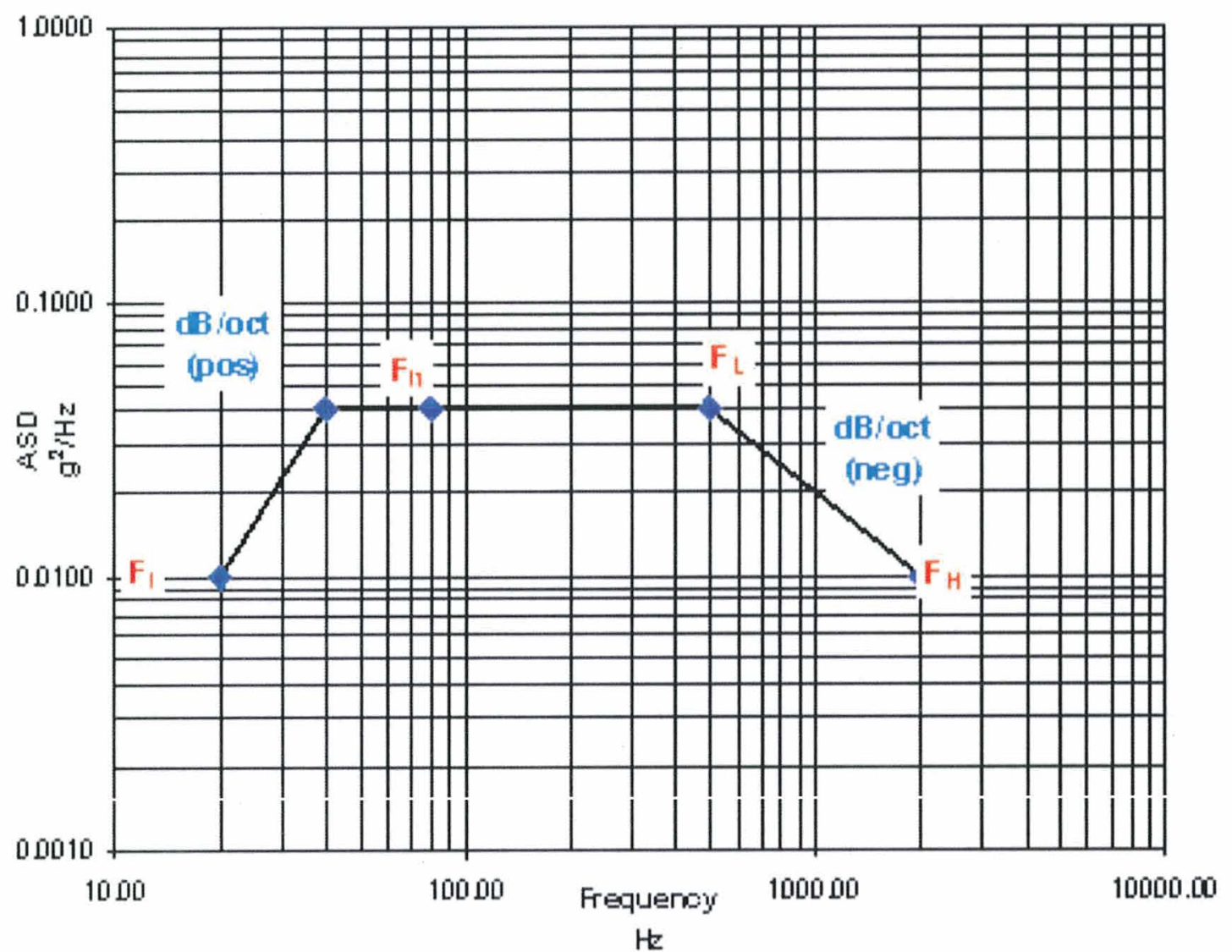

Figure 42. ASD of Random Full Input Level along the Y-Axis (Lateral) 


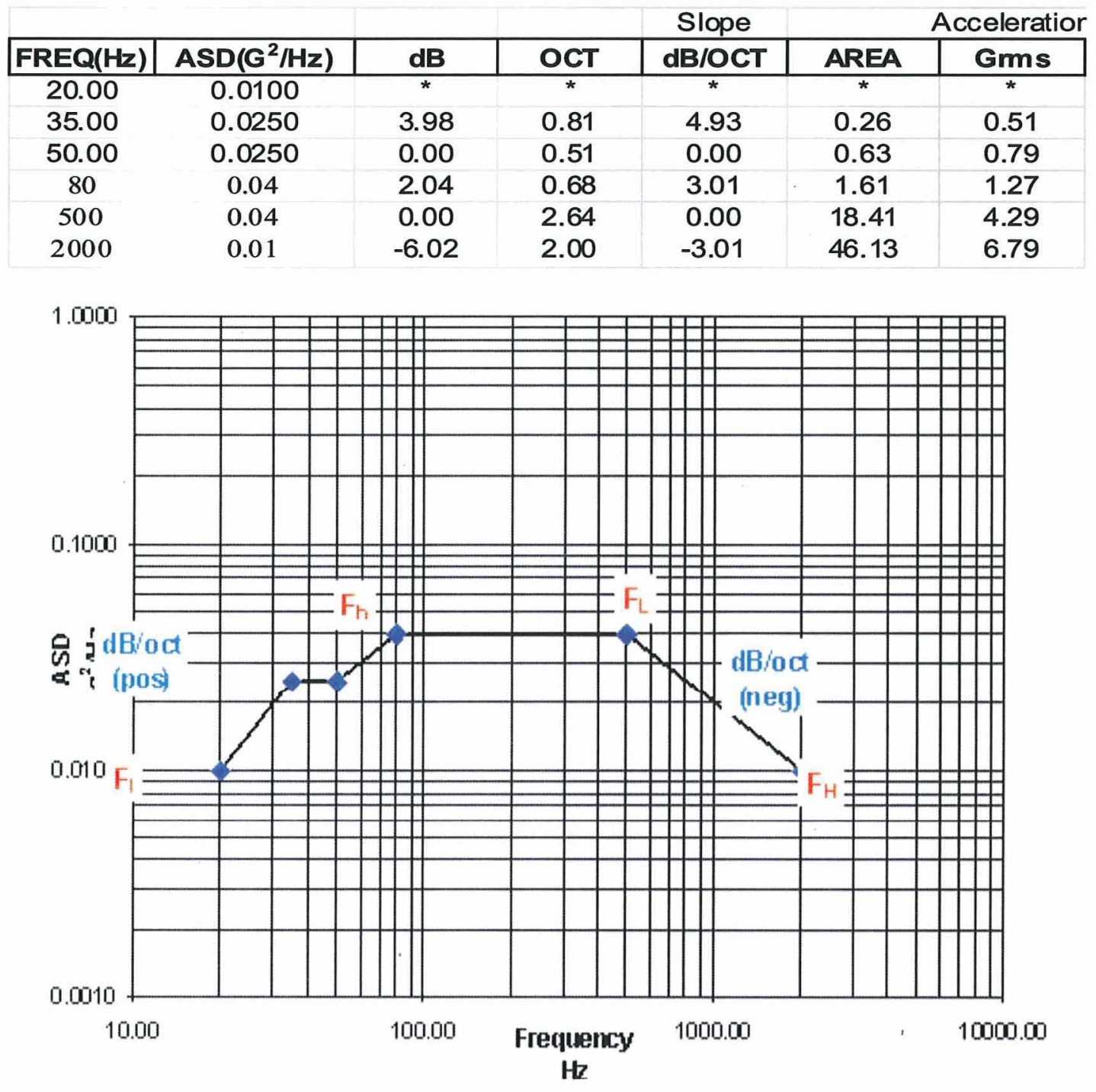

Figure 43. ASD of Random Full Input Level along the Z-Axis Longitudinal. 


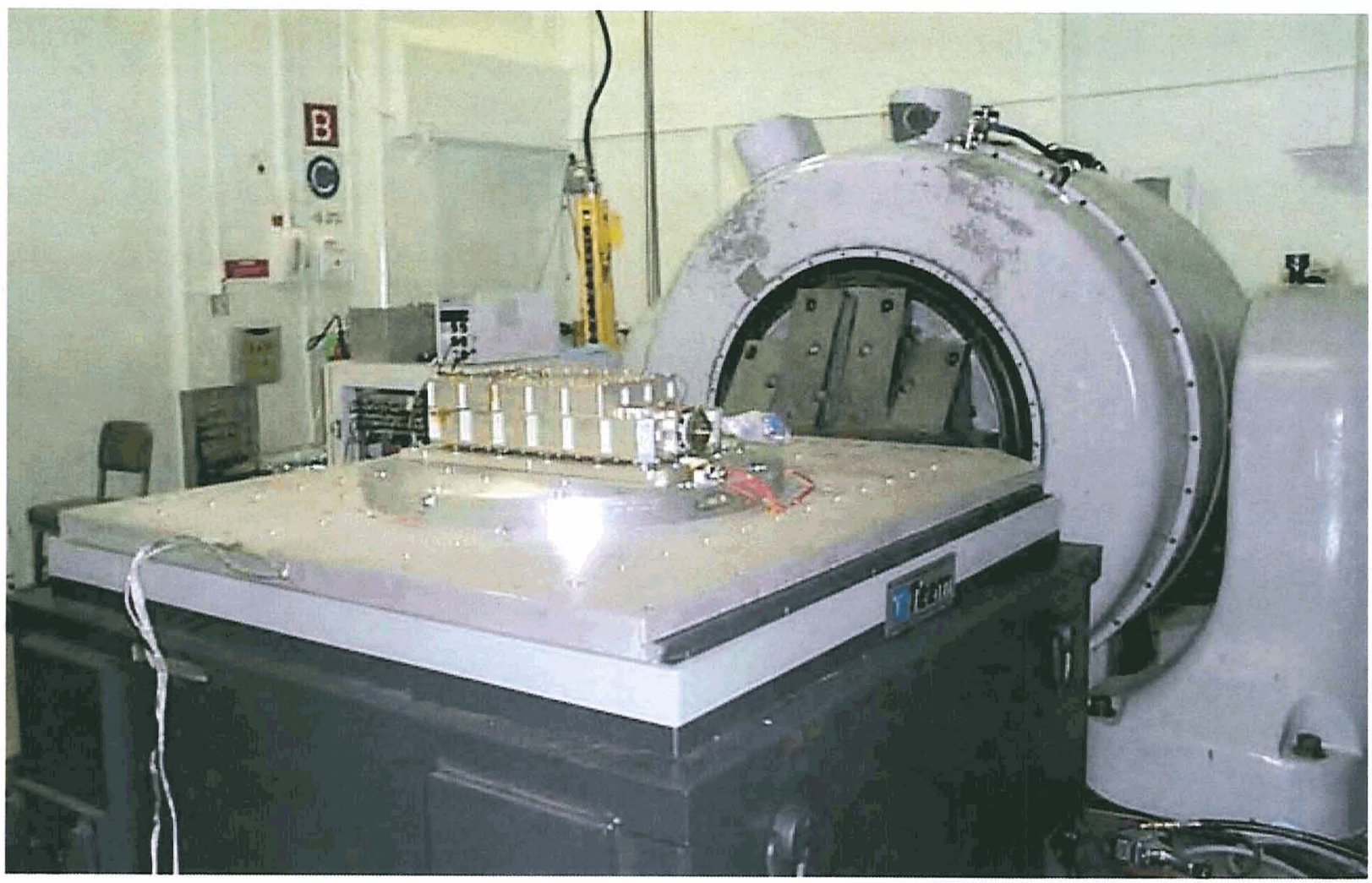

Figure 44. Vibration test of GLAS flight laser at the GSFC test facility. 


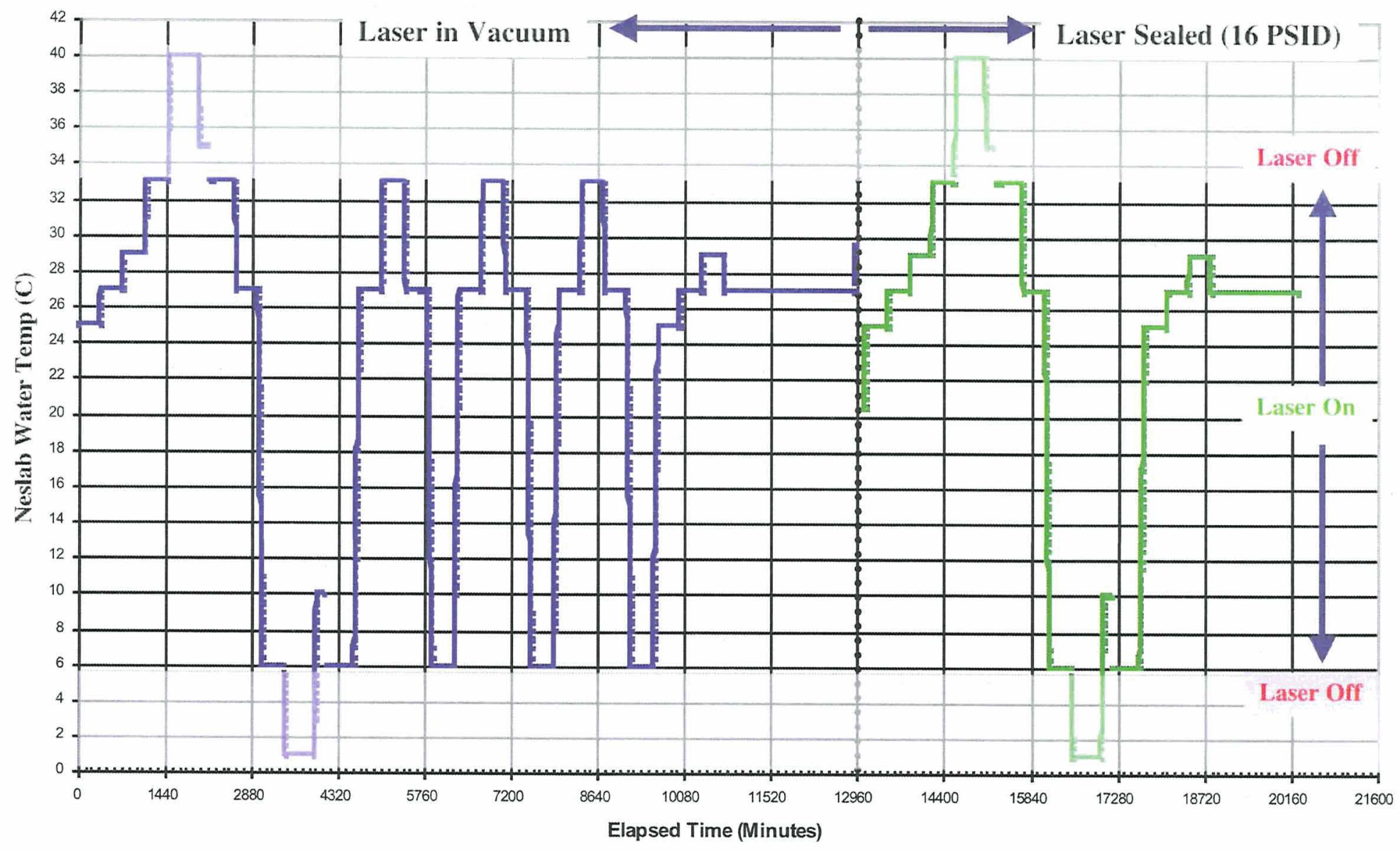

Figure 45. TVAC temperature profile of the GLAS laser environmental test. Two tests were performed in series. First the laser cavity was evacuated and operated in vacuum followed by a pressurized test. In both conditions, the laser was on between the temperature of $6^{\circ} \mathrm{C}$ and $33^{\circ} \mathrm{C}$ and turned off when temperature $>33^{\circ} \mathrm{C}$ and $<6^{\circ} \mathrm{C}$. 


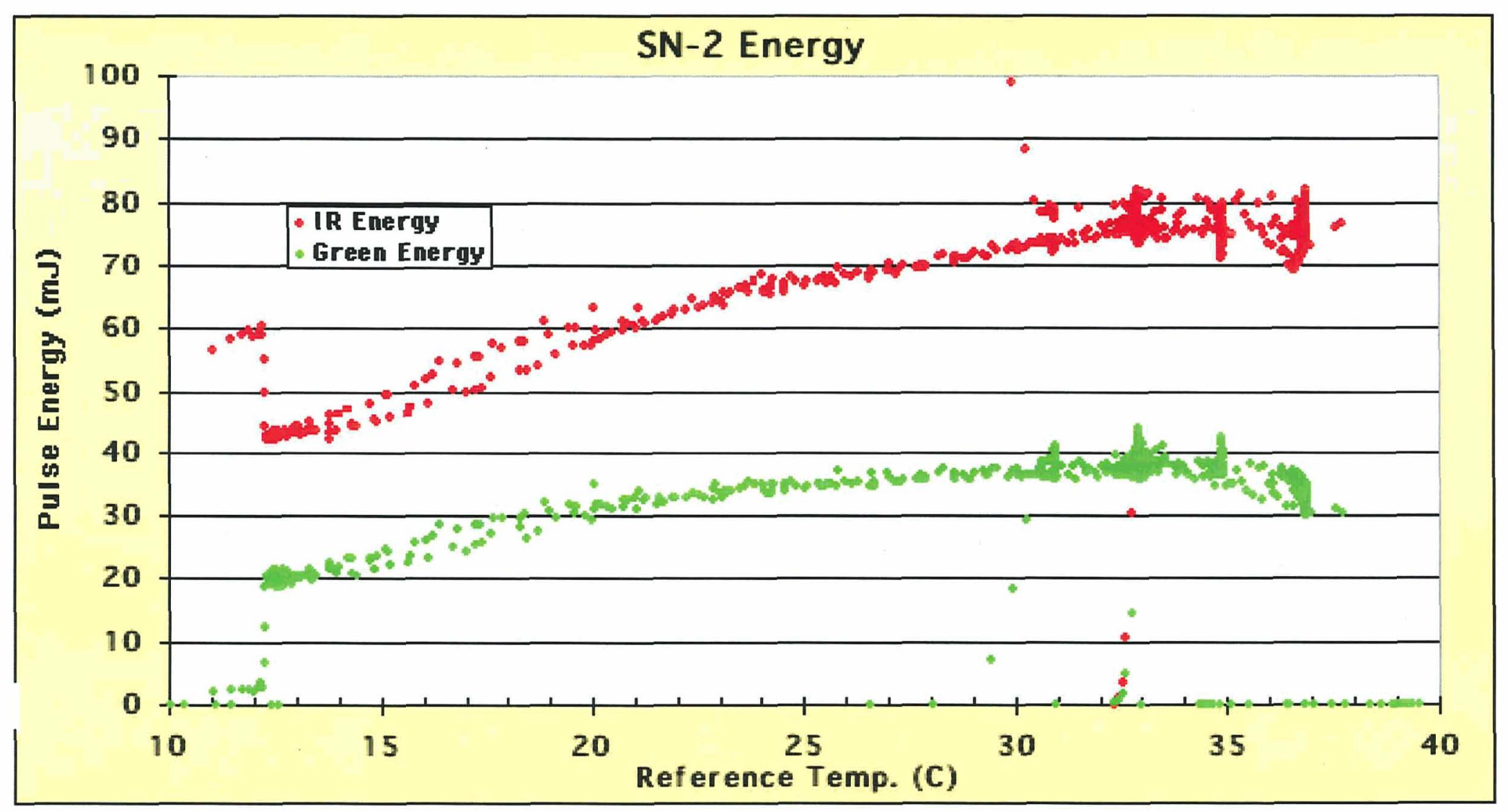

Figure 46 Energies of $1064 \mathrm{~nm}$ and $532 \mathrm{~nm}$ of GLAS flight laser SN2 as function of reference temperature during TVAC tests in vacuum. 


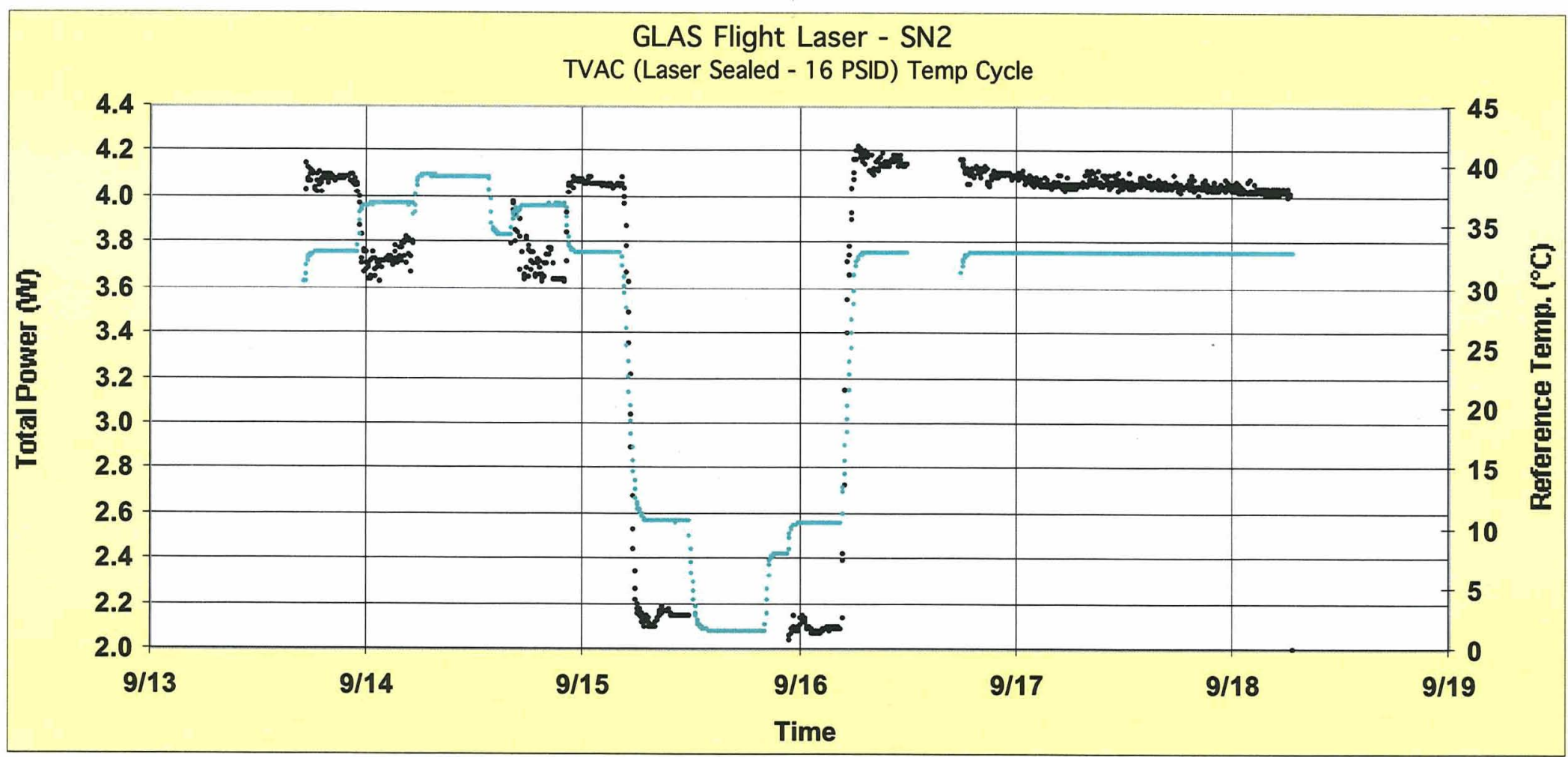

Figure 47. Total power from the laser SN2 throughout the sealed vacuum cycle including a $36 \mathrm{hr}$ operational dwell. The Total power is less than the vacuum case but returned to nominal value when the 16 psid was removed. 

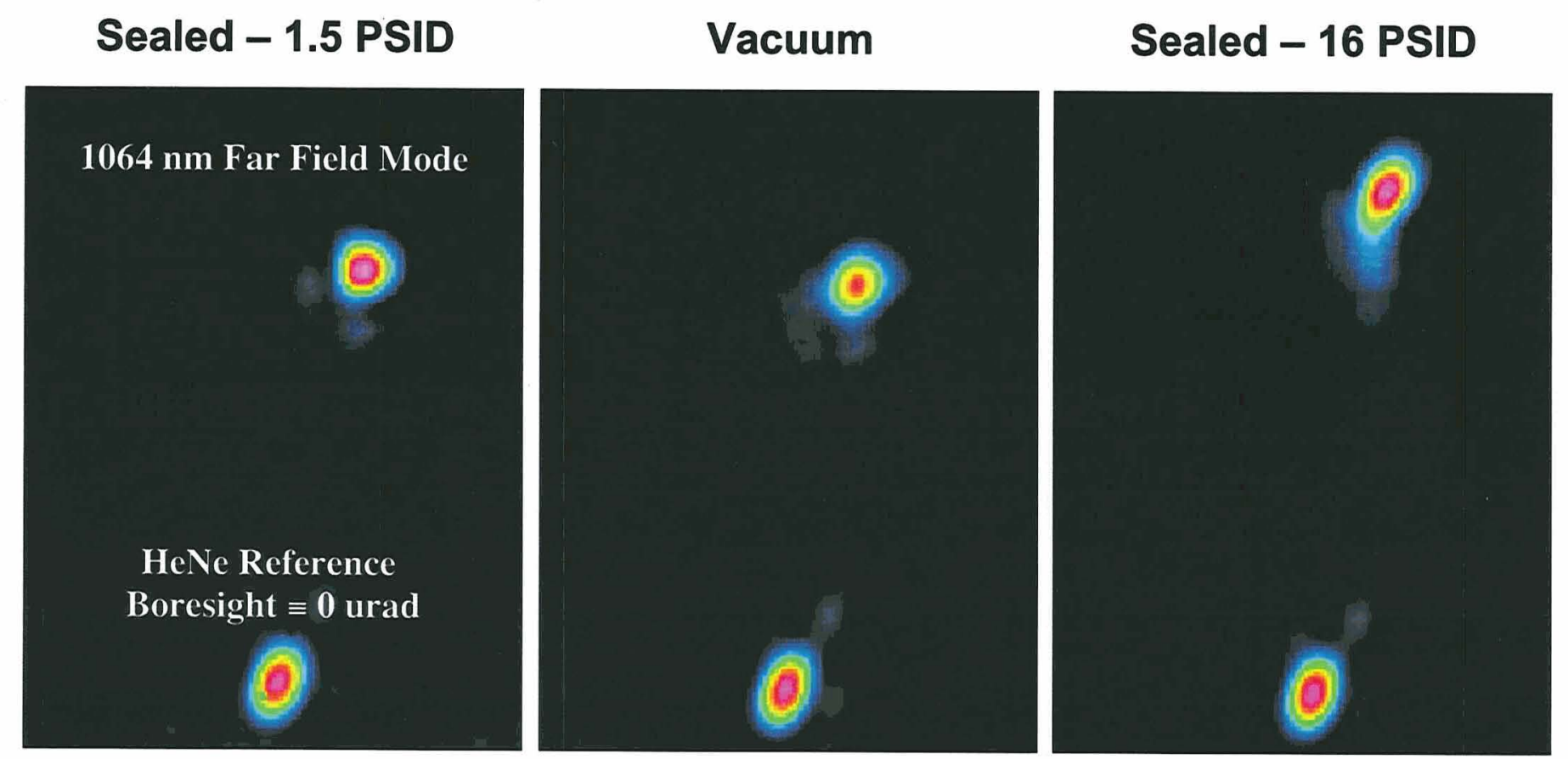

$$
\begin{gathered}
\text { Divergence }=96 \mu \mathrm{rad} \\
\mathbf{R}=480 \mu \mathrm{rad}, \theta=80 \\
\text { Circ }=0.85 \\
\text { "SN2 TVAC 65.ATS" }
\end{gathered}
$$

$$
\begin{aligned}
& \text { Divergence }=117 \mu \mathrm{rad} \\
& \mathbf{R}=462 \mu \mathrm{rad}, \theta=81 \\
& \text { Circ }=0.69 \\
& \text { "SN2 TVAC 51.ATS" }
\end{aligned}
$$

$$
\begin{gathered}
\text { Divergence }=135 \mu \mathrm{rad} \\
\mathbf{R}=567 \mu \mathrm{rad}, \theta=83 \\
\text { Circ }=0.39 \\
\text { "SN2 TVAC 54.ATS" }
\end{gathered}
$$

Figure 48. Mode profiles and relative boresight of GLAS flight laser SN2 at various pressurized and vacuum operation with reference temperature at $33^{\circ} \mathrm{C}$. 


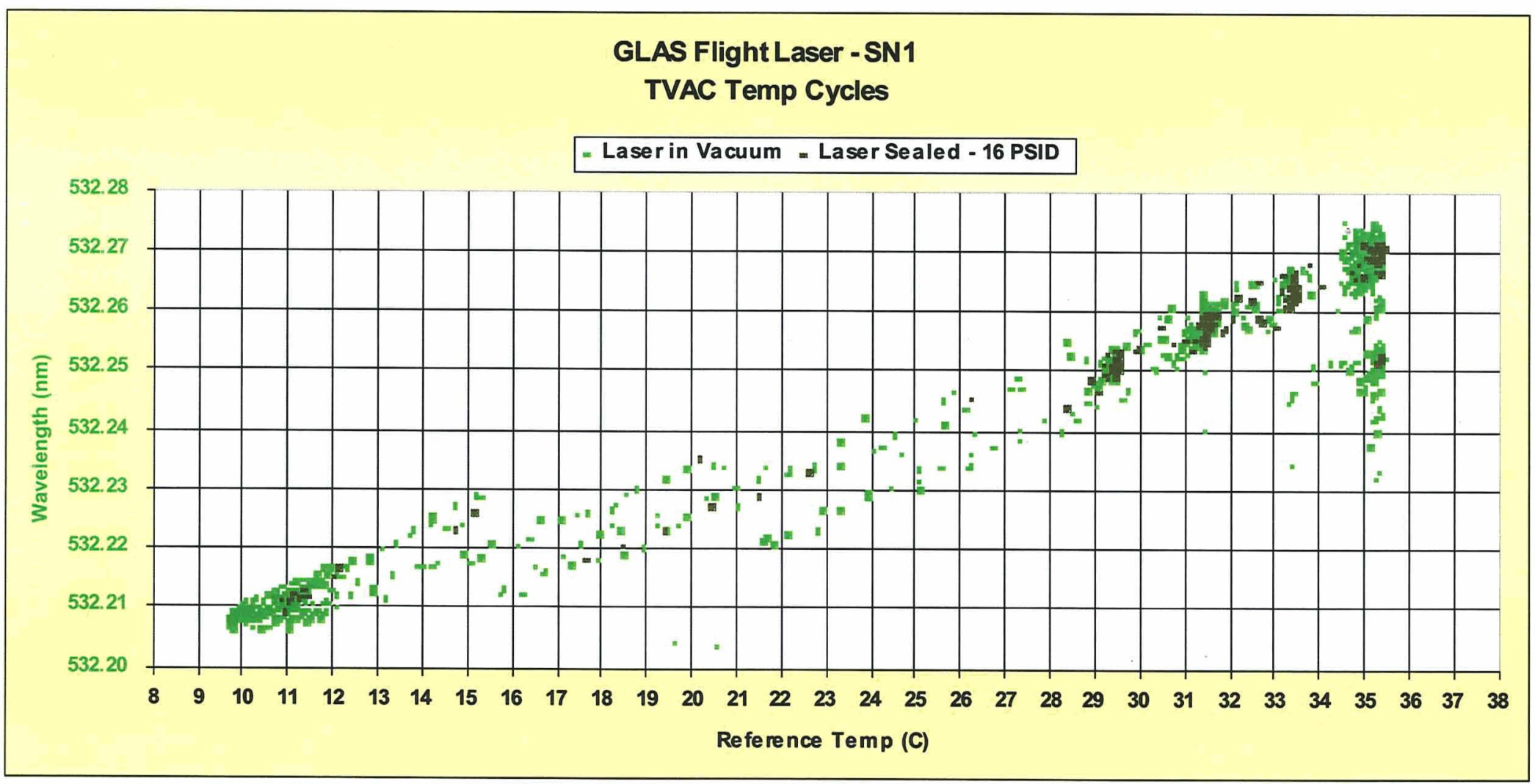

Figure 49. Wavelength measurement at $532 \mathrm{~nm}$ as function of reference temperature during TVAC tests on Laser SN1 under both vacuum and pressurized conditions. 


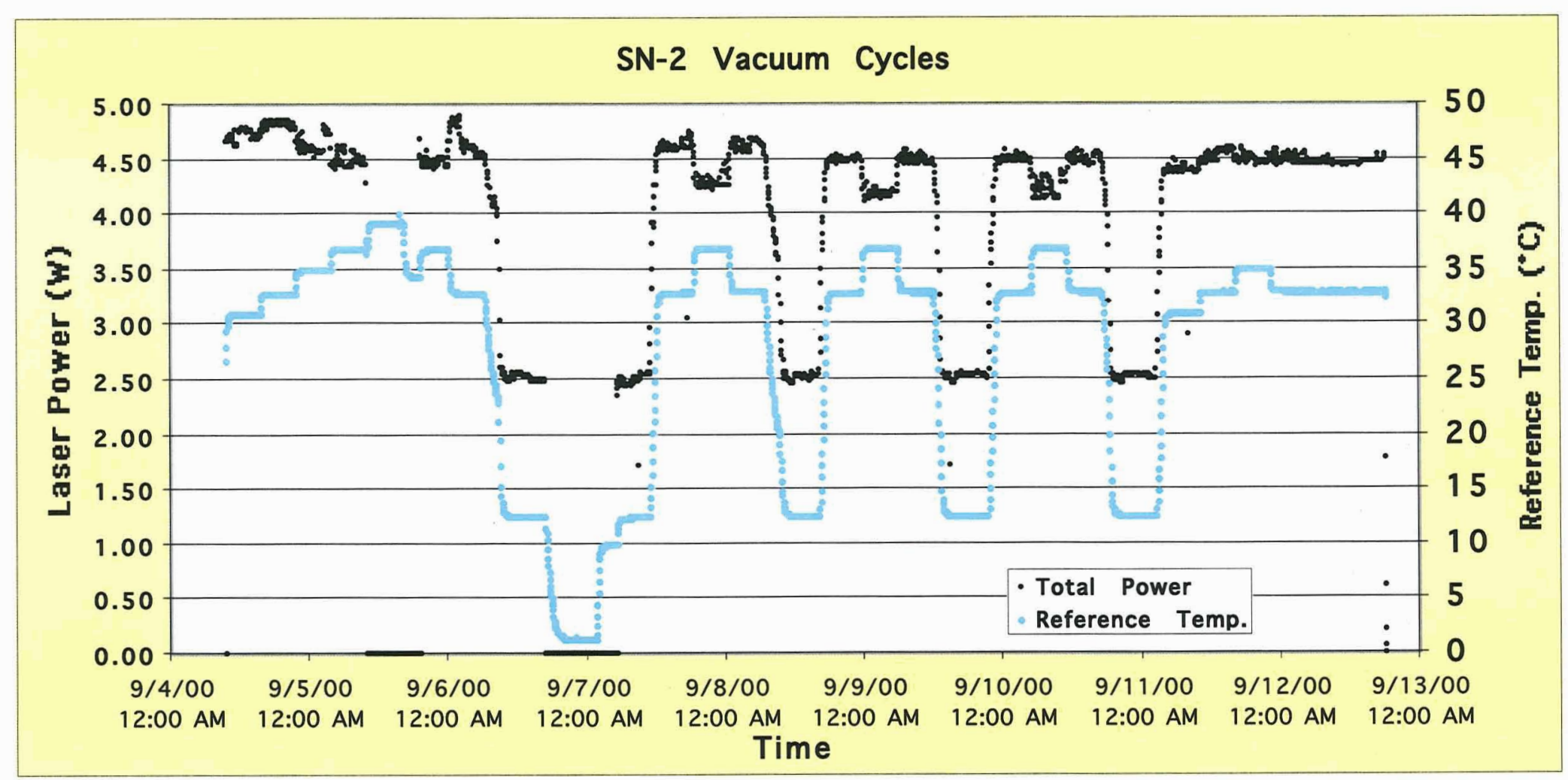

Figure 50. Laser SN2 went through the all-vacuum portion of TVAC environmental test. The laser power and reference temperature (as well as other vital signs) were monitored over the test duration. 
Table 1. Top level optical requirements and resources.

\begin{tabular}{|l|l|}
\hline Property & Specification \\
\hline Pulse Energy (total) & $110 \mathrm{~mJ}$ \\
\hline \multicolumn{1}{|c|}{$1064 \mathrm{~nm}$} & $75 \mathrm{~mJ}$ \\
\hline \multicolumn{1}{|c|}{$532 \mathrm{~nm}$} & $35 \mathrm{~mJ}$ \\
\hline Repetition Rate & $40 \mathrm{~Hz}$ \\
\hline Wavelength (Vacuum) & $\lambda 1=1064.5 \mathrm{~nm} \pm 100 \mathrm{pm}$ \\
\hline & $\lambda 2=532.2 \mathrm{~nm} \pm 50 \mathrm{pm}$ \\
\hline$\lambda 2$ linewidth (FWHM) & $\leq 15 \mathrm{pm}$ shot-to-shot \\
\hline Pulse width & $<6 \mathrm{~ns}$ \\
\hline Divergence & $110(+23,-10) \mu \mathrm{rad}$ \\
\hline Far Field Circularity & $>0.67$ \\
\hline Pointing Jitter & $\pm 11 \mu \mathrm{rad}(1 \mathrm{\sigma})$ \\
\hline Boresight Reference & $<1000 \mu \mathrm{rad}( \pm 50 \mu \mathrm{rad})$ \\
\hline Boresight Stability over temperature & $\pm 50 \mu \mathrm{rad}$ \\
\hline Prime Power & $110 \mathrm{~W}$ \\
\hline Mass & $15.2 \mathrm{Kg}$ \\
\hline Volume & $54 \times 15 \times 25 \mathrm{~cm}^{3}$ \\
\hline
\end{tabular}


Table 2. GLAS Flight Piece Part Hardware Bake-out Temperatures and Durations.

\begin{tabular}{|l|c|c|c|}
\hline \multicolumn{1}{|c|}{ ITEM } & MATERIAL & TEMP $\left({ }^{\circ} \mathrm{C}\right)$ & $\begin{array}{c}\text { DURATION } \\
\text { (Hrs) }\end{array}$ \\
\hline 1. Delrin & Self & 70 & 24 \\
\hline 2. $\quad$ Diodes & Mixed & 70 & 24 \\
\hline 3. Diode and Doubler Harness & PPS, Kynar, Tefzel & 70 & 36 \\
\hline 4. $\quad$ 9 Pin and 26 Pin Connectors & Mixed & 120 & 24 \\
\hline 5. Feedthrough Assemblies & Mixed & 70 & 36 \\
\hline 6. Wires and Cables & Teflon and Tefzel & 150 & 24 \\
\hline 7. Shrink Tubing & Kynar & 150 & 24 \\
\hline 8. $\quad$ Cable ties & Tefzel & 170 & 24 \\
\hline 9. $\quad$ Vespel & Self & 190 & 24 \\
\hline 10. Shoulder washers for Diodes & Ultem & 190 & 24 \\
\hline 11. Parylene straps & Copper, Gold, Parylene & 100 & 24 \\
\hline 12. Laser Cover O-Ring & Viton, Locktite & 70 & 24 \\
\hline 13. Jack Posts & Diallyl Phthalate & 150 & 24 \\
\hline 14. Gasket, O-rings & Viton & 190 & 48 \\
\hline
\end{tabular}


Table 3. Laser parameters being monitored during TCP at the SLTC using Bench Test Equipment (NTE), Instrument level integration and testing using Bench Check-out Equipment (BCE) and telemetry received from the instrument when in orbit.

\begin{tabular}{|c|c|c|c|c|}
\hline $\begin{array}{r}\text { Measurement } \\
\end{array}$ & Specification & SLTC & BCE & In Orbit \\
\hline 1064 Energy & $75 \mathrm{~mJ}$ & 0 & $O$ & O - Digitized start pulse \\
\hline 532 Energy & $35 \mathrm{~mJ}$ & 0 & O & O - Fiber/detector \\
\hline 532 Energy Jitter & TBR & & O & \\
\hline Pulsewidth Jitter & $\pm 5 \%$ shot-to-shot & O & 0 & \\
\hline Profile Far Field Circularity & $>0.67$, Centrally Lobed & O & O & O-SRS \\
\hline Pointing Jitter (Shot-to-Shot) & $\leq 11 \mu \mathrm{r}$ at $1 \sigma$ & 0 & 0 & O-SRS \\
\hline 532 wavelength (Vacuum) & $532.2 \mathrm{~nm} \pm 50 \mathrm{pm}$ & O & $\mathrm{O}$ & \\
\hline 532 linewidth (FWHM) & $\leq 15 \mathrm{pm}$ single shot & O & O & \\
\hline 532 wavelength jitter & $\leq 15 \mathrm{pm}$ shot-to-shot & 0 & 0 & \\
\hline 532 wavelength drift rate & $\leq 10 \mathrm{pm}$ in 60 minutes & & O & O - Etalon temperature \\
\hline Pulse Repetition Rate & $40 \mathrm{~Hz} \pm 0.1$ & O & 0 & \\
\hline Electronics Temperature & & 0 & 0 & O \\
\hline Prime Voltage & & O & 0 & \\
\hline Prime Current & & 0 & 0 & \\
\hline Oscillator Diode Drive Current & & 0 & 0 & O \\
\hline Amplifier Diode Drive Current & & O & 0 & O \\
\hline Diode Drive Current Width & & O & O & ○ \\
\hline Box Pressure & & O & 0 & \\
\hline Boresight $(R, \theta)$ & & O & 0 & 0 \\
\hline Boresight Jitter (Radius) & $\leq 50 \mu \mathrm{rad}$ & 0 & O & O \\
\hline Environment (vacuum, air) & & 0 & O & \\
\hline
\end{tabular}


Table 4. TCP results of Laser SN2 before and after vibration test. The only measurable difference was the boresight shift of 170 $\mu \mathrm{rad}$. The uncertainty of alignment of laser to the alignment plate was $\pm 50 \mu \mathrm{rad}$.

\begin{tabular}{|c|c|c|c|}
\hline Propeny & Specification & Pre-Vib. & Post Vib. \\
\hline TCP Date & & $8 / 30 / 00$ & $9 / 1 / 00$ \\
\hline Reference Temp (C) & & 32.27 & 32.19 \\
\hline Pulse Energy & $110 \mathrm{~mJ}$ & 118 & 118 \\
\hline $1064 \mathrm{~nm}$ & $75 \mathrm{~mJ}$ & 80 & 79 \\
\hline $532 \mathrm{~nm}$ & $35 \mathrm{~mJ}$ & 38 & 39 \\
\hline \multirow[t]{2}{*}{ Wavelength (Vacuum) } & $\lambda_{1}=1064.5 \mathrm{~nm} \pm 100 \mathrm{pm}$ & 1064.47 & 1064.46 \\
\hline & $\lambda_{2}=532.2 \mathrm{~nm} \pm 50 \mathrm{pm}$ & 532.23 & 532.23 \\
\hline$\lambda_{2}$ linewidth (FWHM) & $\leq 15 \mathrm{pm}$ shot-to-shot & 2.26 & 13 \\
\hline Pulse width & $<6 \mathrm{~ns}$ & 6.16 & 6.43 \\
\hline Divergence & $110(+23,-10)$ urad & 79 & 81 \\
\hline Far Field Circularity & $>0.67$ & 0.76 & 0.76 \\
\hline Pointing Jitter & $\pm 11 \operatorname{urad}(1 \sigma)$ & $5, \max =21$ & $6, \max =24$ \\
\hline Boresight Reference & $<1000$ urad $( \pm 50$ urad $)$ & 321 urad, $89^{\circ}$ & 500 urad, $88^{\circ}$ \\
\hline Boresight Stability & \pm 50 urad & See Test Data & See Test Data \\
\hline Prime Power & $110 \mathrm{~W}$ & 111 & 110 \\
\hline
\end{tabular}


Table 5. Parameters and algorithms employed during the spatial measurements.

\begin{tabular}{|c|c|}
\hline Parameters & Algorithm \\
\hline Divergence & $\begin{array}{l}\text { The ratio of the aperture diameter containing } 85 \% \text { of energy to the } \\
\text { OAP mirror focal length. }\end{array}$ \\
\hline Boresight & $\begin{array}{l}\text { Relative position of the GLAS laser far field centroid and the } \\
\text { HeNe reference laser far field centroid }\end{array}$ \\
\hline Beam Jitter & Relative position of the GLAS laser far field centroid to itself. \\
\hline Circularity & $\begin{array}{l}\text { The normalized ratio of the minor to the major axis of the far field } \\
\text { pattern. The major and minor axes dimensions are determined by } \\
\text { Gaussian fit to the GLAS laser far field profile. }\end{array}$ \\
\hline
\end{tabular}


Table 6. Summary of TVAC tests of all three delivered GLAS flight lasers.

\begin{tabular}{|c|c|c|c|c|}
\hline Property & Specification & SN2 (Vacuum) & SN1 (Vacuum) & SN3 (Vacuum) \\
\hline Delivery Date/ \# Shots & & 9/21/01, 65.0 M Shots & 2/7/01, 75.2 M Shots & 2/7/01, 60.2 M Shots \\
\hline Reference Temp (C) & & 32.94 & 31.5 & 29.72 \\
\hline Pulse Energy & $110 \mathrm{~mJ}$ & 113 & 106 & 111 \\
\hline $1064 \mathrm{~nm}$ & $75 \mathrm{~mJ}$ & 76 & 76 & 77 \\
\hline $532 \mathrm{~nm}$ & $35 \mathrm{~mJ}$ & 37 & 30 & 34 \\
\hline \multirow[t]{2}{*}{ Wavelength (Vacuum) } & $\lambda_{1}=1064.5 \mathrm{~nm} \pm 100 \mathrm{pm}$ & 1064.48 & 1064.52 & 1064.50 \\
\hline & $\lambda_{2}=532.25 \mathrm{~nm} \pm 50 \mathrm{pm}$ & 532.24 & 532.26 & 532.25 \\
\hline$\lambda_{2}$ linewidth (FWHM) & $\leq 15 \mathrm{pm}$ shot-to-shot & 2.84 & 0.58 & 0.81 \\
\hline Center Wavelength Jitter & $\operatorname{pm}(1 \sigma)$ & - & 0.32 & 0.1 \\
\hline Pulse width & $<6 \mathrm{~ns}$ & 6.1 & 5.8 & 6.3 \\
\hline Divergence & $110(+23,-10) \mu \mathrm{rad}$ & 118 & 68 & 113 \\
\hline Far Field Circularity & $>0.67$ & 0.70 & 0.82 & 0.63 \\
\hline Pointing Jitter & $\pm 11 \mu \mathrm{rad}(1 \sigma)$ & $4, \max =27$ & $5, \max =23$ & $4, \max =20$ \\
\hline Boresight Reference & $<1000 \mu \mathrm{rad}( \pm 50 \mu \mathrm{rad})$ & $456 \mu \mathrm{rad}, 82^{\circ}$ & $461 \mu \mathrm{rad}, 62^{\circ}$ & $474 \mu \mathrm{rad}, 72^{\circ}$ \\
\hline Boresight Stability & $\pm 50 \mu \mathrm{rad}$ & See Test Data & See Test Data & See Test Data \\
\hline Prime Power & $110 \mathrm{~W}$ & 112 & 112 & 113 \\
\hline Mass & $15.2 \mathrm{Kg}$ & 15.3 & 15.3 & 15.3 \\
\hline Volume & $54 \times 15 \times 25 \mathrm{~cm}^{3}$ & $54 \times 15 \times 25 \mathrm{~cm}^{3}$ & $54 \times 15 \times 25 \mathrm{~cm}^{3}$ & $54 \times 15 \times 25 \mathrm{~cm}^{3}$ \\
\hline
\end{tabular}


Table 7. Summary of GLAS lasers ground testing and in space operation to date (numbers are in unit of millions of shots).

\begin{tabular}{|c|c|c|c|c|}
\hline & $\begin{array}{c}\text { Laser 1 } \\
\text { (SN2) }\end{array}$ & $\begin{array}{c}\text { Laser 2 } \\
\text { (SN1) }\end{array}$ & $\begin{array}{c}\text { Laser 3 } \\
\text { (SN3) }\end{array}$ & $\begin{array}{c}\text { Total } \\
\text { (Millions of Shots) }\end{array}$ \\
\hline Ground Testing (Subsystem + Instrument Level) & 158.8 & 140 & 128.8 & 427.6 \\
\hline On-Orbit (As of 26 June 2006) & 126.8 & 417.5 & 702.3 & 1246.6 (in space) \\
\hline Total Shots per Laser & 285.6 & 557.5 & 831.1 & 1674.2 \\
\hline Status & Failed & Off & $\begin{array}{c}\text { Finished Campaign 3F on 6/26/2006. } \\
\text { Awaiting Start of Campaign 3G }\end{array}$ & \\
\hline
\end{tabular}

